\title{
Transmutation Fuels Campaign FY-09 Accomplishments Report
}

\author{
Lori Braase
}

September 2009

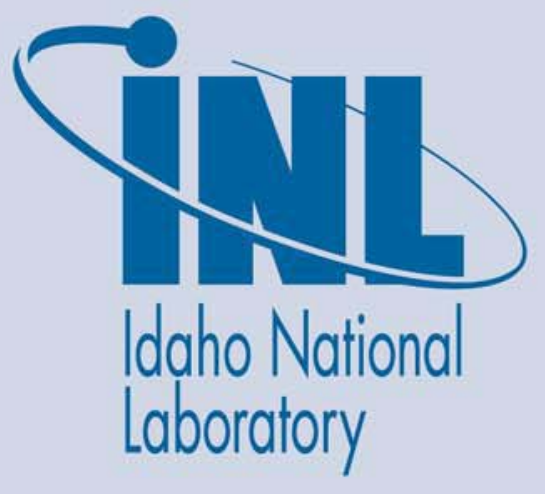

The INL is a U.S. Department of Energy National Laboratory operated by Battelle Energy Alliance 
INL/EXT-09-16834

\title{
Transmutation Fuels Campaign FY-09 Accomplishments Report
}

\author{
Lori Braase
}

September 2009

\begin{abstract}
Idaho National Laboratory
Idaho Falls, Idaho 83415
\end{abstract}

http://www.inl.gov

\author{
Prepared for the \\ U.S. Department of Energy \\ Office of Nuclear Energy \\ Under DOE Idaho Operations Office \\ Contract DE-AC07-05ID14517
}




\section{Transmutation Fuels Campaign FY-09 Accomplishments Report}

Advanced Fuel Cycle Initiative

Prepared for U.S. Department of Energy Transmutation Fuels Campaign

Lori Braase

September 30, 2009 Revision 0 AFCI-FUEL-FUEL-PM-RP-2009-000149 


\section{DISCLAIMER}

This information was prepared as an account of work sponsored by an agency of the U.S. Government. Neither the U.S. Government nor any agency thereof, nor any of their employees, makes any warranty, expressed or implied, or assumes any legal liability or responsibility for the accuracy, completeness, or usefulness, of any information, apparatus, product, or process disclosed, or represents that its use would not infringe privately owned rights. References herein to any specific commercial product, process, or service by trade name, trade mark, manufacturer, or otherwise, does not necessarily constitute or imply its endorsement, recommendation, or favoring by the U.S. Government or any agency thereof. The views and opinions of authors expressed herein do not necessarily state or reflect those of the U.S. Government or any agency thereof. 



\title{
Transmutation Fuels Campaign FY-09 Accomplishments Report
}

\author{
INL/EXT-09-16834
}

Revision 0

\section{AFCI-FUEL-FUEL PM-PR-2009-000149}

September 30, 2009

Prepared by:

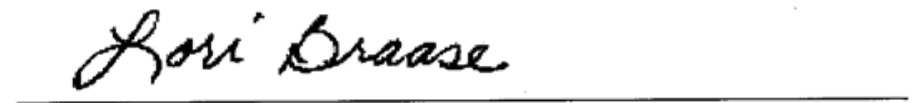

Lori Braase

Transmutation Fuel Campaign Systems Engineer

$\frac{9 / 30 / 09}{\text { Date }}$

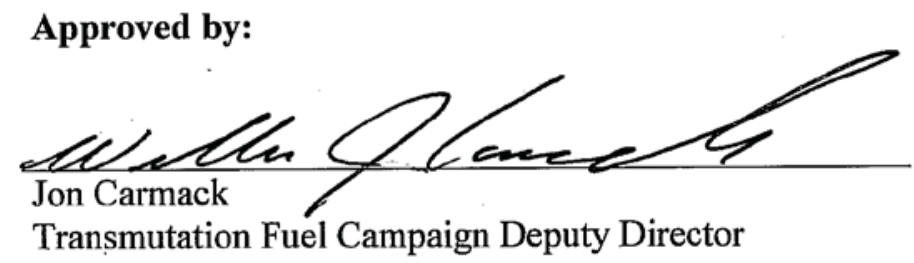





\section{SUMMARY}

This report summarizes the Fiscal Year 2009 (FY-09) accomplishments for the Transmutation Fuels Campaign (TFC). The emphasis is on the accomplishments and relevance of the work. Detailed description of the methods used to achieve the highlighted results and the associated support tasks are not included in this report. The accomplishments are highlighted in the following general areas:

- Campaign Management and Integration

- Oxide Fuel Fabrication and Characterization

- Metal Fuel Fabrication and Characterization

- Core Materials

- Irradiation Testing and Post-Irradiation Examination 
This page intentionally left blank. 


\section{CONTENTS}

SUMMARY $\mathrm{V}$

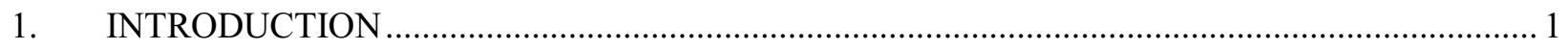

2. CAMPAIGN MANAGEMENT AND INTEGRATION …....................................................... 1

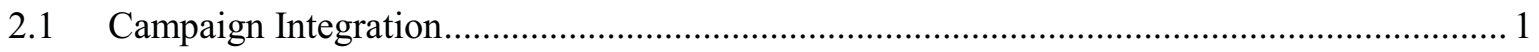

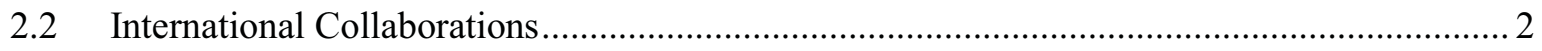

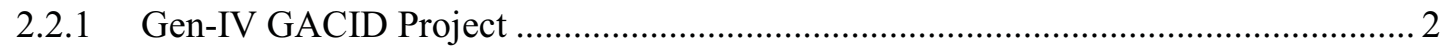

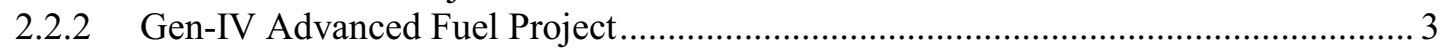

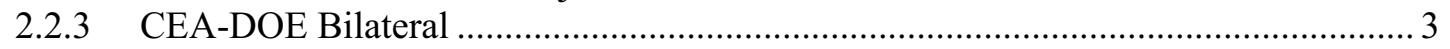

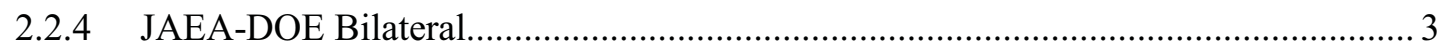

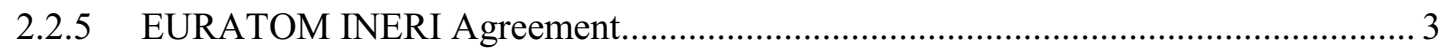

2.3 Fuel Feedstock: (PuAm) $\mathrm{O}_{2}$ Separation Characterization System ........................................ 3

3. OXIDE FUEL FABRICATION AND CHARACTERIZATION …....................................... 4

3.1 Oxide Fabrication Process Development (Process/Structure Relations) ............................... 5

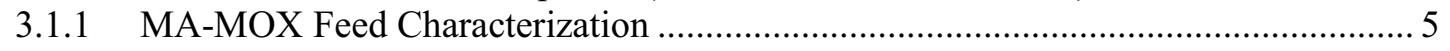

3.1.2 High Quality MA-MOX Pellets ........................................................................ 5

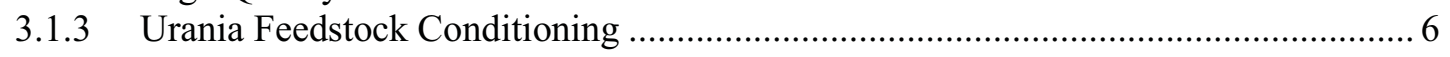

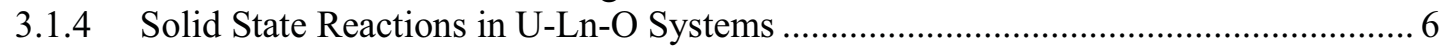

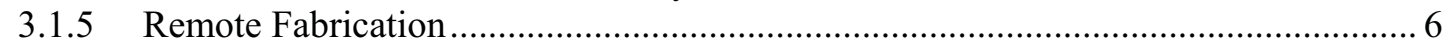

3.2 Oxide Fuel Development (Structure/Property Relations) …............................................ 7

3.2.1 Thermal Etching and Microstructural Analysis .................................................. 7

3.2.2 Coupled Thermophysical Property Studies in U-Ln-O Materials............................... 7

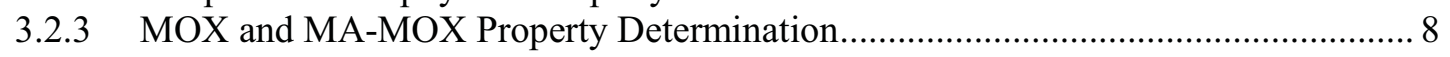

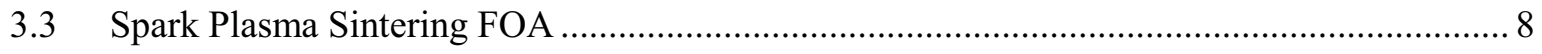

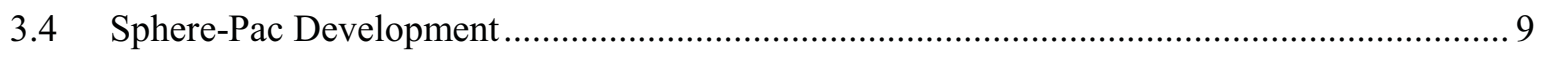

3.4.1 Task 1: Perform Development of Micro/Mini-Sphere Fabrication Process ............... 9

3.4.2 Task 2: Evaluate Levels of Residual Sulfur in Spheres from Resin Loading

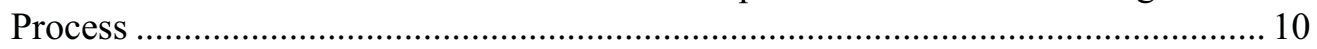

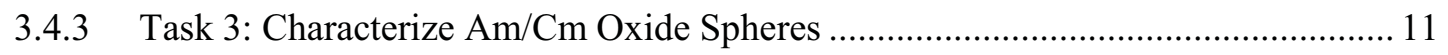

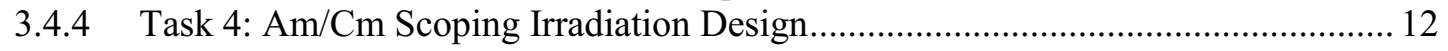

3.4.5 Task 5: International/University Collaborations .................................................. 14

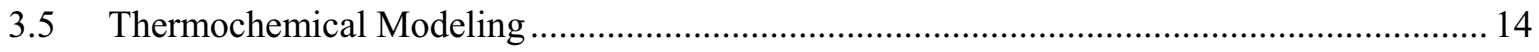

4. METAL FUEL FABRICATION AND CHARACTERIZATION …........................................... 15

4.1 AFC2 General Fuel Characterization................................................................................ 15

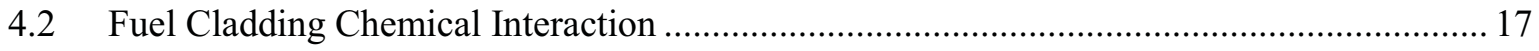

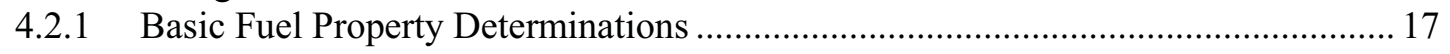

4.3 Laser-Based Characterization Technique Development ................................................. 18

4.3.1 Laser-based thermal effusivity measurement........................................................ 18

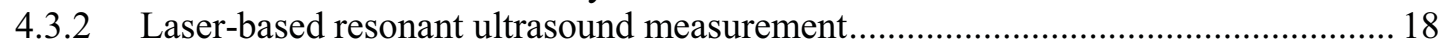

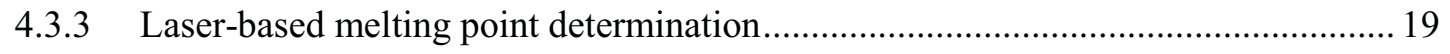

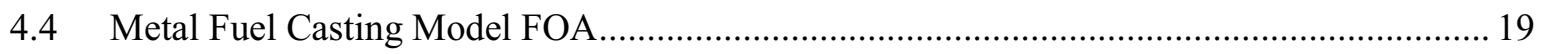

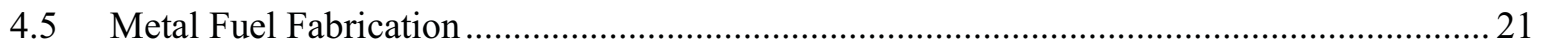




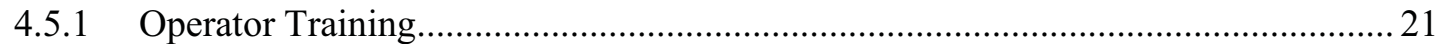

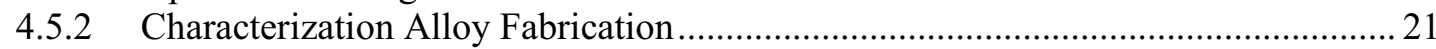

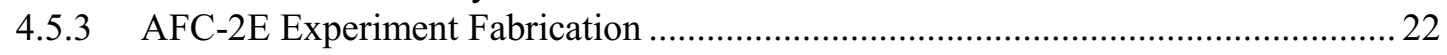

4.6 Metal Fuel Fabrication Process Development …............................................................. 23

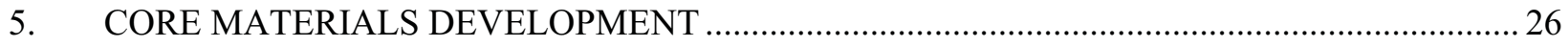

5.1 ACO-3 Duct Specimen Machining, Analysis and Testing …........................................... 27

5.1.1 Tensile, Charpy, Compact Tension and TEM Specimens EDM machining............. 27

5.1.2 Detailed Microstructural Analysis of ACO-3 duct ...................................................... 27

5.2 FFTF/MOTA Specimen Retrieval and Testing.............................................................. 28

5.2.1 MOTA Specimen Retrieval, Sorting, and Dispositioning........................................28

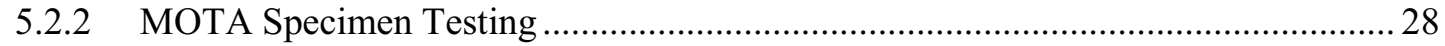

5.3 Development of Cladding Barrier Coatings and Liners for FCCI Mitigation .....................29

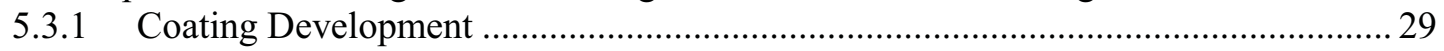

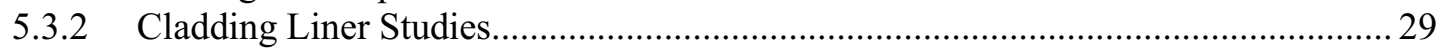

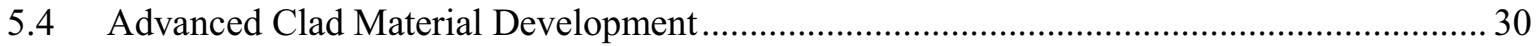

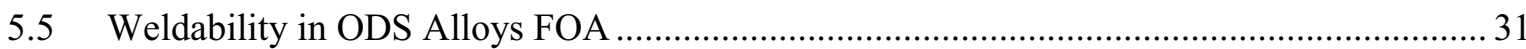

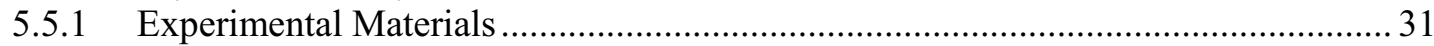

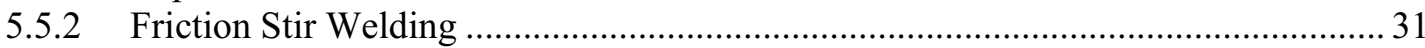

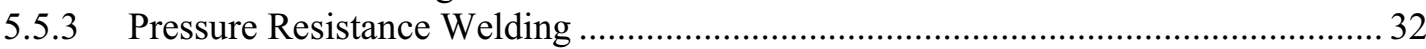

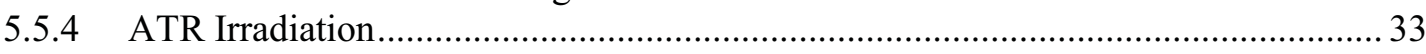

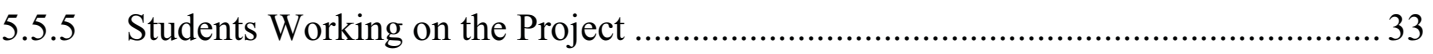

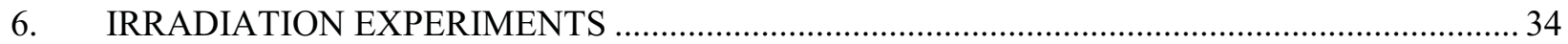

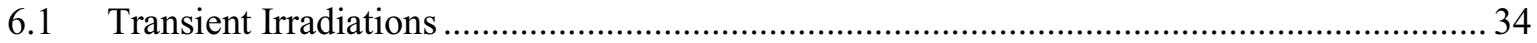

6.2 Experiment Definition and Preliminary Planning for R\&D Emphasis ............................... 34

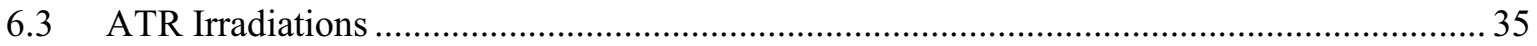

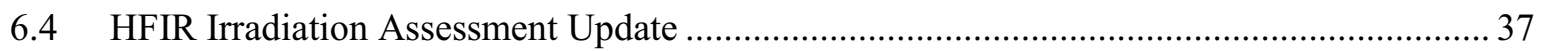

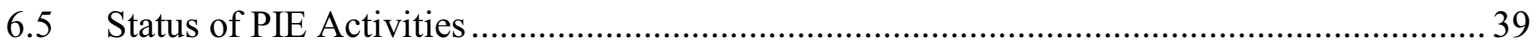

6.5.1 Postirradiation Plan for AFC-1H, AFC-1D, AFC-1G and AFC-2A ......................... 39

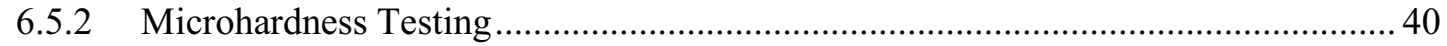

6.5.3 Non-destructive Examinations of AFC-1H, AFC-1D, AFC-1G and AFC-2A …..... 41

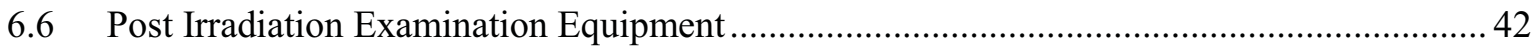

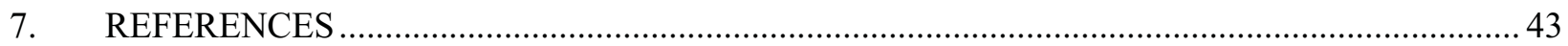

\section{FIGURES}

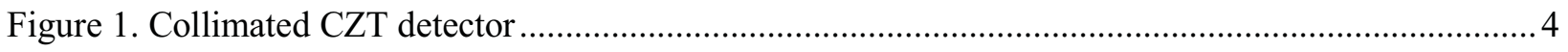

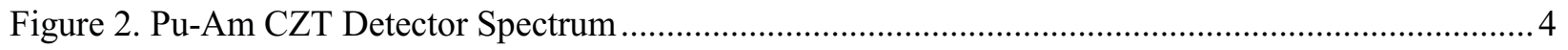

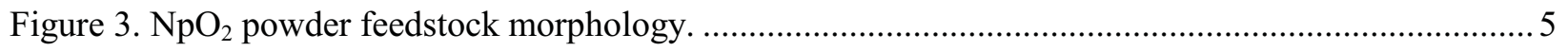

Figure 4. Pellets of four different MOX and MA-MOX compositions fabricated using the simplified process. 
Figure 5. Comparison of calculated and experimental unit cell volumes for different defect types as a function of Ln content. 6

Figure 6. Etched MA-MOX showing NpO2-rich region. .................................................................... 7

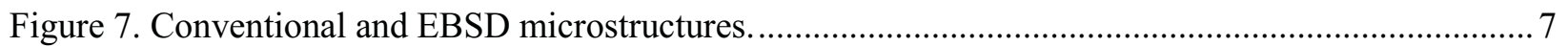

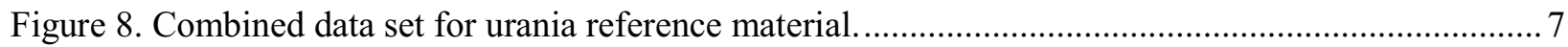

Figure 9. Effect of Dy2O3 Content on the Relative Density and Grain Size of Sintered CeO2 at Different Temperatures (130C per min., $500 \mathrm{MPa}, 5 \mathrm{~min})$....................................................... 8

Figure 10. Infiltration Process for Porous Sol-Gel Particles.................................................................. 9

Figure 11. Evaluating Reduction of $\mathrm{UO}_{3}$ to $\mathrm{U}_{3} \mathrm{O}_{8}$ using Differential Thermal Analysis .......................... 10

Figure 12. X-Ray Diffraction Pattern of Uranium Oxide Particles after Reduction.................................. 10

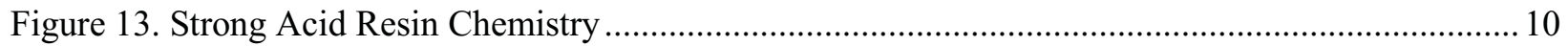

Figure 14. Evaluating Resin Removal using Differential Thermal Analysis.......................................... 11

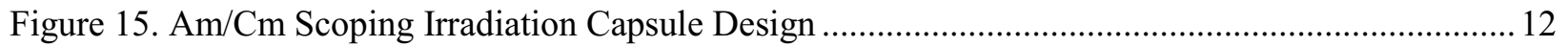

Figure 16. Flux Spectrum for Various Shield Materials ….................................................................... 12

Figure 17. Heat Generation Rate for Various Shield Materials ............................................................ 13

Figure 18. Heat Generation as a Function of HFIR Axial Position ....................................................... 13

Figure 19. Preliminary Thermal Analysis of Am/Cm Scoping Irradiation Capsule .................................. 14

Figure 20. Process Conditions to Achieve Low O:M for Reference MOX Composition........................... 15

Figure 21. BSE images and X-ray maps showing spatial distributions of $\mathrm{U}, \mathrm{Pu}$, and $\mathrm{Zr}$. Bright areas in the maps have relatively high concentrations of the mapped elements; dark areas have low ones.

Figure 22. (A) AFC2-E1 Heating and Cooling Expansion Curves (as-cast) (B) Evaluated Thermal Conductivity of E1 Alloy.....

Figure 23. Back scattered electron image (upper left) and characteristic X-ray maps as labeled showing elemental spatial distributions resulting from fuel - cladding interaction. In particular, note the neodymium penetration into the cladding beyond the zirconium layer in the region where the rare earth $(\mathrm{Nd})$ inclusion was in contact with the cladding

Figure 24. High-temperature X-ray diffraction goniometer that allows direct analysis of high temperature phases and phase transitions.

Figure 25. Left: In situ monitoring of the resonant peak location as a function of annealing temperature. Utilizing EBD data it has been shown that the majority of the frequency shift is due to texture evolution rather than dislocation evolution. Right: Details of microstructure evolution. A textured is imparted by rolling. A well defined cube texture is formed upon annealing.

Figure 26. Schematic for the bench scale caster, which is designed to cast three fuel pins $4 \mathrm{~mm}$ diameter by $250 \mathrm{~mm}$ long. The intrusion of argon gas (blue-green) is shown in a filling simulation on the right.

Figure 27. Filling simulation for an uncoated mold showing early solidification. 20

Figure 28. Geometry of a 60 degree segment of the induction heating model and a plot of induction heating power from a half symmetry simulation. 
Figure 29. Characterization alloy operations 22

Figure 30. AFC-2E Experiment As-Built Data Package .23

Figure 31. Bench scale casting system schematic. Note: the stopper rod lifting mechanism and instrumentation and gas feedthroughs are not shown. 23

Figure 32. U-10Zr pins cast using the BCS. Approximate diameter is $4.3 \mathrm{~mm}(0.170 \mathrm{in}$.). 24

Figure 33. Cast U-10Zr slug microstructure (a) top, (b) middle, and (c) bottom slug portion. 24

Figure 34. Ratio of $\left(\mathrm{Mn}_{0} / \mathrm{Zr}_{0}\right) /\left(\mathrm{Mn}_{\mathrm{f}} / \mathrm{Zr}_{\mathrm{f}}\right)$ versus alloy designation. A ratio of 1 results from no $\mathrm{Mn}$ loss through volatilization. .25

Figure 35. Photo showing the locations where specimens were EDM machined from a plate cut from the ACO-3 duct.

Figure 36. TEM image showing Initiation of void swelling observed for Tirr $=443 \mathrm{C}$, Dose $=155$ dpa. Estimated swelling is $0.3 \%$. 27

Figure 37. In-reactor creep response at $600^{\circ} \mathrm{C}$ of MA-957 compared to HT-9. 28

Figure 38. Steady state in-reactor creep response of MA-957 and HT-9 up to $600^{\circ} \mathrm{C}$. .28

Figure 39. Cross-section TEM micrograph of a TiN coated HT-9 sample following irradiation to $2.0 \mathrm{dpa}$ at $500^{\circ} \mathrm{C}$. .29

Figure 40. SEM image revealing absence of martensite and carbides near cladding-liner interface.......... 30

Figure 41. Atom probe tomographic image showing Y-Ti-O clusters in heat of 14YWT. 30

Figure 42. An optical macrograph of the transverse cross-section of FSW MA956 alloy (bead-onplate configuration). Microstructure of the stir zone as observed via optical microscopy in the bottom image.

Figure 43. An optical micrograph of the transverse cross-section of FSW MA754 alloy. Also shown are the microstructure of the base material and the stir zone as revealed by optical microscopy.

Figure 44. (a) A graduate student from the University of Idaho at work with the PRW machine.

(b) Views of MA957 cladding tube and HT-9 end plug being set up for PRW.

Figure 45. (a) An optical micrograph of the PRW joint cross-section. (b) Two bend-tested samples of the cladding tube - plug PRW joints. .33

Figure 46. Receipt of AFC-2E Capsule at ATR. .36

Figure 47. ATR Core Cross Sectional Diagram Identifying EFT and Outboard A Positions 37

Figure 48. Schematic of the HFIR reactor system; the flux trap region is in the center. 38

Figure 49. Microhardness testing micrographs of 35U-29Pu-4Am-2Np-30Zr metallic alloy fuel irradiated to (a) 4.1 and (b) 5.8 at.\% burnup.

Figure 50. Capsule neutron radiography of AFC-1H, AFC-1D, AFC-1G and AFC-2A using converter (a)dysprosium foil and (b) indium foil. 


\section{TABLES}

Table 1. Results of high-temperature X-ray diffraction analysis of Alloy B2 performed at $650^{\circ} \mathrm{C}$. As-cast and annealed results obtained at room temperature are shown for comparison. 18

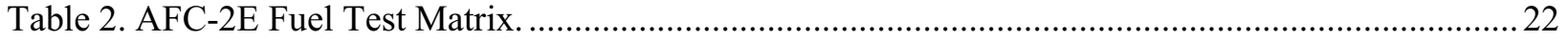

Table 3. Chemical analysis results for uranium and zirconium from BCS cast U-10Zr alloy..................24

Table 4. Chemical analysis results from Mn containing volatility experiments ......................................2 25

Table 5. A summary of tensile properties of MA754 alloy ..................................................................... 32

Table 6. A list of students involved in the project at different universities ............................................. 34

Table 7. Cycle 144A As-Run LHGR, Fission Heat Rates, and Burnup Distribution for AFCI Fuel in the EFT at 43.7 EFPDs (Scaled to East Lobe Source Power of 22.1 MW. ${ }^{2}$.

Table 8. Material compositions of metallic and oxide fuels, assessed for LHGRs in HFIR flux trap irradiation scenarios (as used in ORNL calculations)

Table 9. Summary of linear heat generation rates and neutron flux levels for irradiation in the HFIR flux trap region 
This page intentionally left blank. 


\section{ACRONYMS}

ABR Advanced Burner Reactor Project

AFCI Advanced Fuel Cycle Initiative

Am Americium

ARR Advanced Recycling Reactor

ASCI Advanced Simulation and Computation Initiative

ATR Advanced Test Reactor

BCS Bench-scale Casting System

BISON Better Implicit Simulation of Nuclear Fuel

CEA Atomic Energy Agency (France)

CETE Coupled-End-To-End Process

$\mathrm{Cm} \quad$ Curium

DOE Department of Energy

DOR Direct Oxide Reduction

EBR-II Experimental Breeder Reactor II

EDM Electric Discharge Machining

EPMA Electron Probe Micro-Analyzer

FCCI Fuel Clad Chemical Interaction

FFTF Fast Flux Test Facility

FIB Focused Ion Beam

FRD Functions and Requirements Document

GEN IV Generation IV

GNEP Global Nuclear Energy Partnership

HFEF Hot Fuel Exam Facility

HFIR High-Flux Isotope Reactor

INL Idaho National Laboratory

JAEA Japan Atomic Energy Agency

LANL Los Alamos National Laboratory

LLNL Lawrence Livermore National Laboratory

LTA Lead Test Assembly

LWR Light Water Reactor

MFC Materials and Fuels Complex (INL)

MOTA Materials Open Test Assembly

MOX Mixed Oxide Fuel 
MXRD Microscale X-Ray Diffractometer

$\mathrm{Np} \quad$ Neptunium

PIE Post Irradiation Examination

PIRT Phenomenon Identification and Ranking Tables

PMB Project Management Board

PMI Predictive Maturity Index

PMP Project Management Plan

PNNL Pacific Northwest National Laboratory

$\mathrm{Pu} \quad$ Plutonium

QAP Quality Assurance Plan

RD\&D Research, Development, and Demonstration

R\&TD Research and Technology Development

RW Office of Radioactive Waste Management (DOE)

SEM Scanning Electron Microscope

SET Separate-Effects Test (also called phenomenological testing)

STDM Scanning Thermal Diffusivity Microscopy

TFC Transmutation Fuels Campaign

TFCIG Transmutation Fuels Campaign Integration Group

TIMS Thermal Ionization Mass Spectrometer

TIO GNEP Technical Integration Office

TREAT Transient Reactor Test Facility

TRL Technology Readiness Level

TRU Transuranic

TVA Tennessee Valley Authority

U Uranium

US United States

$\mathrm{V} \& \mathrm{~V} \quad$ Verification and Validation

VPSC ViscoPlastic Self-Consistent

WBS Work Breakdown Structure

WP Work Package 


\section{Transmutation Fuels Campaign Fiscal Year 2009 Accomplishments Report}

\section{INTRODUCTION}

One of the major research and development areas under the Advanced Fuel Cycle Initiative (AFCI) is transmutation fuels. Considerable progress was made during fiscal year 2009 (FY-09) on this topic and this report emphasizes the accomplishments. The technical and process details leading up to the results are not presented but the technical contact is provided for each section. The accomplishments highlighted in this report are consistent with the Transmutation Fuels Campaign (TFC) work breakdown structure (WBS).

\section{CAMPAIGN MANAGEMENT AND INTEGRATION}

The TFC is responsible for the development of advanced nuclear fuels supporting closure of the nuclear fuel cycle. One of the most challenging aspects of the AFCI TFC is the management, direction, and coordination of the major research and development activities across multiple national laboratories and universities working to achieve this goal. Significant redirection of the AFCI program was undertaken in FY-09 to move to a science-based research approach. This change was incorporated into the strategy and planning packages during the mid-year review.

In addition, several management activities were accomplished in FY-09 that supports the overall goals of the AFCI program. The TFC facilitated a meeting between ORNL and LANL to coordinate the planning and use of CETE products. Support was provided to the Tennessee Valley Authority (TVA) options assessment effort lead by SRNL. A significant external review of the metal fuel fabrication (casting) activities was conducted by representatives from industry, other DOE national laboratories, and universities.

This section highlights the accomplishments for campaign integration, International collaborations, fuel design and analyses, and feedstock development.

\subsection{Campaign Integration}

The transmutation fuels development team was organized as the Transmutation Fuels Campaign in the later part of FY-07. A number of high-level TFC documents were published in FY-08. In FY-09, the AFCI research direction changed to a science-based approach. A new TFC management document, TFC Implementation Plan ${ }^{1}$, was written to communicate the new direction of AFCI research and development activities in preparation for FY-10. It also includes strategies for the next 30-40 years. It was submitted to the Department of Energy Office of Nuclear Energy Headquarters in September 2009.

Four Transmutation Fuels Campaign Integration Group (TFCIG) meetings were conducted during FY-09. In general, the meetings consisted of technical presentations that provided the status of R\&D efforts. The meeting locations and dates are listed below.

- Salt Lake City, Utah on October 27-28. Discussions focused on future opportunities and work scope. Representatives from the Nuclear Regulatory Commission (NRC), DOE Office of Nuclear Energy, the Independent Review Group, and Industry were in attendance.

- Knoxville, Tennessee on February 10-11, 2009. Discussions focused on identifying potential strategic changes in work scope based on the projected new R\&D programmatic direction. ORNL 
provided a tour of HIFR and the CETE process facilities. Representatives from Industry were in attendance.

- Richland, Washington June 2-3, 2009. PNNL provided tours of the Fast Flux Test Facility (FFTF) and the Fuels and Materials Examination Facility (FMEF), specifically the Radiochemical Processing Lab (RPL) and the Materials Sciences Lab. Representatives from Industry were in attendance.

- Salt Lake City, Utah, August 26-27, 2009. FY-10 work scope was discussed, including relative input from the industry representatives.

The TFC research staff routinely publishes technical accomplishments in a variety of peer reviewed technical journals. Four specific peer review journal articles are highlighted below:

- The EBR-II X501 minor actinide burning experiment, M.K. Meyer, S.L. Hayes, W.J. Carmack, *, H. Tsai, Journal of Nuclear Materials (2009), doi:10.1016/j.jnucmat.2009.03.041

- Metallic fuels for advanced reactors, W.J. Carmack, *, D.L. Porter, Y.I. Chang, S.L. Hayes, M.K. Meyer, D.E. Burkes, C.B. Lee, T. Mizuno, F. Delage, J. Somers, W.J. Carmack et al., Journal of Nuclear Materials (2009), doi:10.1016/j.jnucmat.2009.03.007

- Stephen J. Reese, Kenneth L. Telschow, Thomas M. Lillo, and David H. Hurley, On the Establishment of a Method for Characterization of Material Microstructure Through Laser-Based Resonant Ultrasound Spectroscopy, IEEE Transactions on Ultrasonics, Ferroelectrics, and Frequency Control, Vol. 55, No. 4, April 2008. This paper was featured on the cover of the IEEE Transactions.

- Phase Characteristics of a U-22Pu-4Am-2Np-40Zr Metallic Alloy Containing Rare Earths. D.E. Burkes, J.R. Kennedy, T. Hartmann, L.N. Squires. J. Phase Equil. And Diff. (2009) 30, 309 317.

\subsection{International Collaborations}

Internationally, researchers are very active with collaborations including Korea, France, Japan, and EURATOM. Under the GEN-IV SFR Advanced Fuel Project, the AFCI Transmutation Fuels Campaign was principally responsible for writing the metal section of the Sodium Fast Reactor Fuels Comparison Report and for collating the contributions of four international participants into the March 2009 issue of the report to the SFR Steering Committee. This report was published in March 2009 and issued to the Steering Committee at the meeting in Seoul, Korea, March 6-8, 2009.

\subsubsection{Gen-IV GACID Project}

The Global Actinide Cycle International Demonstration (GACID) project seeks to demonstrate the irradiation and performance of MA-bearing MOX fuel in the Monju reactor in Japan. Critical to this effort is the supply of feedstock materials needed to fabricate characterization samples and fuels for the irradiation tests.

Np and Am Feedstock Supply - In the fall of 2008, the Transmutation Fuels Campaign arranged for the shipment of 18 grams of $\mathrm{NpO}_{2}$ and 20 grams of $\mathrm{AmO}_{2}$ to CEA-Marcoule, France. This activity required the support of the Savannah River National Laboratory, the Oak Ridge National Laboratory, and the Idaho National Laboratory.

MOX and MA-MOX Material Property Characterization - To achieve licensing for MA-bearing MOX fuel in the Monju reactor, extensive material property measurements must be made. These measurements will 
be used to accurately predict the fuel performance and behavior while under irradiation in Monju. The U.S. performed thermal property measurements in support of GACID at the Los Alamos National Laboratory.

\subsubsection{Gen-IV Advanced Fuel Project}

The Gen-IV SFR Advanced Fuel project provides the means for collaboration on the development of advanced fuels for sodium fast reactors including metallic, ceramic, nitride, and carbide fuel systems. The U.S. coordinated and published the SFR Fuels Comparison report assembled from the contributions of all participants in the project. Each section of this report has been published in referred journal articles or is currently being prepared for publication. The U.S. representative to this project will become the project management board (PMB) chair for 2010.

\subsubsection{CEA-DOE Bilateral}

In the fuels area, the U.S. DOE and CEA are jointly pursuing the assessment of the $\mathrm{UO}_{2}$-Am system as a transmutation system for Am. Researchers from DOE and CEA are currently studying the irradiation performance of an irradiation experiment testing this concept. The analyses of CEA and DOE will be shared and compared.

\subsubsection{JAEA-DOE Bilateral}

This year the JAEA-DOE Bilateral activity centered on developing future collaborative fuel research and development activities. Key in this regard is the definition and planning of transient fuel experiments needed to understand fuel response to and behavior under off-normal and over-power conditions. A workshop including the participation of JAEA, CEA, and DOE representatives was held on May 5-6, 2009 at the Idaho National Laboratory. The summary report from this meeting is available.

\subsubsection{EURATOM INERI Agreement}

EURATOM-DOE collaborative fuel research and development have focused on specific technical staff exchanges on fabrication and characterization methods with the Joint Research Center-Institute of Transuranium Elements. In July 2009, ITU staff visited the Idaho National Laboratory to discuss technologies for ceramic fuel grinding methods and ferritic-martensitic cladding welding technologies. Future exchanges will include technical exchanges on EPMA characterization methods as well as exchange of irradiated nuclear fuel specimen for round-robin characterization and comparison.

\subsection{Fuel Feedstock: (PuAm) $\mathrm{O}_{2}$ Separation Characterization System}

A specialized in-cell (PuAm) $\mathrm{O}_{2}$ gamma-ray detector system is being developed to monitor the initial $\mathrm{Pu}-$ Am inventory and spatial distribution during heating and deposition process. The amount of the Am and $\mathrm{Pu}$ will be measured in the reaction vessel, in the transfer tube, and the cold-finger where the separated Am metal is expected to deposit. The characterization system uses three state-of-the-art Cadmium-ZincTelluride (CZT) semiconductor detectors that are small and yet with limited shielding providing sufficient resolution and sensitivity to quantify $241 \mathrm{Am}$ and 239Pu inside the Fuel Cycle Facility. Figure 1 shows the Fuel Cycle Facility (FCF) in-cell shielding and collimated detector design and Figure 2 shows a CZT gamma-ray spectrum of plutonium with associated americium. The three shielded and collimated detectors are mounted on a slide system to allow any area of the separation system to be monitored. Automated data acquisition and analysis software allows continuous monitoring of release, transport, deposition, and product purity during the separation process. For additional information, contact Paul Lessing at paul.lessing@inl.gov. 


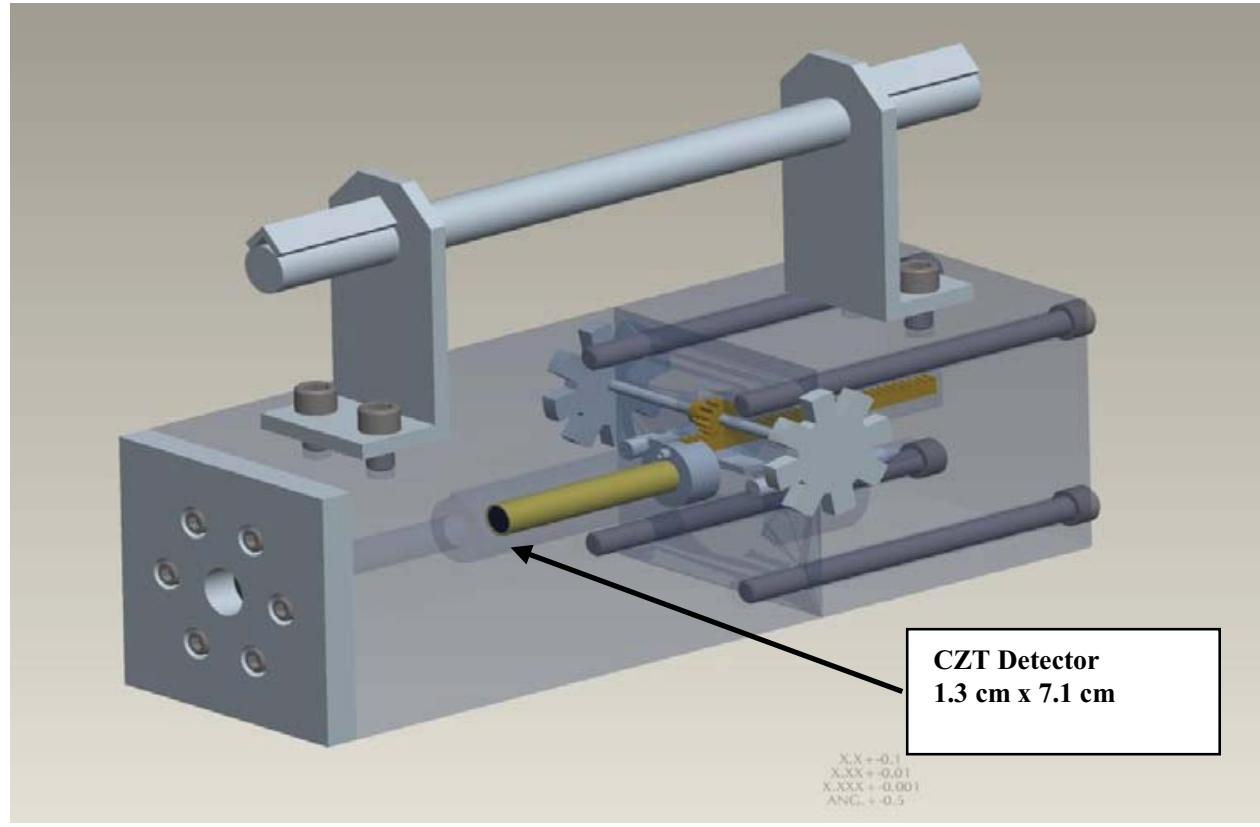

Figure 1. Collimated CZT detector

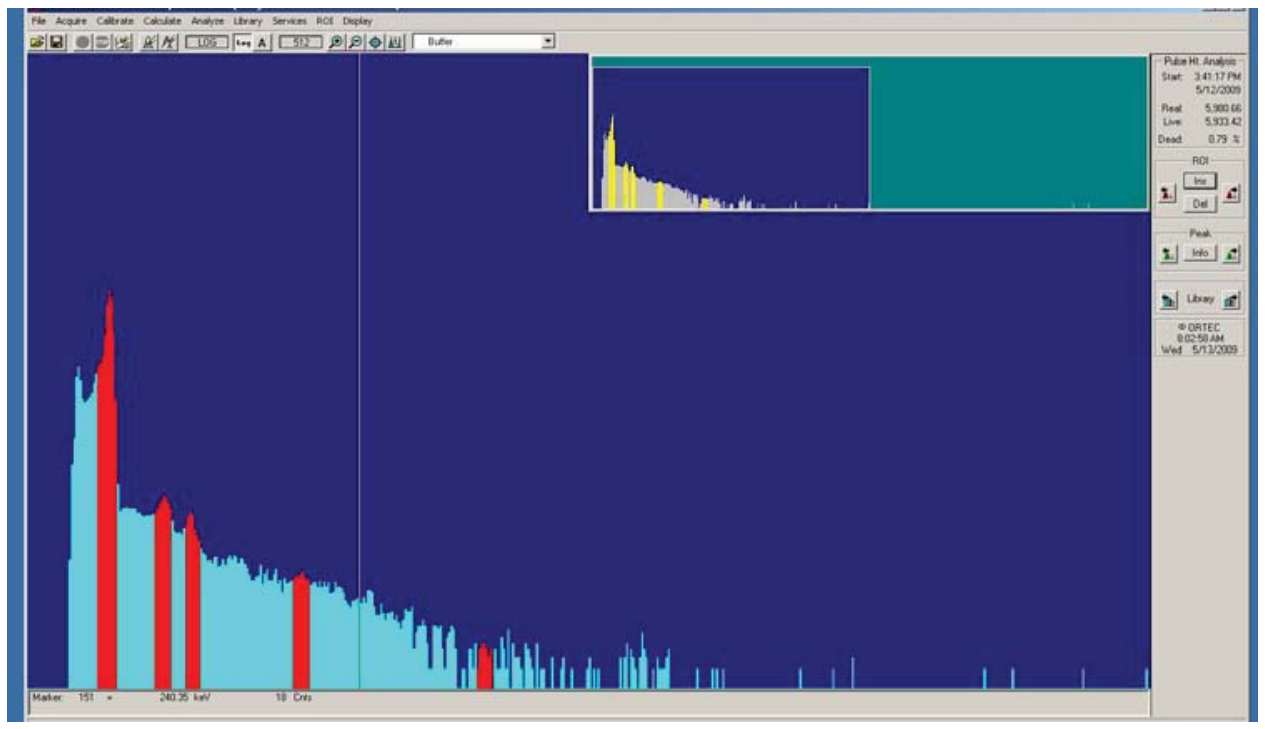

Figure 2. Pu-Am CZT Detector Spectrum

\section{OXIDE FUEL FABRICATION AND CHARACTERIZATION}

Key to the success of the Transmutation Fuels Campaign is the development of reliable low-loss fuel fabrication methods and the characterization of both fresh and irradiated fuels. Fuels fabrication activities support fuels testing and irradiation activities in the program. Ceramic fuel fabrication and characterization accomplishments for FY-09 are discussed in this section. The contact for oxide fuel development is Ken McClellan at kmcclellan@lanl.gov. 


\subsection{Oxide Fabrication Process Development (Process/Structure Relations)}

Understanding and establishing the relationships between chemistry, fabrication process and resulting microstructure is critical to developing the capability to design and control oxide fuel microstructures. Key tasks in FY-09 included characterization of individual oxide feedstocks, studies of the effects of conditioning treatments on the processing of urania, and fabrication of high quality pellets for processing and properties studies.

\subsubsection{MA-MOX Feed Characterization}

The ability to control microstructure in mixed oxide fuel fabricated using conventional powder metallurgical $(\mathrm{P} / \mathrm{M})$ processes is dependent upon the chemical and physical characteristics of the constituent feedstock powders. In FY-09, detailed characterization of the powder purities and morphologies were completed. Characterization included phase analysis by XRD, particle morphology analysis by SEM, particle size distribution by laser scattering, and particle surface area analysis by the BET method. Substantial differences were identified between each powder in terms of surface area and morphology and those differences can be related to specific processing requirements. This starting material characterization provides the foundation for subsequent feed

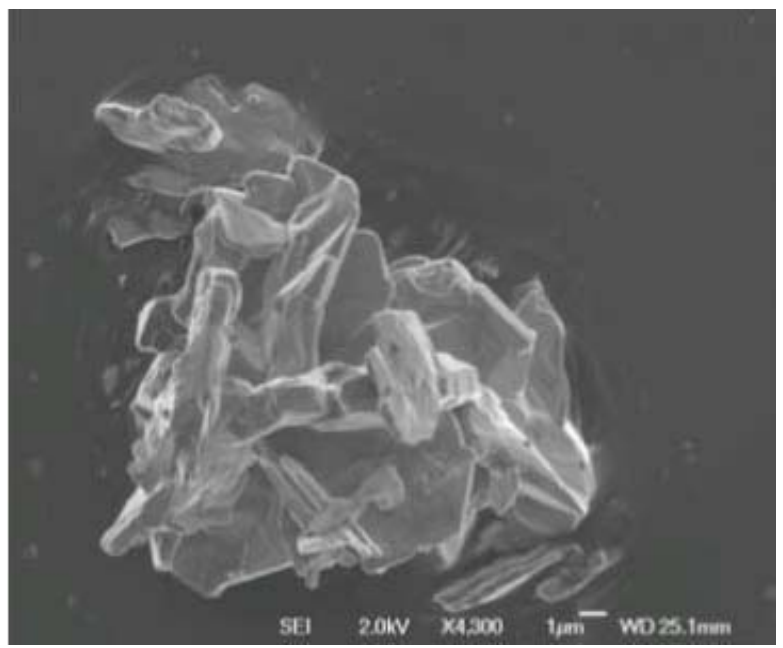

Figure 3. $\mathrm{NpO}_{2}$ powder feedstock morphology. conditioning research that will further enable microstructural control using available actinide oxide feedstocks.

In addition to the physical characteristics, the chemical purity of the powders was also examined. The key result was in the neptunium oxide feedstock which was shown to have substantial impurity content. This addresses an outstanding concern of possible Np loss during fabrication of the AFC-2C/D fuel, namely, this establishes that there was not substantial process loss. This is consistent with thermochemical models and results from JAEA.

\subsubsection{High Quality MA-MOX Pellets}

Emphasis was placed on property measurements on MOX and MA-MOX using the conventional $\mathrm{P} / \mathrm{M}$ approach. Results from the AFC-2C/D fabrication demonstrated that high quality samples for characterization with improved uniformity and lower defect contents would require changes in the fabrication protocol. Accordingly, the process was simplified with respect to feedstock content and furnace profile. This resulted in substantial improvements in pellet quality, uniformity and integrity. Samples using this process were produced

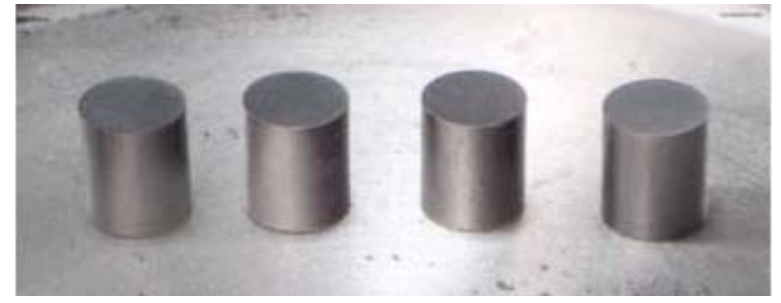

Figure 4. Pellets of four different MOX and MAMOX compositions fabricated using the simplified process. 
for characterization and property determination (specific heat, thermal expansion, thermal diffusivity, lattice parameter and elastic constants). Compositions that were fabricated included: $\left(\mathrm{U}_{0.80}, \mathrm{Pu}_{0.20}\right) \mathrm{O}_{2}$, $\left(\mathrm{U}_{0.70}, \mathrm{Pu}_{0.30}\right) \mathrm{O}_{2},\left(\mathrm{U}_{0.75}, \mathrm{Pu}_{0.20}, \mathrm{~Np}_{0.02}, \mathrm{Am}_{0.03}\right) \mathrm{O}_{2}$, and $\left(\mathrm{U}_{0.65}, \mathrm{Pu}_{0.30}, \mathrm{~Np}_{0.02}, \mathrm{Am}_{0.03}\right) \mathrm{O}_{2}$.

\subsubsection{Urania Feedstock Conditioning}

One objective for process/structure relation studies is to establish the knowledge base and techniques necessary in order to be able to achieve desired fuel microstructures. The process details required to control those microstructures is strongly influenced by the physical and chemical characteristics of the feed powder. The realities of a closed fuel cycle with recycled actinide oxide feedstock coming from a variety of reactors, means that it is necessary to be able to condition any given powder in order to enable microstructural control during fabrication. Studies of feed conditioning of existing urania powders have identified key parameters and processes to change and control the powders reactivity and flow characteristics. This was achieved by comparing and contrasting different thermal and mechanical treatments performed on "good" and "bad" urania powders.

\subsubsection{Solid State Reactions in U-Ln-O Systems}

The conventional $\mathrm{P} / \mathrm{M}$ fabrication route currently employed in the US program for mixed oxide fuel fabrication is based upon reaction of constituent powders to form a solid solution during the sintering process. The extent of the reaction is dependent upon thermodynamic stability of product phases and the reaction kinetics. The kinetics are strongly influence by the nature and distribution of lattice defects in the oxide materials. In order to more fundamentally understand the reaction kinetics, solid solutions were formed by conventional $\mathrm{P} / \mathrm{M}$ processing using U-Ln-O model systems. The reacted samples were then characterized for homogeneity and lattice parameter. In parallel, atomistic models were developed for the system examining the change in lattice parameter as a function of composition and defect type. By comparing the experimentally determined lattice parameter and the atomistic model-based predictions, the dominant lattice defect types were identified.

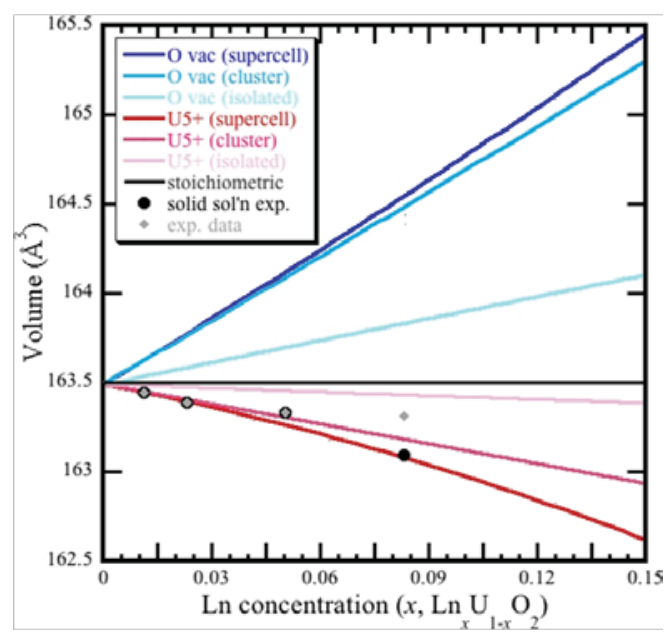

Figure 5. Comparison of calculated and experimental unit cell volumes for different defect types as a function of Ln content.

\subsubsection{Remote Fabrication}

The CMR Wing-9 made progress in various areas while also adjusting scope to the reality that the program no longer had a strong driver for remote oxide fuel fabrication in the near-term. The key accomplishment was that the stand alone operations study was completed on February 11, 2009. The study concluded that Wing 9 can be operated on a standalone basis and that operation on this basis would extend the service life of the wing by several years. 


\subsection{Oxide Fuel Development (Structure/Property Relations)}

The properties of oxide fuel pellets are determined by their chemistry, phase content and microstructure. Accordingly, understanding of the relationships between structure and properties is necessary in order to be able to optimize existing or develop new oxide fuels with targeted performance characteristics. Key FY-09 tasks included technique development for accurate microstructural characterization, integrated property measurements on U-Ln-O materials, and property measurements on MOX and MA-MOX materials.

\subsubsection{Thermal Etching and Microstructural Analysis}

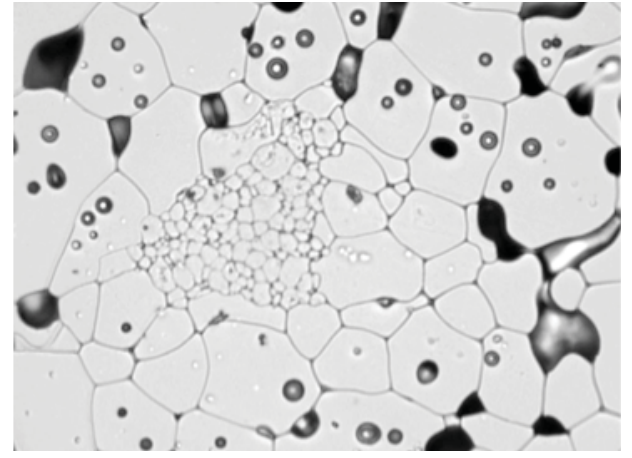

Figure 6. Etched MA-MOX showing $\mathrm{NpO} 2$-rich region.

Chemical etching is the conventional approach to enhance visibility of grain boundaries of sintered oxide pellets in order to enable quantitative microstructural analysis. However, the type and efficiency of a given chemical etchant varies with fuel composition and by its very nature generates corrosive waste containing actinide residue. As an alternative to this conventional chemical etching a thermal etching protocol was developed and demonstrated for urania, MOX and MA-MOX. Conventional microstructural characterization via quantitative stereology was successfully performed on these samples.

The thermal etching approach also better supports advanced microstructural characterization using electron back scattered diffraction (EBSD) infrastructure. During FY-09, initial EBSD scans were performed on both urania and MOX pellets. Quantitative analysis of grain sizes, orientation, texture, and grain boundary types was initiated and will continue in FY-10. In addition to providing insight into the specific nature of sintered oxide fuel microstructures, data from this analysis provide important information and guidance for transport model development being done under the Fundamental Materials Models component of the program.
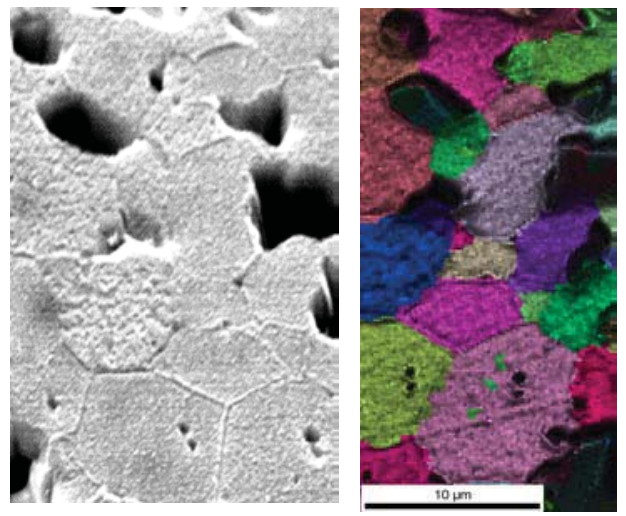

Figure 7. Conventional and EBSD microstructures.

\subsubsection{Coupled Thermophysical Property Studies in U-Ln-O Materials}

Properties and corresponding in-pile performance of oxide fuels are dependent upon the fuel chemistry and structure (both macroand micro-structures). Due to the complex interrelationships between chemistry, structure and thermophysical properties, it has been shown to be advantageous to integrate data sets from various thermodynamic and transport property measurements in order to more efficiently elucidate the structure/property relations of interest. Appropriate infrastructure and protocols were developed and demonstrated for U-Ln-O systems, primarily U-Ce-O and U-

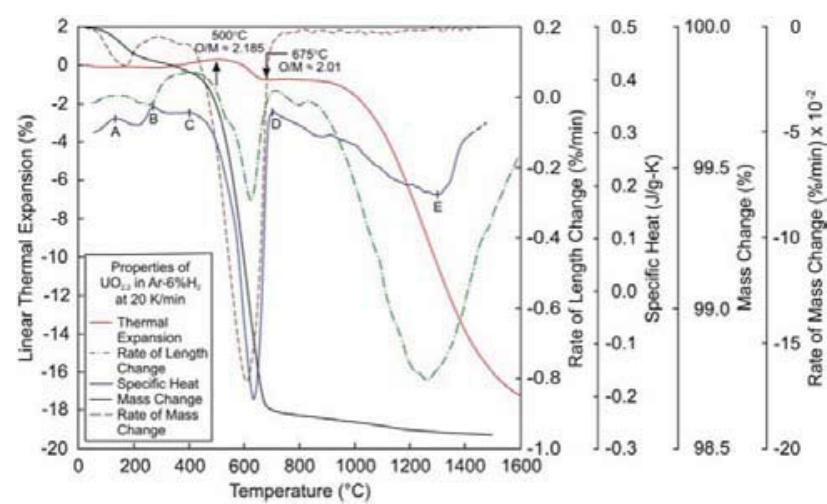

Figure 8. Combined data set for urania reference material. 
(La, Ce, Pr, Nd)-O. Coordination between the thermophysical property measurements (LANL) and thermochemical model development (ORNL) was established and will be a key relationship in the future.

\subsubsection{MOX and MA-MOX Property Determination}

The first structure/property relation studies were initiated in the US program for MA-MOX. This required chemical and microstructural characterization of archive AFC-2C/D pellets and of fresh MOX and MAMOX pellets fabricated using the simplified fabrication process. Chemical and microstructural characterization targeted phase content and distribution, homogeneity, grain morphology and size distribution, pore morphology and size distribution, and lattice parameter as a function of composition and oxygen-to-metal ratio $(\mathrm{O} / \mathrm{M})$. Property measurements were initiated for four MOX and MA-MOX compositions: $\left(\mathrm{U}_{0.80}, \mathrm{Pu}_{0.20}\right) \mathrm{O}_{2},\left(\mathrm{U}_{0.70}, \mathrm{Pu}_{0.30}\right) \mathrm{O}_{2},\left(\mathrm{U}_{0.75}, \mathrm{Pu}_{0.20}, \mathrm{~Np}_{0.02}, \mathrm{Am}_{0.03}\right) \mathrm{O}_{2}$, and $\left(\mathrm{U}_{0.65}, \mathrm{Pu}_{0.30}, \mathrm{~Np}_{0.02}\right.$, $\left.\mathrm{Am}_{0.03}\right) \mathrm{O}_{2}$. Initial property measurements were focused on thermal expansion, specific heat, and elastic constants. Measurements will continue in FY-10 focusing on these properties as a function of temperature, starting $\mathrm{O} / \mathrm{M}$ and atmosphere ( $\mathrm{Ar}$ and $\mathrm{Ar}-6 \% \mathrm{H}_{2}$ ).

\subsection{Spark Plasma Sintering FOA}

Low-temperature sintering routes offer increased variety to the materials properties of sintered bodies because the sintering mechanisms can be different than conventional bulk densification mechanisms. Spark plasma sintering (SPS) is a low-temperature, high-pressure sintering process that has growing interest and that has been shown to alter the materials properties - enough to induce commercial production for some applications. A collaborative effort was organized to include four universities and recruited an internationally recognized and the domestic leader of SPS - Professor Zuhair Munir at UC Davis - to lead the SPS experimentation.

Progress has been made to understand the potential benefits of this technique using surrogates for nuclear fuels, and a milestone report is scheduled for December 2009. Focus areas lie in establishing sintering parameters in relation to materials properties of the sintered bodies at near theoretical and less than theoretical densities (See Figure 9 for example). Nanocrystalline and microcrystalline powders have been used as starting materials. The technical progress presented at a quarterly review meeting was sufficient to prompt commercial and university interest, e.g., one university researcher arranged to purchase a SPS machine.

Other accomplishments besides technical may be noted. Graduate students have been introduced to the materials science of nuclear fuels.

Relationships have been developed and contacts

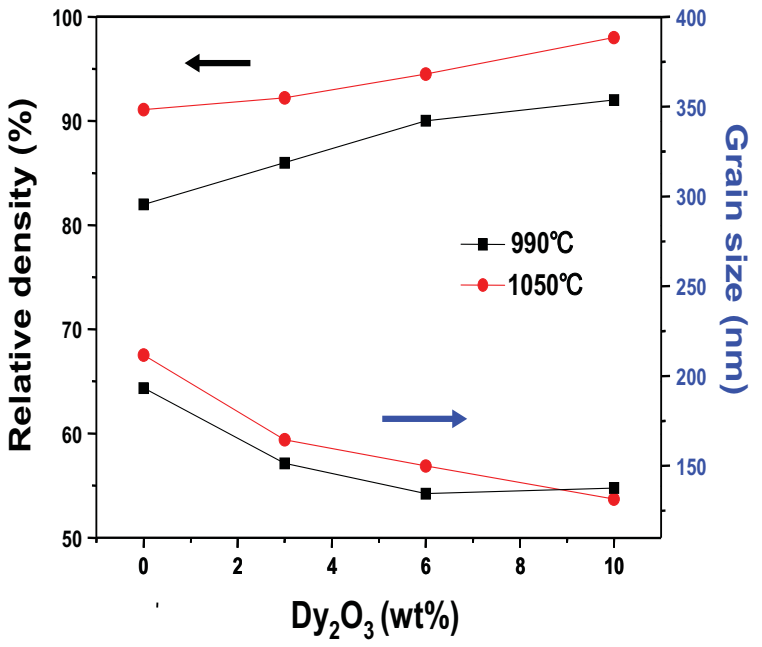

Figure 9. Effect of Dy2O3 Content on the Relative Density and Grain Size of Sintered $\mathrm{CeO} 2$ at Different Temperatures (130C per min., $500 \mathrm{MPa}, 5 \mathrm{~min}$ ) have been made to assure future progress even outside the realm of SPS. In particular, the ability to characterize oxide fuels has been enhanced at University of Nevada - Las Vegas through a joint faculty appointment. For additional information, contact Robert Mariani at Robert.mariani@inl.gov. 


\subsection{Sphere-Pac Development}

The scope of the FY-09 Sphere-Pac work package included five tasks:

1. Perform development of micro/mini-spheres fabrication process

2. Evaluate levels of residual sulfur in spheres from resin loading process

3. Characterize $\mathrm{Am} / \mathrm{Cm}$ oxide spheres

4. Am/Cm oxide scoping irradiation design

5. International/University collaborations.

A description of each task and a progress summary to date is given below. For additional information, contact Stewart Voit at voitsl@ornl.gov.

\subsubsection{Task 1: Perform Development of Micro/Mini-Sphere Fabrication Process}

The fabrication of spherical particles for nuclear fuel/targets is accomplished via one of two routes; gelation (internal or external) or resin loading. Historically, the gelation approach has been used to fabricate near fully dense particles of a single composition. This approach has been successfully demonstrated for the fabrication of spherical particles for a driver fuel type application; however, particles used as a transmutation target may need to contain minor actinides but at a smaller fraction of the total matrix.

The FY-09 Sphere-Pac work package is focused on developing a process that will allow the fabrication of a porous particle of a base composition. A second minor actinide bearing phase will be infiltrated into the particle open porosity then the two-phase particle will be sintered to final density. Figure 10 shows a process flow diagram for the infiltration process.

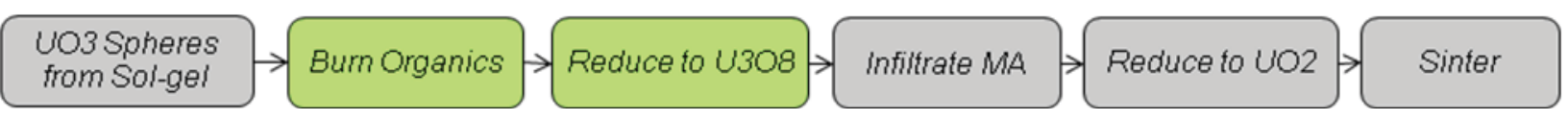

Figure 10. Infiltration Process for Porous Sol-Gel Particles

Uranium trioxide spheres from the sol-gel external gelation process were chosen for the initial studies. The reduction of $\mathrm{UO}_{3}$ particles to $\mathrm{U}_{3} \mathrm{O}_{8}$ is the critical step for the retention of open and interconnected porosity thus this work focused on the steps shaded green as shown in Figure 10. During these steps, the reduction parameters; such as, furnace ramp rate, temperature, and atmosphere, must be chosen so that the residual organic material does not burn off too rapidly and the reduction to $\mathrm{U}_{3} \mathrm{O}_{8}$ proceeds with minimal sintering so that particle pores remain open and interconnected. A series of experiment runs have been performed under varied conditions and an example of the results is shown in Figure 11.

Differential Thermal Analysis (DTA) was used to evaluate reaction rates and the temperatures at which reactions initiate and come to completion. The preliminary DTA results show that the residual organic materials is burned off by $\sim 450^{\circ} \mathrm{C}$ and that the $\mathrm{UO}_{3}$ to $\mathrm{U}_{3} \mathrm{O}_{8}$ phase transition occurs near $600^{\circ} \mathrm{C}$ and is atmosphere dependent. Preliminary X-Ray Diffraction (XRD) results of the particles after reduction indicate a second phase which is possibly $\mathrm{UO}_{3}$ or $\mathrm{UO}_{2}$ (see Figure 12). The data suggest that process improvements can be made that will allow slow burn of the organic component and controlled reduction to $\mathrm{U}_{3} \mathrm{O}_{8}$. Further work must be done to indentify preferred processing parameters for the reduction and to characterize the nature of the porosity. 


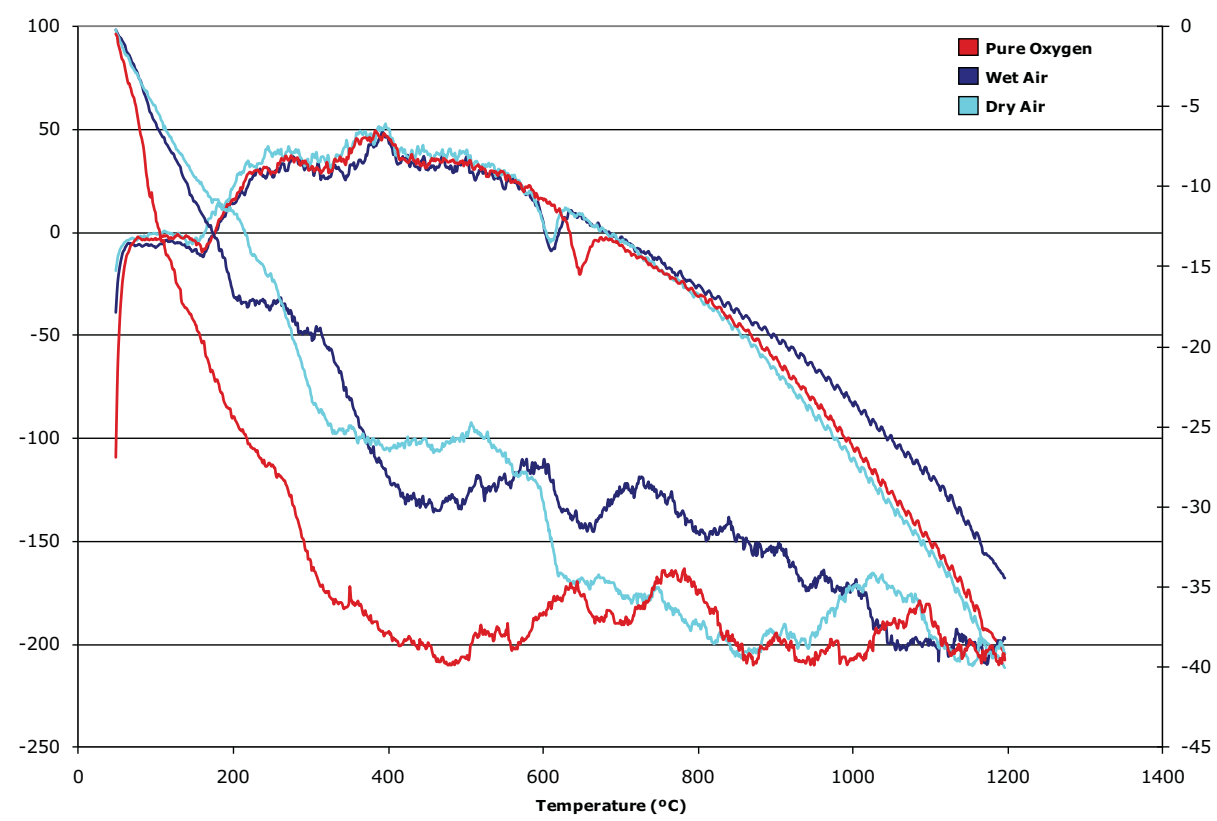

Figure 11. Evaluating Reduction of $\mathrm{UO}_{3}$ to $\mathrm{U}_{3} \mathrm{O}_{8}$ using Differential Thermal Analysis
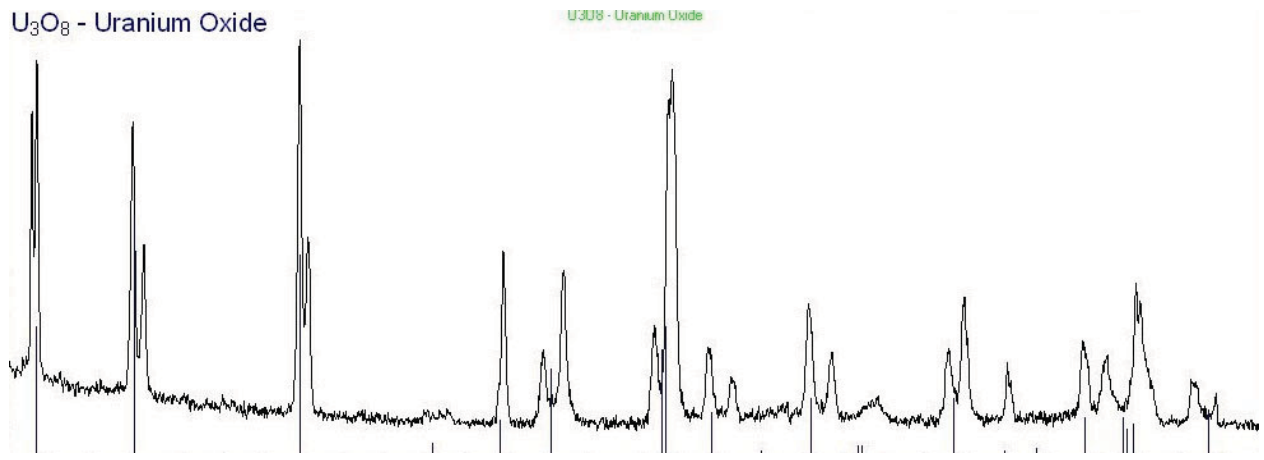

Figure 12. X-Ray Diffraction Pattern of Uranium Oxide Particles after Reduction

\subsubsection{Task 2: Evaluate Levels of Residual Sulfur in Spheres from Resin Loading Process}

An alternative to the gelation technique for fabricating spherical particles is the resin loading process. In this process, metal cations with a +3 valence state are dissolved in a nitric acid solution then contacted on a column of resin beads, in this case DOWEX-50W. The resin is made up of an aromatic hydrocarbon ring and a sulfonic acid group. Three of these compounds combine with one +3 cation as shown in Figure 13.

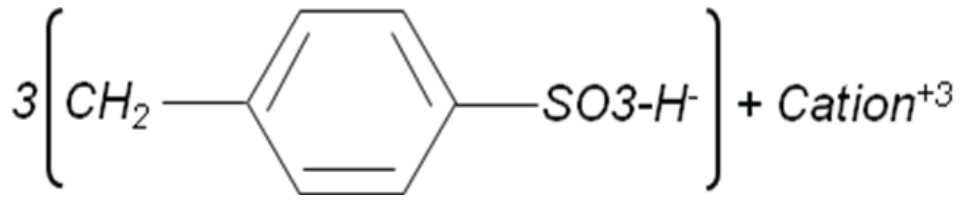

Figure 13. Strong Acid Resin Chemistry 
The first step in the present study was to establish the reaction enthalpy and temperatures at which the resin has been completely removed. This work was performed using a DTA under conditions of varied temperature, ramp rates, and atmospheres. Preliminary results are shown in Figure 14.

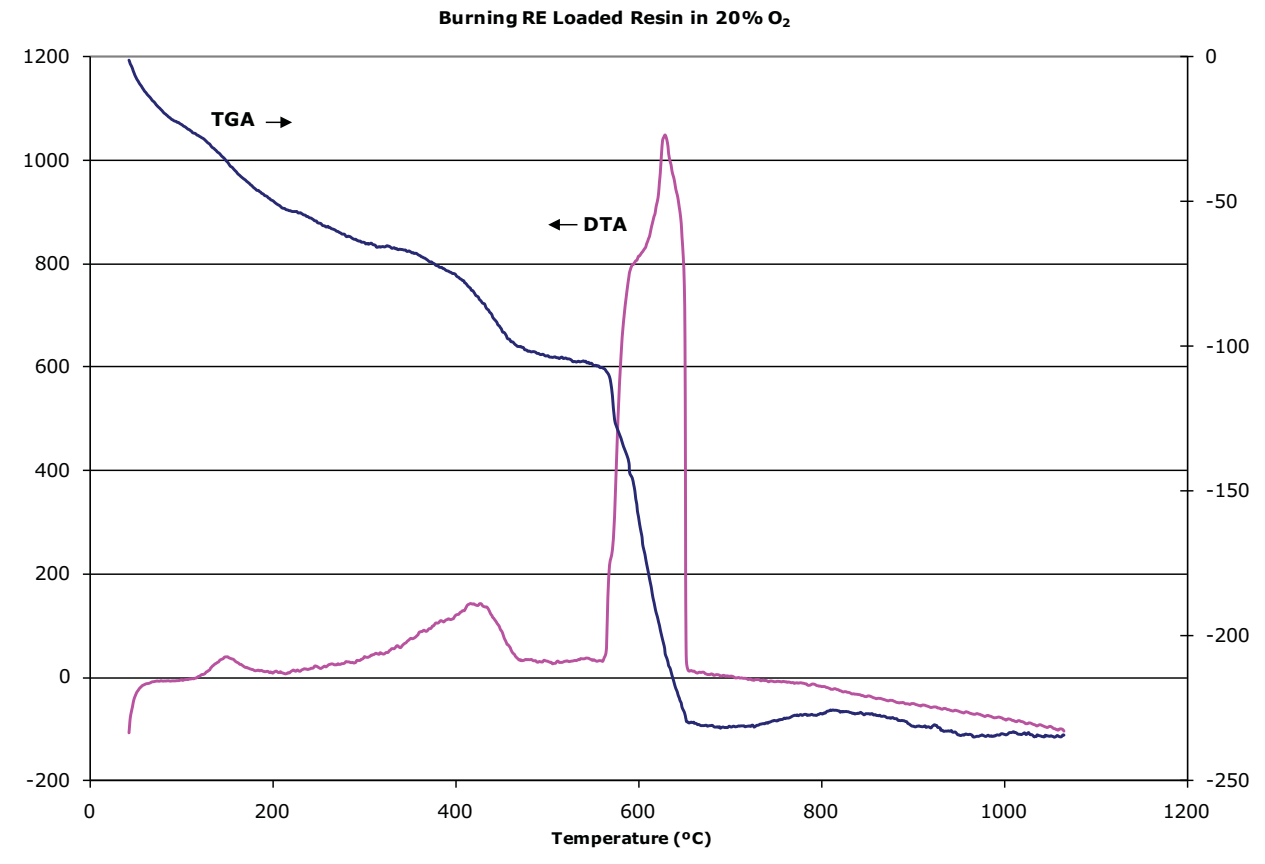

Figure 14. Evaluating Resin Removal using Differential Thermal Analysis

Historically, the resin removal process has been performed at $800^{\circ} \mathrm{C}$; however, the result shown in Figure 14 reveals that the resin removal can be completed by $\sim 650^{\circ} \mathrm{C}$. This result is significant in that it demonstrates the ability to vary process conditions potentially allowing greater control of particle characteristics. The next step in this work will be the evaluation of residual sulfur levels in the calcined particles. This will be studied by thermally treating a series of samples at various temperatures and atmospheres then analyzing each sample for residual sulfur impurity.

\subsubsection{Task 3: Characterize $\mathrm{Am} / \mathrm{Cm}$ Oxide Spheres}

Am/Cm oxide spheres are being fabricated in the hot cell area of the Radiochemical Engineering Development Center (REDC) and supplied to the Fuels R\&D program. The fabrication of these spheres is expected to be complete by $9 / 2 / 2009$ at which time the batch will be sampled for analysis. The Am/Cm oxide particles will be analyzed for particle size, surface area, phase content, residual impurities, and morphology. It is expected that the particle size, surface area, and phase content will be completed by the end of FY-09. The impurity and morphology analysis will be performed at the beginning of FY-10 using carryover dollars. 


\subsubsection{Task 4: Am/Cm Scoping Irradiation Design}

The goal of this task was to achieve a design for scoping irradiation of $\mathrm{Am} / \mathrm{Cm}$ oxide particles using a rabbit-type irradiation capsule. Results from the irradiation test should reveal information on helium generation rates from $\mathrm{Am} / \mathrm{Cm}$ oxide as a function of time, temperature, and microstructure. Using a hydraulic rabbit, time-resolved information related to helium generation and bubble formation should be revealed. The preliminary capsule design is shown in Figure 15.

The capsule design consists of the sample loaded in a quartz tube which is surrounded by a thermal neutron shield and the aluminum rabbit housing. Various shield materials were evaluated for effectiveness at filtering thermal and epithermal neutrons. Figure 16 shows the flux spectrum for various shield materials. Europium was chosen because of the more effective shielding of epithermal neutrons which translates to a reduction in the heat generation rate. The heat generation rate as a function of shield material and High Flux Isotope Reactor (HFIR) axial position are shown in Figure 17 and Figure 18, respectively.

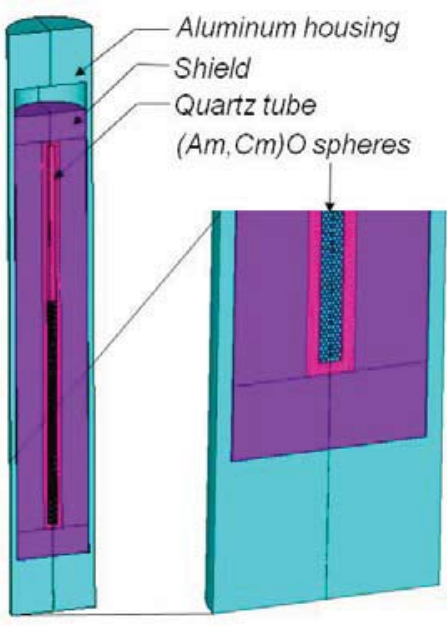

Figure 15. Am/Cm Scoping Irradiation Capsule Design

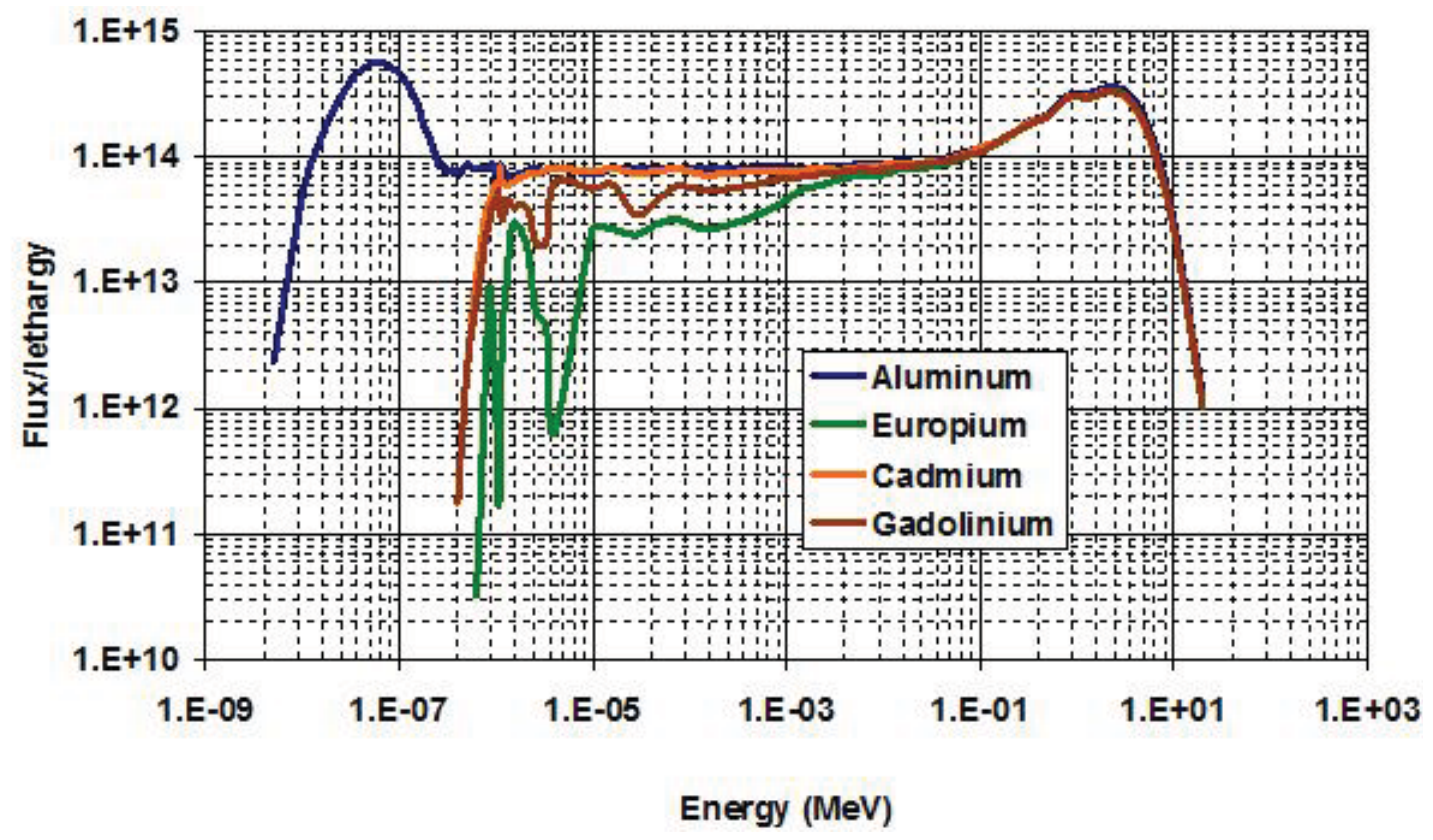

Figure 16. Flux Spectrum for Various Shield Materials 


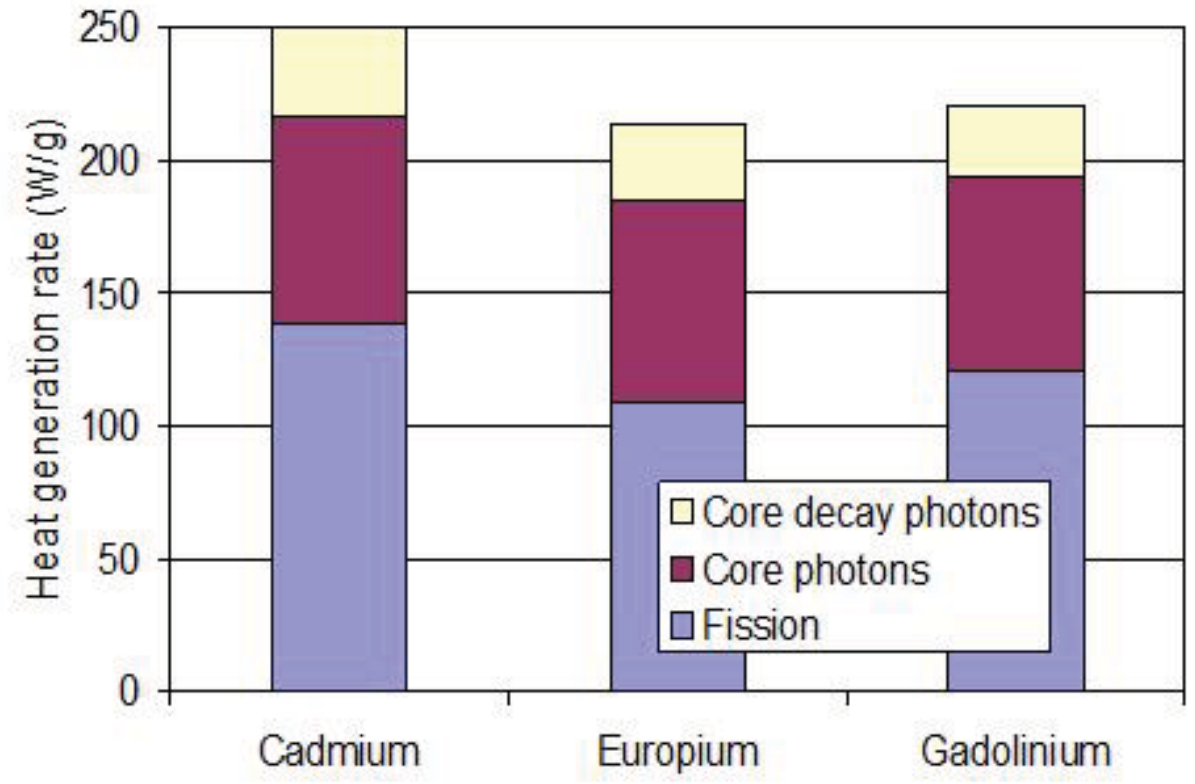

Figure 17. Heat Generation Rate for Various Shield Materials

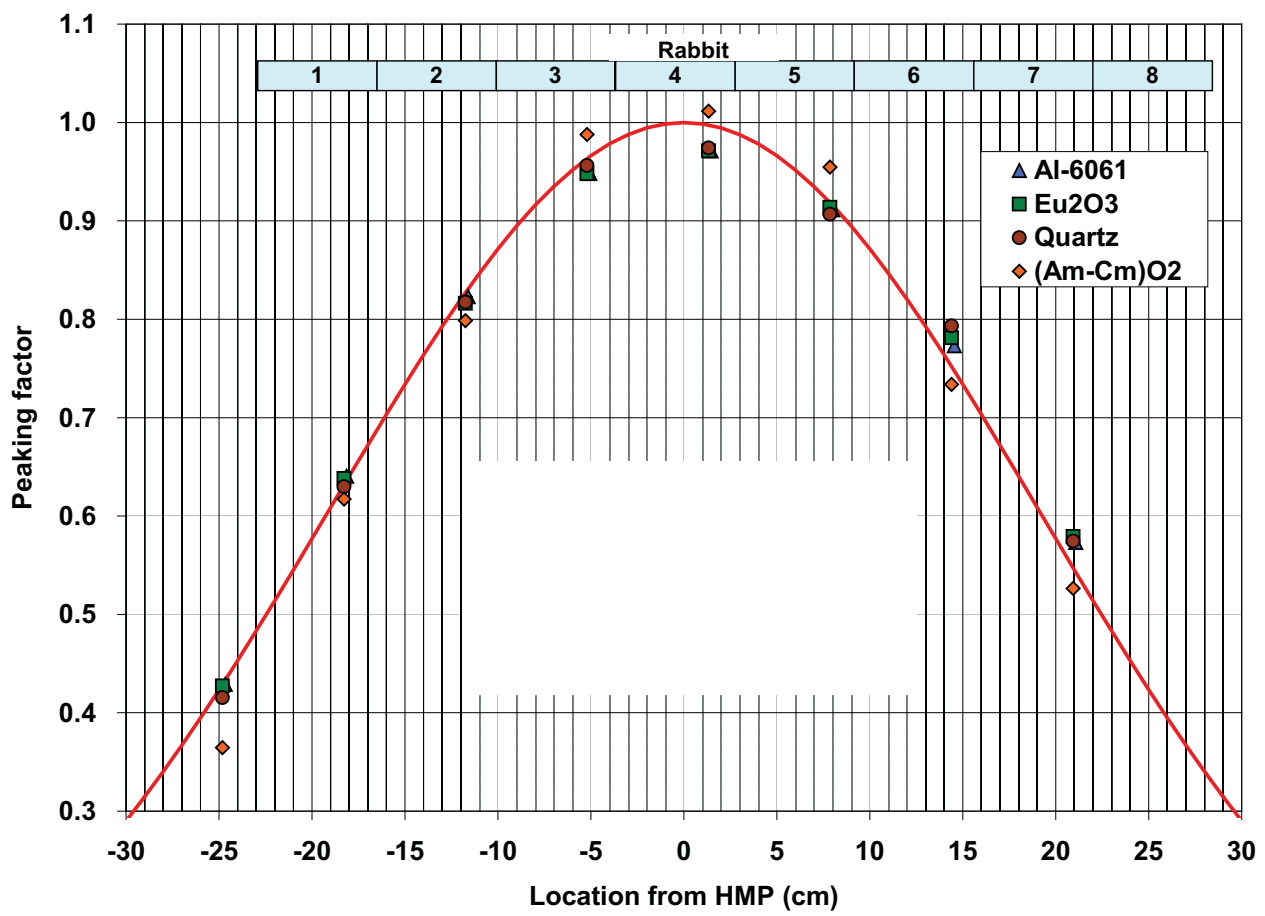

Figure 18. Heat Generation as a Function of HFIR Axial Position 
The location of rabbit positions 1 through 9 with respect to the HFIR midplane is shown in Figure 18. The HFIR midplane is designated as the " 0 " position on the abscissa. For the initial thermal analysis, rabbit position 1 was chosen. This corresponds to approximately -20 $\mathrm{cm}$ from the HFIR midplane. At this position, the maximum temperature in the sample is approximately $1000^{\circ} \mathrm{C}$ and is designated $\mathrm{T}_{\max }$ in Figure 19.

The amount of sample chosen for the first analysis was 5000 particles, which corresponds to a sample length of approximately 0.63 inches. The thermal analysis reveals an axial temperature gradient in the sample of $\sim 200^{\circ} \mathrm{C}$ which is too large to reveal temperature related helium release data. The next design iteration will include changes in sample size and radial thickness in order to flatten the axial and radial temperature profile.

\subsubsection{Task 5: International/University Collaborations}

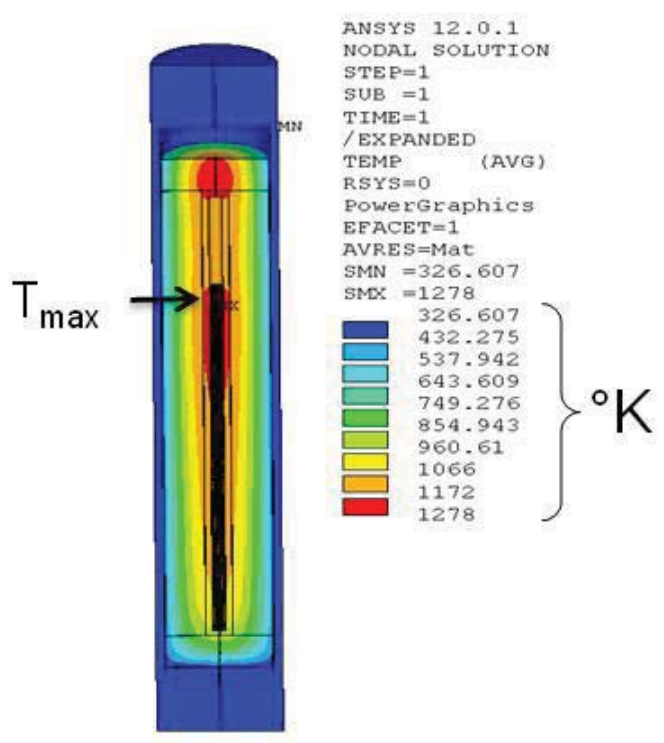

Figure 19. Preliminary Thermal Analysis of $\mathrm{Am} / \mathrm{Cm}$ Scoping Irradiation Capsule

Discussions with colleagues at the Institute for Transuranium Elements (ITU) regarding sphere-pac research and development have been initiated and there is general agreement between the research staff that an International Nuclear Energy Research Initiative (I-NERI) proposal should written to cover research on particle fuels/targets and submitted for consideration.

\subsection{Thermochemical Modeling}

An effort is underway at ORNL to generate critical information regarding phase equilibria and thermochemistry of the transuranic fuels and targets for burning in nuclear reactors. The effort includes gathering historical data from the literature for use with current computational tools to advance the understanding of phase equilibria and thermo-chemical information in support of accelerated fuels development.

The computational approach uses a compound energy formalism based model of the (U,Pu) $\mathrm{O}_{\mathrm{x}}$ system to generate $\mathrm{pO}_{2}, \mathrm{H}_{2}: \mathrm{H}_{2} \mathrm{O}$, and $\mathrm{CO}: \mathrm{CO}_{2}$ data to help inform oxygen to metal ratio experimental work at LANL. Initial work has begun with an assessment of the thermochemical processing conditions for oxidation/reduction of hyperstoichiometric $\mathrm{UO}_{2+\mathrm{x}}$. Oxygen to metal $(\mathrm{O}: \mathrm{M})$ ratios of approximately $2.00-$ 2.04, can be achieved via dew point control of a humidified $\mathrm{Ar}-6 \% \mathrm{H}_{2}$ process gas stream; however, at higher oxygen stoichiometries, the water vapor pressure is too close to the total pressure resulting in an upper limit with respect urania oxidation using the hydrogen process gas system. A CO: $\mathrm{CO}_{2}$ process gas system may be more practical in the hyperstoichiometric regime.

The compound formalism based model was also used to assess the thermochemical processing conditions for reduction of hypostoichiometric $\left(\mathrm{U}_{80}, \mathrm{Pu}_{20}\right) \mathrm{O}_{2-\mathrm{x}}$ and $\left(\mathrm{U}_{70}, \mathrm{Pu}_{30}\right) \mathrm{O}_{2-\mathrm{x}}$ during fuel fabrication. The calculation identified the partial pressure of moisture in the furnace $\mathrm{Ar}-6 \% \mathrm{H}_{2}$ gas stream as a function of $\mathrm{O}: \mathrm{M}$ and temperature. These values were then correlated with the partial pressure of moisture in the Ar$6 \% \mathrm{H}_{2}$ gas stream above the water bath as a function of water bath temperature. Results from this analysis are shown in Figure 20 and the indication is that it may be difficult to achieve an oxygen to metal (O:M) ratio $<1.98$ using Ar- $6 \% \mathrm{H}_{2}$ flowing through a chilled water bath, except at very high furnace temperatures. An alternate method for achieving low O:M values would be to perform a time dependent anneal with dry $\operatorname{Ar}-6 \% \mathrm{H}_{2}\left(\Delta \mathrm{GO}_{2}=-530 \mathrm{~kJ} / \mathrm{mol} @ 1700^{\circ} \mathrm{C}\right)$. 

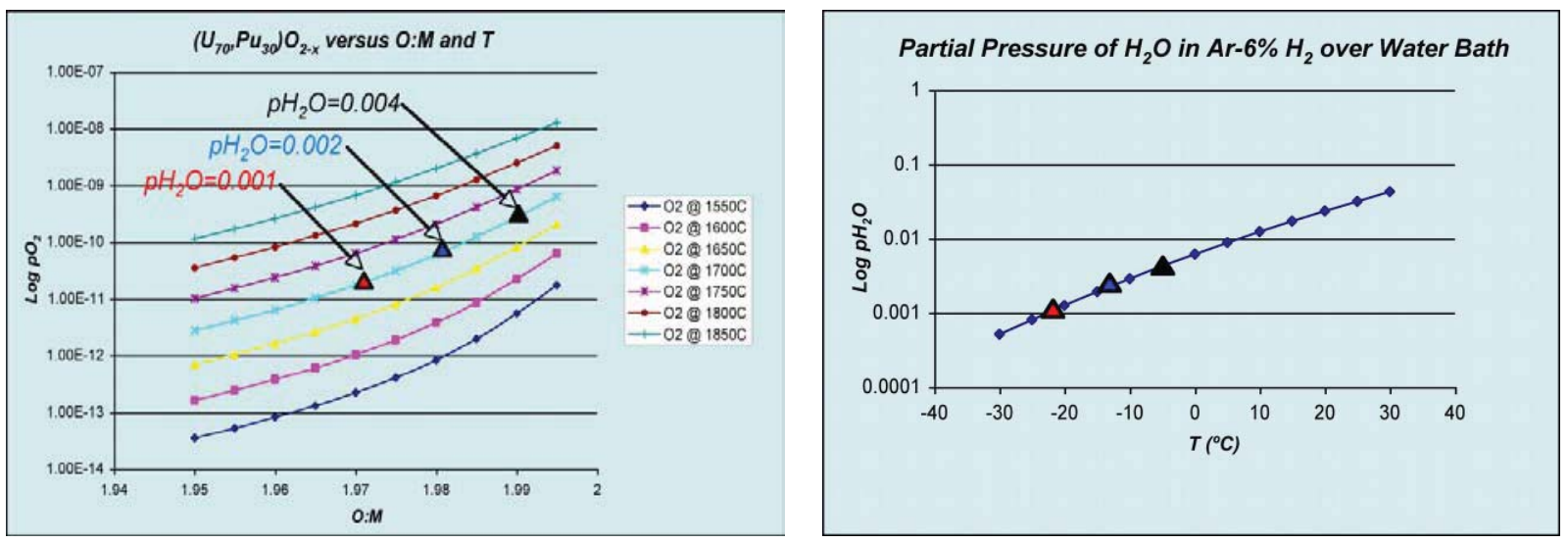

Figure 20. Process Conditions to Achieve Low O:M for Reference MOX Composition

In parallel with the computation work, an effort was initiated to investigate the thermochemistry of uranium oxide - lanthanide oxide systems. The first step undertaken is a comprehensive review of literature data with respect to lanthanide oxide non-stoichiometry and phase equilibria. The data collected in the first phase is being used to build a database of thermochemical and phase equilibrium properties of the U-Ce-O system. The database will be used to support thermochemical model development and to identify gaps in the data that can be filled by experimental work.

Critical to the success of the thermochemical modeling effort is the close coordination with oxide fuel colleagues at LANL. ORNL staff members have participated in an oxide fuel thermochemistry video conference on May $20^{\text {th }}$ and a coordination meeting held at LANL on July 15 . Topics discussed included the close coupling of experiment and modeling of compositions in the U-Ce-O system, solidus and liquidus of hyperstoichiometric urania, and future oxide thermochemistry work package planning. For additional information, contact Stewart Voit at voits1@ornl.gov.

\section{METAL FUEL FABRICATION AND CHARACTERIZATION}

Metallic fuel fabrication and characterization accomplishments for FY-09 are discussed in this section. The contact for metal fuel development is Rory Kennedy at rory.kennedy@inl.gov.

\subsection{AFC2 General Fuel Characterization}

Irradiation experiments are being conducted in the Advanced Test Reactor (ATR) to investigate fresh metallic fuels loaded with plutonium, americium and neptunium. A strong emphasis is placed on understanding the performance of these transuranics in a fast reactor because the neutronics are more efficient for burning them. Since the ATR does not have the ideal fast neutron spectrum, an experimental basis was developed to gauge ATR tests with respect to a well-characterized fast reactor.

The AFC-2E Test is a continuation of a series of irradiation experiments designed to investigate fuel performance for the AFCI, and it provides the gauge for understanding AFCI irradiation test results in a fast reactor context, such as EBR-II. The six fuel rodlets that have been fabricated into fuel elements have one of two chemical compositions: $70 \mathrm{U}-20 \mathrm{Pu}-10 \mathrm{Zr}$ and $65 \mathrm{U}-20 \mathrm{Pu}-3 \mathrm{Am}-2 \mathrm{~Np}-10 \mathrm{Zr}$. The irradiation testing of these compositions supplements the limited irradiation data for fuels loaded with transuranics, and it enables important analyses of the transuranic loading effects.

Two of the six rodlets were made from fuel that was archived when EBR-II fuel was prepared. As a result, their performance allows differences in fabrication to be assessed (arc-melted in ATR versus injection molded in ATR). The performance of the $\mathrm{U}-\mathrm{Pu}-\mathrm{Zr}$ rodlets in ATR can be compared to the 
performance for fuels in EBR-II, so that differences in the neutronics for these two reactors can be assessed (arc-melted and injection-molded in ATR versus injection-molded in EBR-II). Most important, the performance of the freshly cast U-Pu-Zr rodlets in ATR will be compared to the rodlets loaded with americium and neptunium, so that the benefits of the fuel cycle can be quantified.

The fuel slugs have been cast and the fuel rodlets have been fabricated. The chemistry and isotopics of the fuel alloys were measured. As a reference point for two of the as-cast alloys (the two chemical compositions), microstructures were observed with the SEM (see Figure 21).

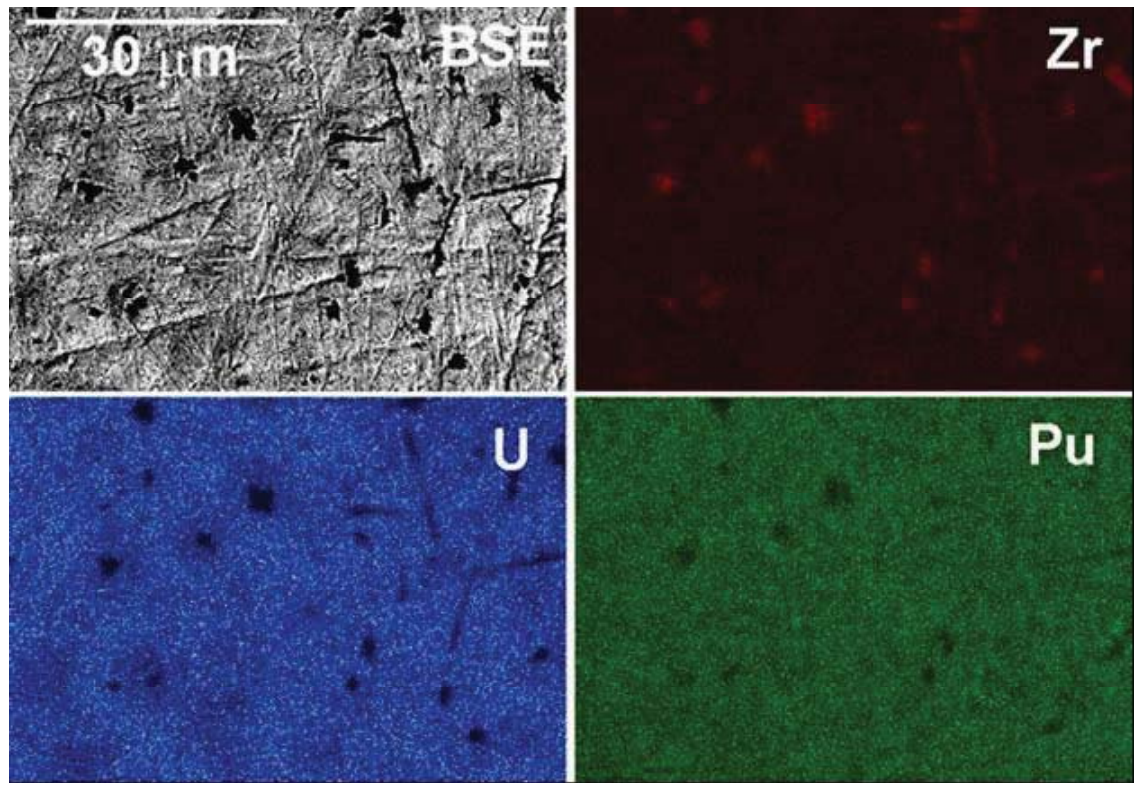

Figure 21. BSE images and X-ray maps showing spatial distributions of $\mathrm{U}, \mathrm{Pu}$, and $\mathrm{Zr}$. Bright areas in the maps have relatively high concentrations of the mapped elements; dark areas have low ones.

Thermal properties were also determined for these two alloys, since there is scant literature for the ternary and higher alloys. The thermal characterization included thermo-mechanical analysis, differential scanning calorimetry, and laser flash diffusivity. Further analysis of the thermal characterization results gave the thermal conductivity for the two compositions (see Figure 22). These data provide starting-point information against which fuel irradiation performance can be compared. For additional information, contact Tom O’Holleran at thomas.oholleran@inl.gov.

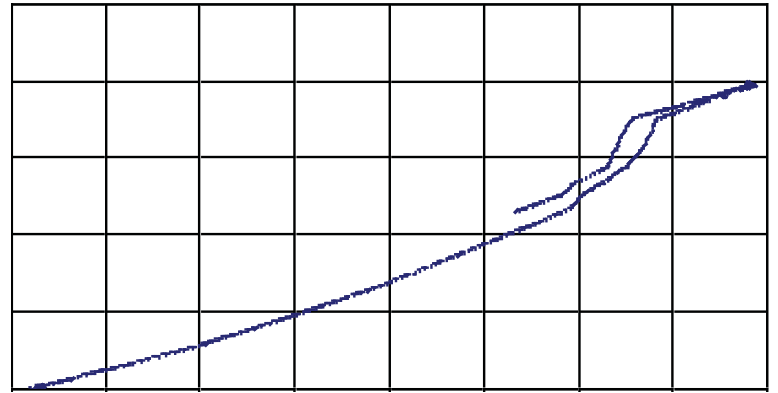

(A)

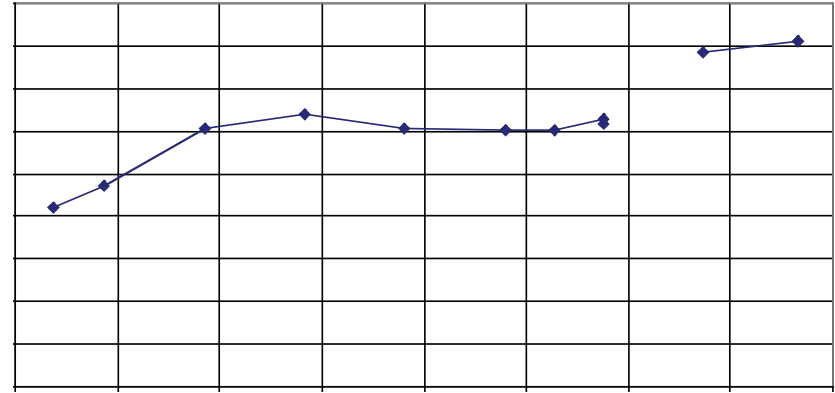

(B)

Figure 22. (A) AFC2-E1 Heating and Cooling Expansion Curves (as-cast) (B) Evaluated Thermal Conductivity of E1 Alloy. 


\subsection{Fuel Cladding Chemical Interaction}

The issue of fuel-cladding interaction is of critical importance to fuel performance. Quantification of the thermodynamic and kinetic aspects of the chemical interaction between the fuel and cladding material will allow simulated projection of fuel failure events. Evidence has been presented in the past that the buildup of lanthanide fission products in the fuel can enhance the chemical interaction between the fuel and cladding. Diffusion couple studies were performed to investigate the influence of lanthanide additions (up to $8 \mathrm{wt} \%$ representing potential end-of-life concentrations in the fuel) on the fuel-cladding-chemical interaction, with particular emphasis on identifying the early onset of interactions that may lead to cladding failure. Figure 23 shows the results of a diffusion couple experiment involving a fuel composition with 8 weight percent rare earth (RE) addition (52U 20Pu $3 \mathrm{Am} 2 \mathrm{~Np} 15 \mathrm{Zr} 8 \mathrm{RE}$ ). This experiment was heated at $550^{\circ} \mathrm{C}$ for 300 hours. The formation of a zirconium layer at the fuel - cladding interface is not unusual, and normally seems to act as a diffusion barrier inhibiting fuel - cladding interactions. However, in this experiment, a rare earth layer (represented by neodymium) can be seen to have penetrated through the zirconium lay and into the cladding. Further work is needed to fully characterize this interaction. Contact Jim Cole at James.cole@inl.gov.
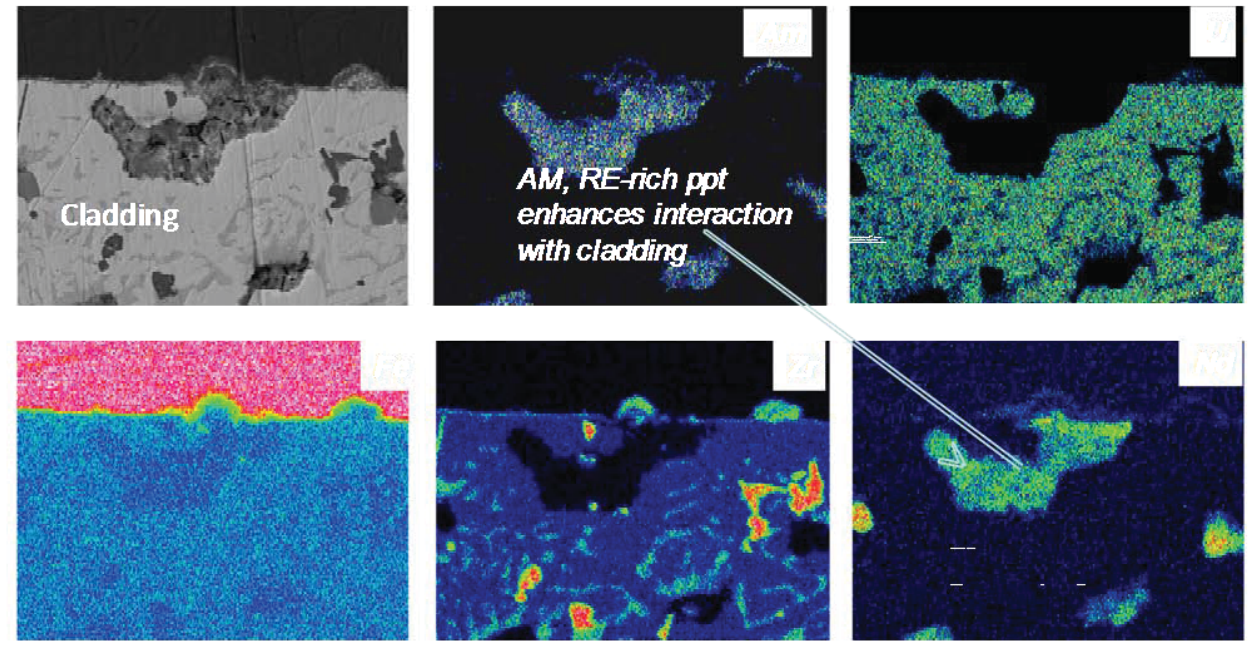

Figure 23. Back scattered electron image (upper left) and characteristic X-ray maps as labeled showing elemental spatial distributions resulting from fuel - cladding interaction. In particular, note the neodymium penetration into the cladding beyond the zirconium layer in the region where the rare earth $(\mathrm{Nd})$ inclusion was in contact with the cladding.

\subsubsection{Basic Fuel Property Determinations}

The development of physics based modeling and simulation will require experimental determination of fundamental properties of the actinides and relevant actinide bearing materials (alloys and ceramics) for both validation and verification of the models and as input data where necessary. A major advancement for obtaining this data was achieved with installation of a high-temperature X-ray diffraction goniometer (see Figure 24). This apparatus allows direct, near real time observation and analysis of high-temperature phases and phase transitions, eliminating the need for separate heat treatments and quenches. Heat treating and quenching to freeze in high temperature phases can introduce uncertainty into interpretation of the results, particularly if phase transition kinetics are rapid. Table 1 shows early results using this apparatus. These analyses were performed on Alloy B2 (U-55Pu-20Zr). 


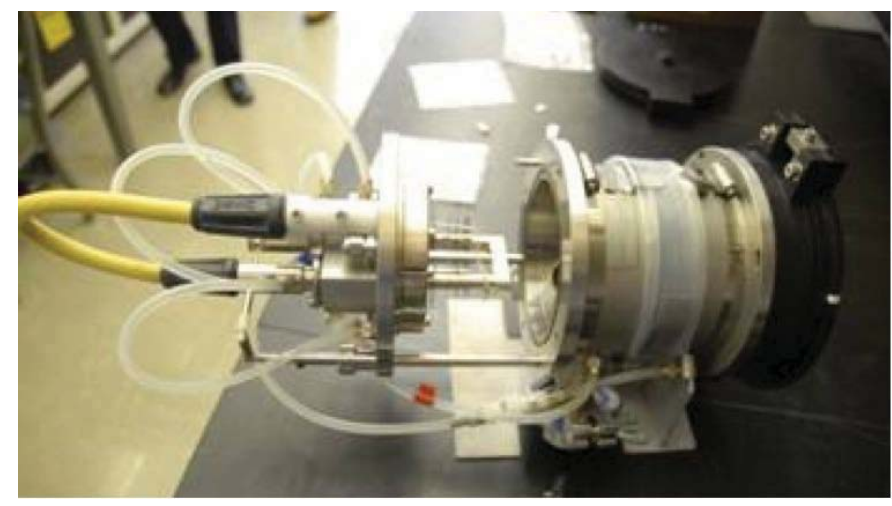

Figure 24. High-temperature X-ray diffraction goniometer that allows direct analysis of high temperature phases and phase transitions.

Table 1. Results of high-temperature X-ray diffraction analysis of Alloy B2 performed at $650^{\circ} \mathrm{C}$. As-cast and annealed results obtained at room temperature are shown for comparison.

\begin{tabular}{|c|c|c|c|c|c|c|c|}
\hline Condition & Phase-> & $\boldsymbol{\delta}\left(\mathbf{U Z r}_{\mathbf{2}}\right)$ & $\boldsymbol{\zeta} \mathbf{P u}-\mathbf{U}$ & $\boldsymbol{\alpha} \mathbf{U}$ & $\boldsymbol{\gamma} \mathbf{U}$ & $\boldsymbol{\alpha} \mathbf{Z r}$ & $\delta \mathbf{P u}$ \\
\hline As-cast & $\mathrm{Wt} \%$ & 77.0 & 19.8 & 2.8 & 0.4 & - & - \\
\hline Annealed & $\mathrm{Wt} \%$ & 1.2 & 24.6 & 11.0 & - & 59.1 & 4.1 \\
\hline $650 \mathrm{C}$ & $\mathrm{Wt} \%$ & 57.9 & 29.5 & 0.6 & 4.8 & 7.2 & - \\
\hline
\end{tabular}

\subsection{Laser-Based Characterization Technique Development}

\subsubsection{Laser-based thermal effusivity measurement}

Idaho National Laboratory has established a subcontract with Utah State University to construct and test a laser-based apparatus to measure thermal effusivity. In combination with thermal diffusivity measurements, thermal effusivity can provide a spatially resolved map of thermal conductivity. Based on the thermoreflectance technique, researchers at Utah State University have derived a relationship between the phase lag of the reflected signal and the thermal effusivity of the sample. Currently efforts are directed at constructing and testing a preliminary measurement apparatus.

\subsubsection{Laser-based resonant ultrasound measurement}

A large portion of the effort this year involved design and construction of a high temperature furnace for in situ measurement of mechanical properties. The furnace has been constructed and the initial stages of testing have begun. We have continued our work relating microstructure evolution to changes in the resonant ultrasound spectrum. This approach is based on monitoring microstructure evolution upon recrystallization. Utilizing electron backscatter diffraction data to interpret our results we have identified an approach that is capable of isolating the influence of texture from that of dislocations. In collaboration with Paul Millet and Michael Tonks with the Fission Gas Behavior work-package, we are investigating the efficacy of this approach to serve as a validation metric for phase field models of grain growth. 


\subsubsection{Laser-based melting point determination}

We have completed the preliminary design for a laser-based apparatus to measure the melting point temperature of irradiated materials. The approach is based on heating the sample with a pulsed laser and measuring the temperature by monitoring the black body radiation. For more information, contact Dave Hurley at david.hurley@inl.gov

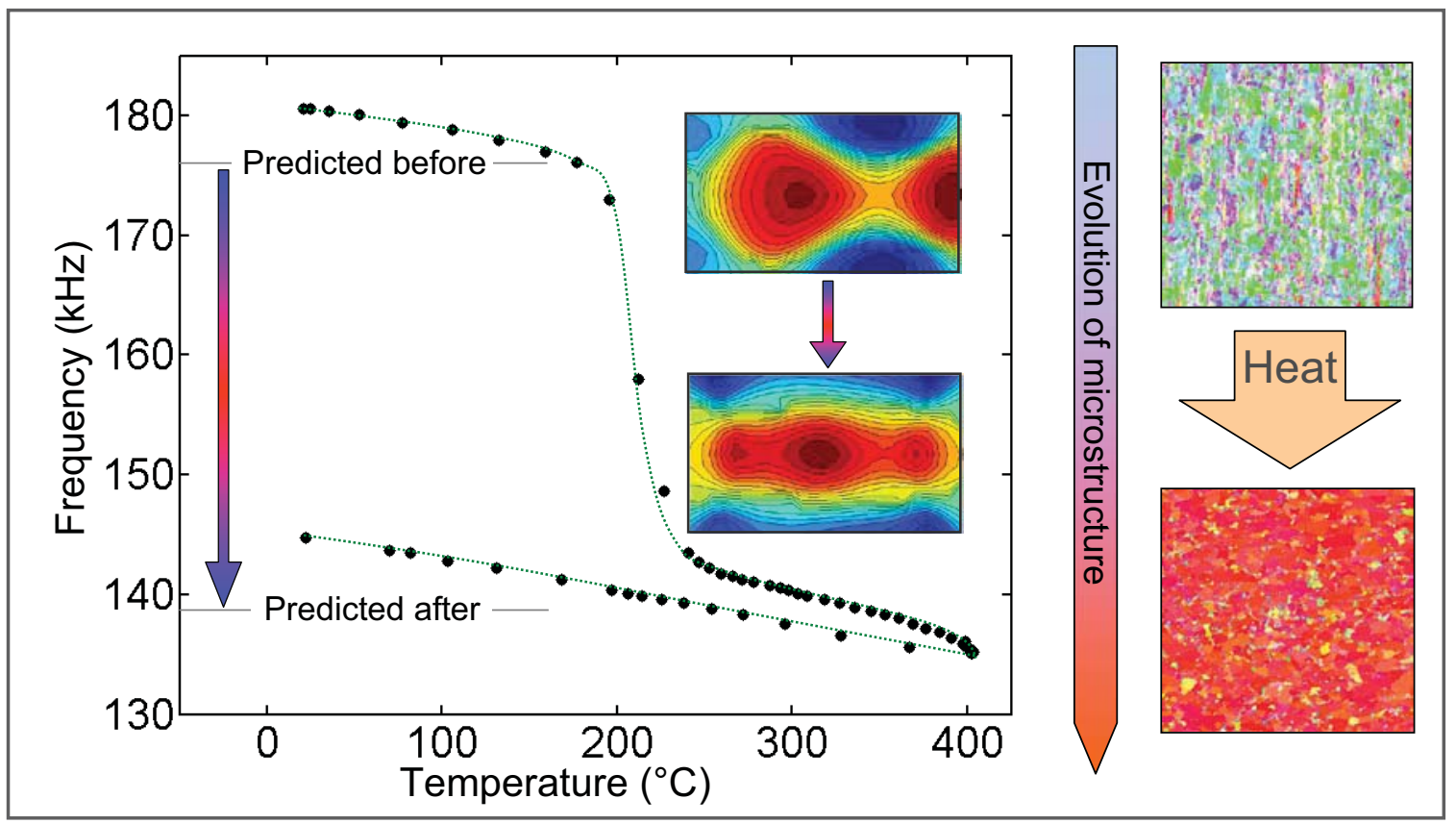

Figure 25. Left: In situ monitoring of the resonant peak location as a function of annealing temperature. Utilizing EBD data it has been shown that the majority of the frequency shift is due to texture evolution rather than dislocation evolution. Right: Details of microstructure evolution. A textured is imparted by rolling. A well defined cube texture is formed upon annealing.

\subsection{Metal Fuel Casting Model FOA}

Truchas, a multi-physics integrated code, is used to support the metal fuel casting technology development. Simulations incorporating fluid flow, heat transfer and phase change were used to analyze an existing bench scale caster (BSC) for metal fuel casting. The main accomplishments were to analyze the fluid dynamics of the inlet of the mold, evaluate the degree of solidification during filling and develop the capability to simulate the induction preheating of the mold using a conical coil.

Previous analysis had suggested that the volume of the mold above the rods should be reduced to try to keep the argon gas driving the molten fuel alloy into the mold from entering the rod volume. Further work indicates that the design of the crucible and stopper rod also plays a role in this problem. Figure 26 shows the conditions where the argon gas intrudes into the partially filled mold. It would be desirable to use an uncoated graphite mold to cast metallic fuel, but analysis with Truchas indicates that the metal will solidify too quickly to fill the mold given the current limitations in mold temperature and filling rate (Figure 27). 

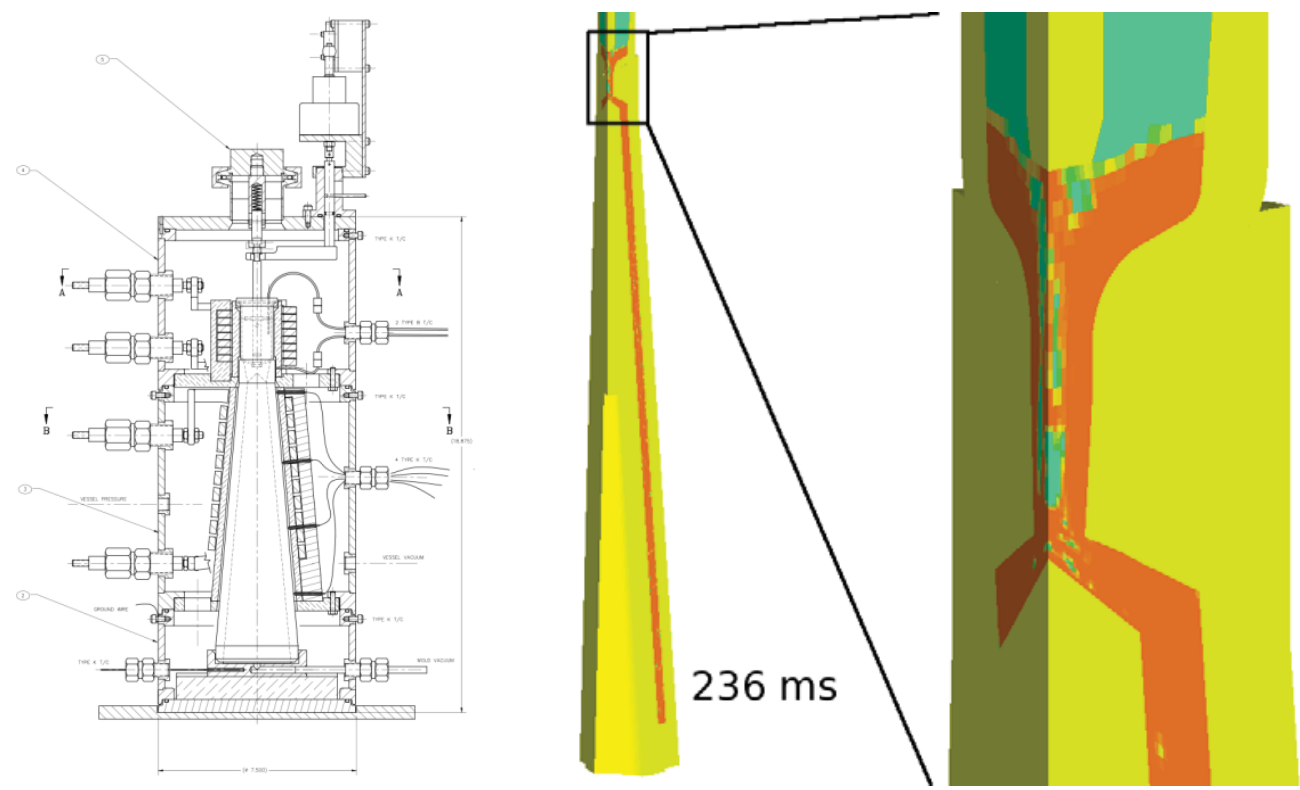

Figure 26. Schematic for the bench scale caster, which is designed to cast three fuel pins $4 \mathrm{~mm}$ diameter by $250 \mathrm{~mm}$ long. The intrusion of argon gas (blue-green) is shown in a filling simulation on the right.

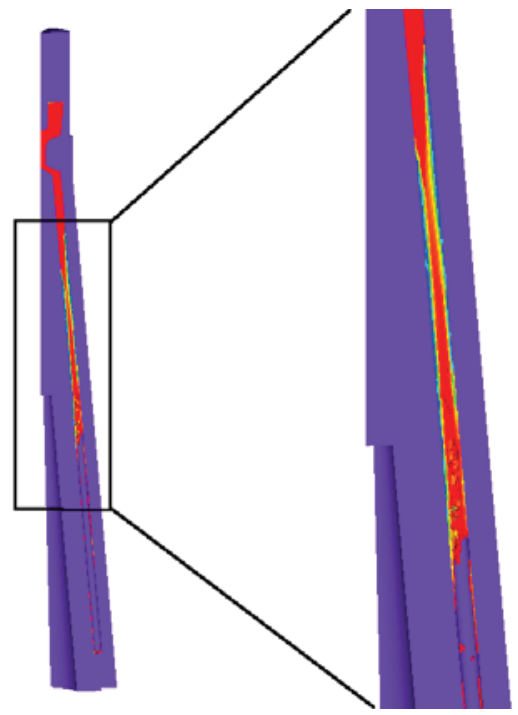

$100 \%$ liquid

$100 \%$ Solid

Graphite mold

Figure 27. Filling simulation for an uncoated mold showing early solidification.

As part of this project the induction heating capabilities of the Truchas code were enhanced to include conical induction coils such as the mold preheat coil on the BSC. Figure 28 shows initial results for the power generated in the mold, calculated from the current and frequency used in one of the BSC experiments. The average heating rates agree approximately with the experimental results. The heat transfer boundary and interface conditions must be evaluated before a detailed comparison with the experimental results can be made. One limitation of the current design in the BSC is that the mold cannot be preheated to an optimum temperature for casting. A validated induction heating model should help guide improvements in the experimental design and induction power supply parameters. For additional information, contact David Korzekwa at dak@lanl.gov. 

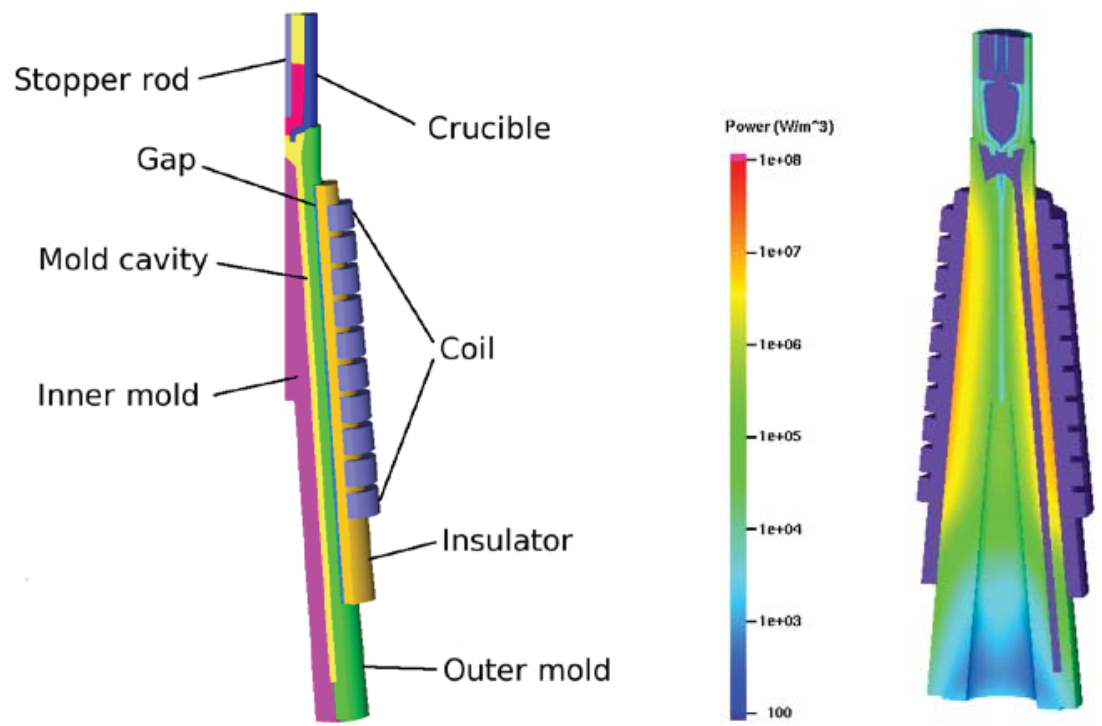

Figure 28. Geometry of a 60 degree segment of the induction heating model and a plot of induction heating power from a half symmetry simulation.

\subsection{Metal Fuel Fabrication}

There are three primary accomplishments for FY-09 within the Fuel Fabrication work package.

1. Maintained operator training and qualifications for three (3) technicians to work within FMF and the AFCI glove box.

2. Fabricated six (6) alloys for characterization by personnel within the Fuel Characterization work package.

3. Completed the fuel slug fabrication and experiment assembly for the AFC-2E experiment.

\subsubsection{Operator Training}

Although not routinely mentioned as an accomplishment. The requirements for maintaining qualification in a HAZ CAT 2 nuclear facility are significant. During FY-09 the qualifications for 3 operators/supervisors where maintained to allow fuel casting, fuel sectioning, fuel transfers, rodlet welding, capsule welding and all the other operations required to fabricate and transfer fuels as well as assemble the fuel into a reactor ready experiment assembly.

\subsubsection{Characterization Alloy Fabrication}

The following characterization alloys where fabricated during FY-09.

1. AFCI-B7-F24 61U-24Pu-15Zr

2. AFCI-B8-F25 43.5U-36.5Pu-20Zr

3. AFCI-A3-F26 58.5U-20Pu-3Am-2Np-15Zr-1.5RE

4. AFCI-A4-F27 40.5U-30Pu-5Am-3Np-20Zr-1.5RE

5. AFCI-A7-F28 52U-20Pu-3Am-2Np-15Zr-8RE 


\section{AFCI-A5-F29 41U-30Pu-5Am-3Np-20Zr-1RE}

These alloys where sectioned and prepared for a number of characterization operations performed under the characterization work packages. The following pictures show some of the characterization alloys being prepared and sectioned for transfer to the AL for testing.
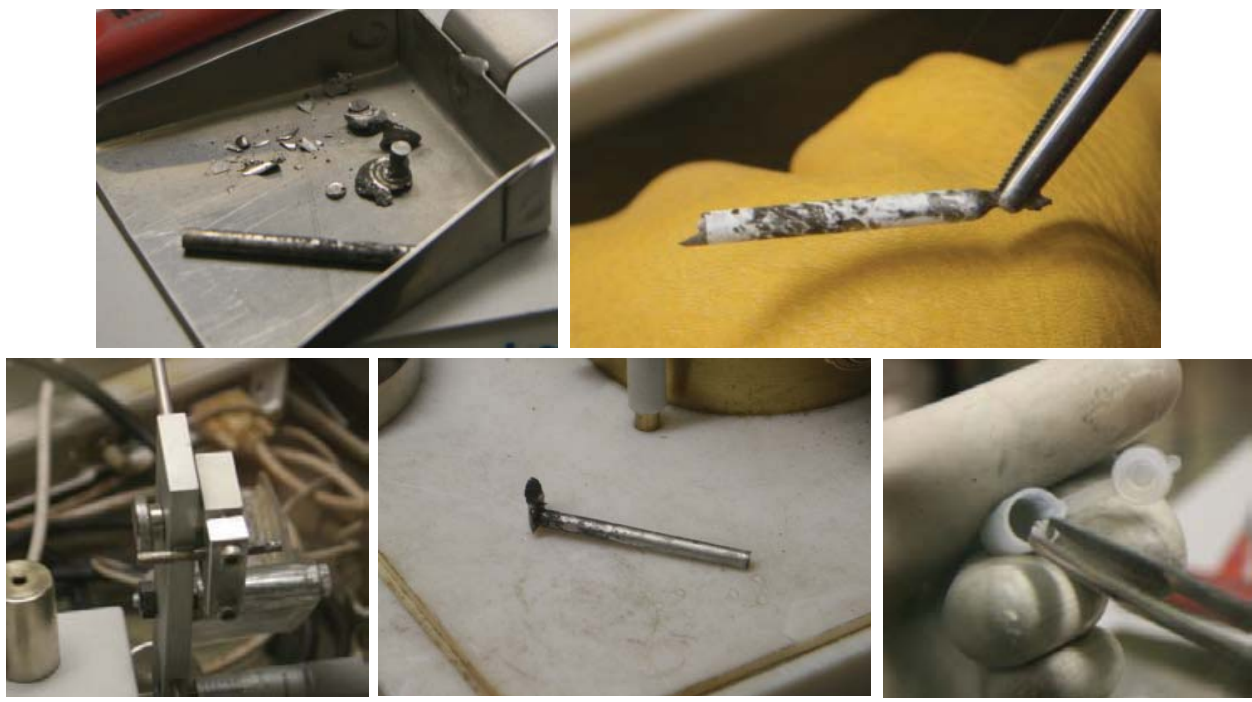

Figure 29. Characterization alloy operations

\subsubsection{AFC-2E Experiment Fabrication}

The AFC-2E Experiment was fabricated, assembled and shipped to ATR during FY-09. This experiment will tie together fabrication techniques and allow the direct comparison of data from fuel irradiated in EBR-II and irradiated in ATR. Table 2 shows the alloys and enrichments for the AFC-2E experiment.

Table 2. AFC-2E Fuel Test Matrix.

\begin{tabular}{|c|c|c|c|}
\hline Rodlet & AFC-2E Metallic Fuel Compositions $\dagger$ & ${ }^{235}$ U Enrichment & Designation \\
\hline AFC2E-R1 & 70U-20Pu-10Zr & 0.70 & E1 \\
\hline AFC2E-R2 & 70U-20Pu-10Zr(EBR-II) & 0.48 & E2 \\
\hline AFC2E-R3 & 65U-20Pu-3Am-2Np-10Zr & 0.45 & E3 \\
\hline AFC2E-R4 & 70U-20Pu-10Zr & 0.40 & E4 \\
\hline AFC2E-R5 & 65U-20Pu-3Am-2Np-10Zr & 0.50 \\
\hline AFC2E-R6 & 70U-20Pu-10Zr (EBR-II) & E6 \\
\hline \multicolumn{2}{|c|}{+ Fuel composition expressed in weight percent. } \\
\hline
\end{tabular}


The documentation for all of the materials, assembly steps and quality assurance inspections are compiled in the AFC-2E As-Built Data Package. This document is used by the assigned quality engineer to evaluate and certify that all technical and functional requirements for the experiment where met during fabrication and assembly of the experiment. Although not the actual experiment product, this binder represents the documentation of several hundred thousand dollars worth of effort to produce the actual experiment. Contact Tim Hyde at timothy.hyde@inl.gov for more information on metal fuel fabrication.

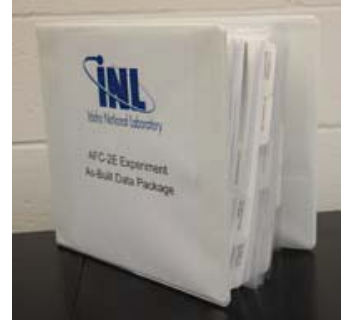

Figure 30. AFC-2E Experiment As-Built Data Package

\subsection{Metal Fuel Fabrication Process Development}

The metal fuel fabrication process development work was divided into three groups; casting parameter development, specie volatility mitigation, and crucible or mold material/fuel alloy melt interaction. Significant accomplishments in each area will be discussed in the following sections. An overall accomplishment was an independent review of the work package by an independent team of experts in casting and fuel fabrication. The review committee consisted of experts from the casting industry; Alan Moore, Y-12 National Security Complex, Courtney Johnson, Wagstaff Applied Technologies, Prof. David Olson, Colorado School of Mines, Deniece Korzekwa, Los Alamos National Laboratory, and Dr. Leon Walters, private consultant, retired Argonne National Laboratory Engineering Division Director. The committee provided positive comments on the direction, accomplishments, and status of the metal fuel fabrication process development work as well as provided some specific suggestions for future directions.

Using the bench scale casting system (BCS), schematically shown in Figure 31, a multi-pin casting run was successful in casting pins. The cast uranium $10 \mathrm{wt} \%$ zirconium pins are shown in Figure 32, as can be seen the overall length is approximately 178 $\mathrm{mm}$ (7 in.) with an approximate diameter of $4.3 \mathrm{~mm}$ ( 0.170 in.). A pin from this casting batch was sectioned removing samples from the top, bottom, and middle for microstructural analysis as well as chemical analysis. The analysis showed the U-Zr composition to be consistent the length of the pin, and showed the typical martensitic structure with zirconium rich precipitates. Table 3 shows the compositional variations while Figure 33 shows typical micrographs showing the microstructure. This work is important because previous to this all metal fuel had been cast using a counter gravity injection casting technique. This work showed that very high aspect ratio fuel pins can be cast from elemental feedstocks using inductive melting and gravity pouring into a reuseable graphite mold.

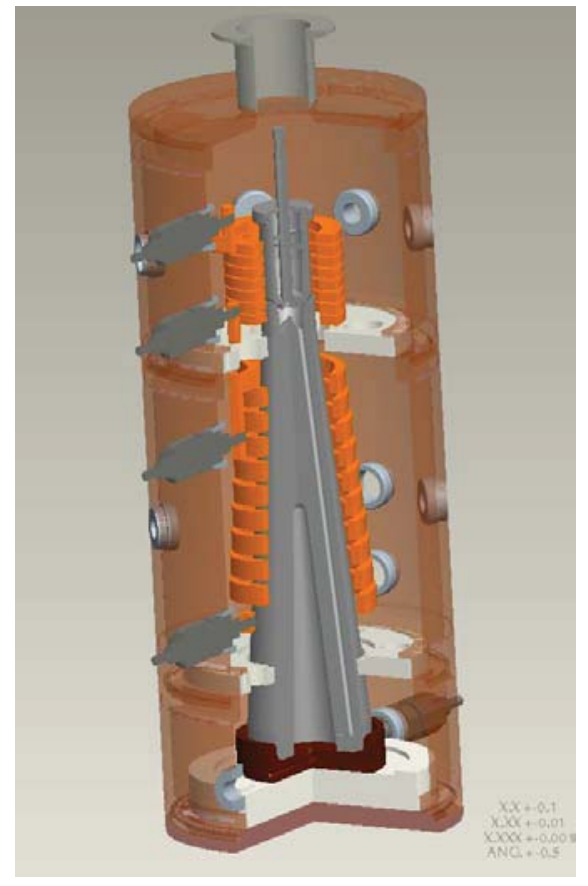

Figure 31 . Bench scale casting system schematic. Note: the stopper rod lifting mechanism and instrumentation and gas feedthroughs are not shown. 


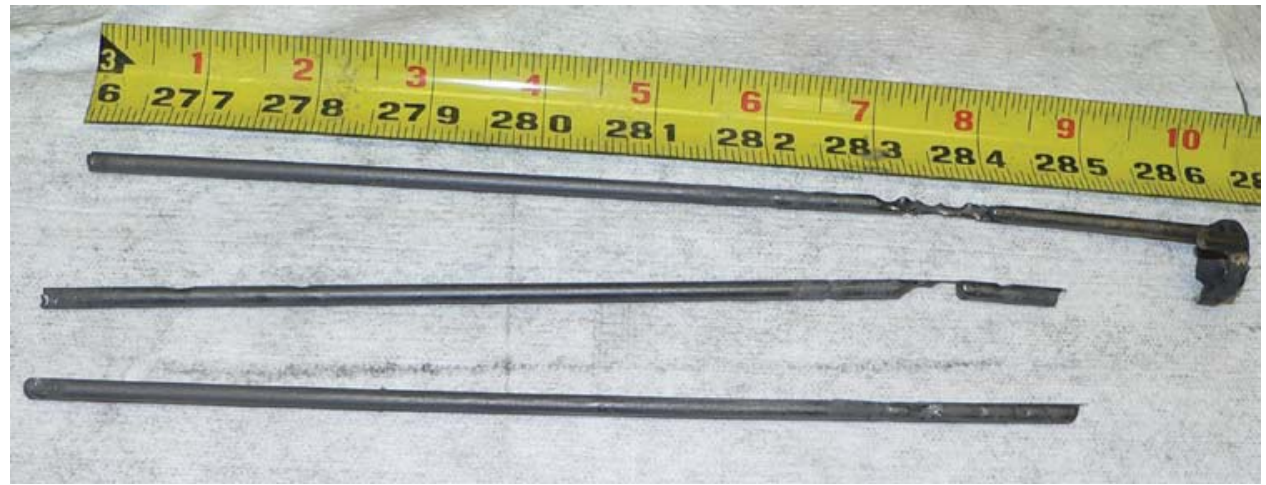

Figure 32 . U-10Zr pins cast using the BCS. Approximate diameter is $4.3 \mathrm{~mm}(0.170 \mathrm{in}$.$) .$

Table 3. Chemical analysis results for uranium and zirconium from BCS cast U-10Zr alloy.

\begin{tabular}{|c|c|c|}
\hline Position & U wt\% & Zr wt\% \\
\hline Top & 86.8 & 10.06 \\
\hline Middle & 87.7 & 10.3 \\
\hline Bottom & 87.1 & 10.3 \\
\hline
\end{tabular}

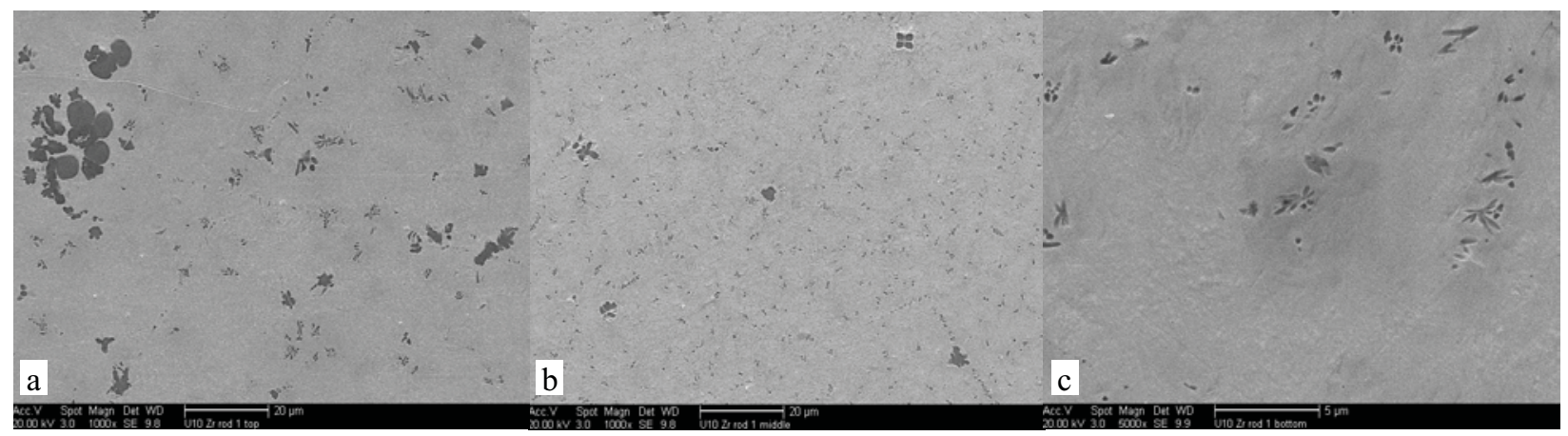

Figure 33. Cast U-10Zr slug microstructure (a) top, (b) middle, and (c) bottom slug portion.

After it was shown that the pins could be successfully cast several parameters were varied such as melt super heat, differential pressure application, mold pre-heat, and mold coatings. What was seen was that the parameter space for successful casting of these pins is not very large and results can be dramatically affected by such things as crucible coatings and melting atmosphere purity. Generally if the mold preheat was decreased or coatings removed the pins were not as long and did not reach the bottom of the mold cavities. When the melt super heat was increased or a pressure differential applied across the mold and crucible the resulting pins were segmented and often had large hollow sections.

Two comments made by the independent review committee directed the program to 1) look into using metallic sheaths in the mold cavities to not only protect the mold from the aggressive melt but also potentially protect the fuel and cladding from interaction under irradiation and 2) pursue other novel casting techniques such as continuous casting and microwave casting. Following these comments three pins have been successfully cast using a zirconium sheaths. Analysis is still on going to show the level of bonding between the sheath material and fuel alloy and parameters will need to be optimized in order to improve casting yield, but pins were successfully cast, showing the feasibility of this approach. Although work will not be completed this year, contracts have also been placed with two outside vendors to further evaluate the feasibility of microwave and continuous casting. Microwave Synergy, Inc. will produce a 
mold and crucible assembly and cast several runs using a titanium copper alloy to test the compatibility of the crucible material against an aggressive melt and to characterize the mixing action of the microwave heating. To evaluate the feasibility of continuous casting Wagstaff Applied Technologies will perform initial heat and fluid flow modeling of a continuous casting. Also, a conceptual design for a small system capable of casting three pins simultaneously in a variety of applicable pin diameters in a glovebox type system will be produced. This work will continue into next year.

The metal fuel cycle has been consistently questioned on its ability to retain volatile metallic elements such as americium during the casting process. To address this concern for gravity casting using the BCS several experiments were run using manganese as a surrogate for americium. An elemental charge of U$10 \mathrm{Zr}-5 \mathrm{Mn}$ (based on weight) was prepared and heated for 15 minutes at $1450^{\circ} \mathrm{C}$ under 4 different pressures ranging from dynamic vacuum to 800 torr. After each run the crucible lid was examined for any condensate from the melt and each melt was chemically analyzed. Table 4 also shows the chemical analysis results with an uncertainty of $\pm 3 \%$. Figure 34 shows the results as a plot of alloy ID versus the initial manganese/zirconium ratio over the final manganese to zirconium ratio. This measurement was used to account for only volatility losses since the zirconium has a very low vapor pressure. A ratio of greater than 1 indicates a loss of manganese. Table 4 also shows the chemical analysis results with an uncertainty of $\pm 3 \%$.

Table 4. Chemical analysis results from Mn containing volatility experiments

\begin{tabular}{|c|c|c|c|c|}
\hline Alloy ID No. & Approximate Pressure (torr) & U wt. \% & Zr wt. \% & Mn wt. \% \\
\hline 1 & Dynamic Vacuum $(<.7)$ & 83.60 & 11.00 & 4.77 \\
\hline 2 & 800 & 84.40 & 11.30 & 5.72 \\
\hline 3 & 300 & 83.10 & 11.60 & 5.90 \\
\hline 4 & 550 & 82.00 & 11.20 & 5.74 \\
\hline
\end{tabular}

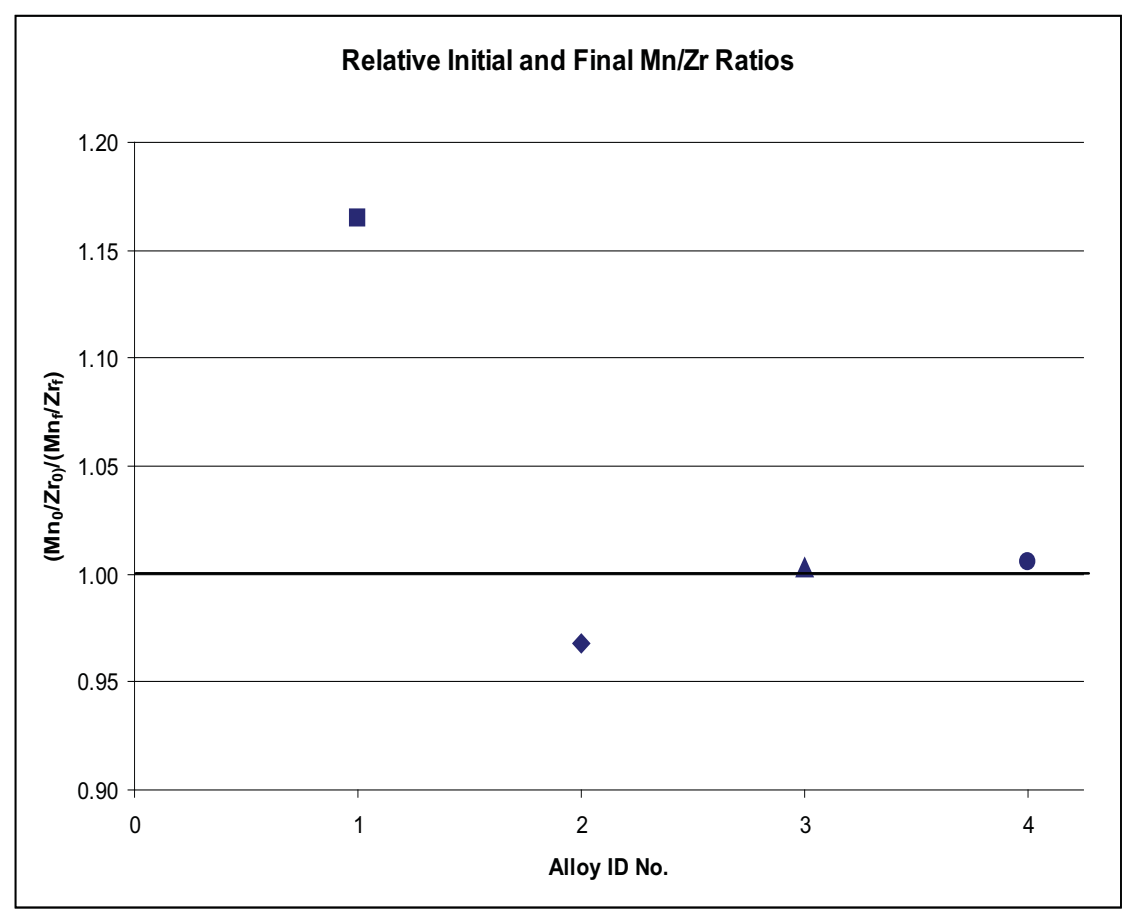

Figure 34. Ratio of $\left(\mathrm{Mn}_{0} / \mathrm{Zr}_{0}\right) /\left(\mathrm{Mn}_{\mathrm{f}} / \mathrm{Zr}_{\mathrm{f}}\right)$ versus alloy designation. A ratio of 1 results from no Mn loss through volatilization. 
The independent review committee suggested that perhaps the reason for high retention rates at relatively low over pressures was the low molecular mass of the manganese (54.938) compared with the mass of argon (39.948). This was a cause for concern because americium has a molecular weight of 243 . To address this concern, similar experiments were conducted using samarium, molecular weight of 150.36. Chemical analysis of the experiment is still ongoing, but initial indication from condensate presence and weight indicate that although a larger over pressure is needed to reduce the volatilization to insignificant levels, the over pressure is still quite modest, on the order of 1-1.5 atmospheres absolute. These pressures can easily be obtained in furnaces without adding significantly to the design.

Work has also been ongoing to characterize an appropriate material for permanent crucible and mold coatings. There is a significant amount of data for uranium and other reactive melt interaction with possible coating materials, however, much of this data was collected at conditions excessively aggressive when compared to casting conditions encountered in the BCS, temperatures outside of the casting regime, test durations were on the order of hours, and many tests were done in very aggressive environments such as pure zirconium. Therefore, the literature was reviewed to identify likely candidates keeping in mind the likely casting environment. Five materials were identified; $\mathrm{HfN}, \mathrm{ZrC}, \mathrm{HfC}$, TiC, and $\mathrm{Y}_{2} \mathrm{O}_{3}$. $\mathrm{HfC}$ was not tested because of difficulties in obtaining suitable feedstocks. The remaining four materials were plasma sprayed onto niobium discs and rods. Each sample was heated to $1600^{\circ} \mathrm{C}$ in order to densify the coatings. After heat treating the samples were thermal cycled to $1450^{\circ} \mathrm{C}, 5,10$, and 20 times. After cycling the samples did not show significant degradation. Finally the coated rods were exposed to a U-20Zr melt at $1550^{\circ} \mathrm{C}$ for 15 minutes. After samples were exposed, samples were taken from the area of contact, however, analysis of these samples is ongoing. The first samples showed that a slower heat up rate was necessary for the coated samples. A significant amount of coating spalled off during heat up because of the extremely high heating rates. When the heat up rate was slowed down the samples performed better, however, as stated previously analysis is currently ongoing.

In conclusion, this year's accomplishments included casting U-10Zr alloy into a permanent graphite mold, casting into a metallic zirconium sheathed mold, and parameter optimization. Experiments were also run using manganese and samarium confirming retention of volatile specie by moderate over pressures. Finally, possible candidate crucible coating materials were deposited on niobium rods and discs, thermally cycled, and exposed to U-20Zr melts at $1550^{\circ} \mathrm{C}$ for 15 minutes, analysis is ongoing on these samples. Contact Randy Fielding at randall.fielding@inl.gov for more information.

\section{CORE MATERIALS DEVELOPMENT}

The development of advanced cladding for high burnup performance is focused in three areas: development of advanced cladding, characterization of irradiated advanced cladding, and development of fabrication methods for advanced cladding. In these areas, significant accomplishments have been gained over the FY-09 year. In the cladding research and development area, specific accomplishments were made in:

- Fabricating HT-9 cladding tubes with vanadium liners

- Characterization and measurement of properties of historical FFTF irradiated ACO-3 duct materials and MOTA samples

- Electro-deposition of a titanium nitride coating and co-drawing vanadium liners on the inside of HT-9 steel cladding tubes

- Development of $25 \mathrm{~kg}$ heats of oxide dispersion steels (ODS)

- Welding and joining of ODS steels. 


\subsection{ACO-3 Duct Specimen Machining, Analysis and Testing}

\subsubsection{Tensile, Charpy, Compact Tension and TEM Specimens EDM machining}

Seven plates cut from the ACO-3 duct have been EDM machined into tensile, compact tension and Charpy specimens at the LANL Sigma complex. A piece of a plate from which some specimens were EDM machined is shown in Figure 35. Total specimens machined were 144 Charpy, 57 compact tension, 126 tensile specimens and 500 TEM. Specimens have doses up to 155 dpa from being irradiated in the Fast Flux Test Facility (FFTF) at irradiation temperatures from 370 to 505C. This data will determine design limits for HT-9 and aid in developing multiscale models of radiation effects in cladding materials. This activity met a level 2 milestone on January 12,

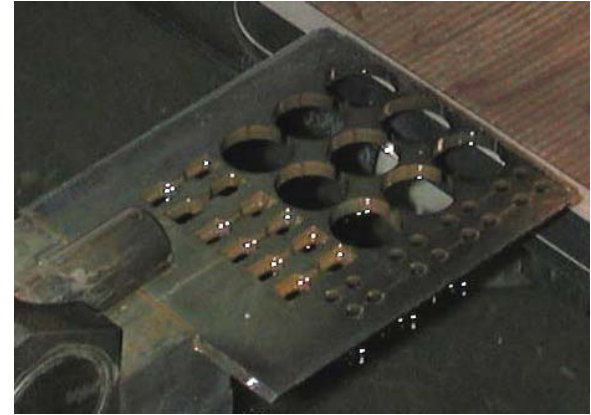

Figure 35. Photo showing the locations where specimens were EDM machined from a plate cut from the ACO-3 duct. 2009. The Charpy and compact tension specimens have been sent to ORNL for testing while the tensile specimens are being tested at LANL. Initial testing is underway.

\subsubsection{Detailed Microstructural Analysis of ACO-3 duct}

To aid in the development of atomistic models and to gain a fundamental understanding of radiation effects after high dose fast reactor exposures, detailed microstructural examinations are underway at INL and LANL. INL is investigating the microstructures using Transmission Electron Microscopy. Specimens were investigated after three different exposures: Tirr $=383 \mathrm{C}$, dose $=28 \mathrm{dpa}$, Tirr $=443 \mathrm{C}$, dose $=155 \mathrm{dpa}$ and Tirr $=$ $505 \mathrm{C}$, dose $=4 \mathrm{dpa}$. Initial results show a fine distribution of small clusters after low temperature irradiation (383C), some voids and second phase formation after irradiation to $155 \mathrm{dpa}$ at $443 \mathrm{C}$ and very little change after low dose irradiation (4 dpa) at $505 \mathrm{C}$. An image is shown in Figure 36 of the void distribution ( $\sim 0.3 \%$ swelling) in the specimens irradiated to $155 \mathrm{dpa}$ at $443 \mathrm{C}$. A detailed analysis of this microstructure was published in the Journal of Nuclear Materials, B. H. Sencer, J. R. Kennedy, J. I. Cole, S. A. Maloy, F. A. Garner, "Microstructural analysis of an HT9 fuel assembly duct irradiated in FFTF to 155 dpa at 443C,"

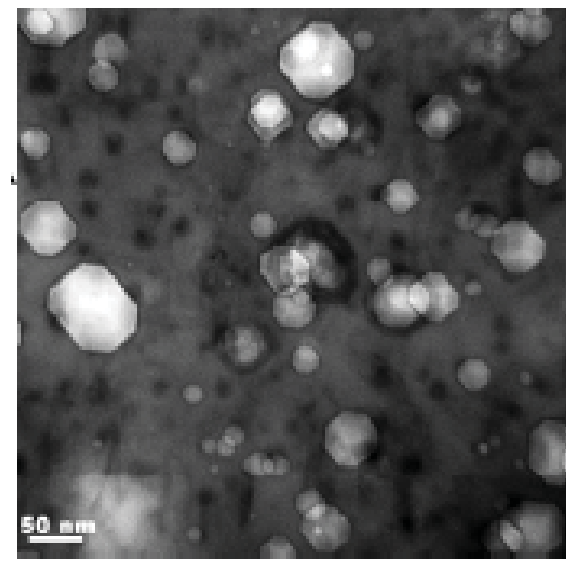

Figure 36. TEM image showing Initiation of void swelling observed for Tirr $=443 \mathrm{C}$, Dose $=155$ dpa. Estimated swelling is $0.3 \%$. Journal of Nuclear Materials 393 (2009) 235-241.

Small Angle Neutron Scattering measurements have been performed at the Los Alamos Neutron Scattering Center (LANSCE) using the LQD (Low Q Diffractometer). Measurements were made on thin slices $(0.5 \mathrm{~mm}$ thick) cut in the CMR hot cells from the ACO-3 duct. These measurements will be used to quantify second phase and void formation in the ACO-3 duct materials. Analysis of data is underway. For additional information, contact Stuart Maloy at maloy@lanl.gov. 


\subsection{FFTF/MOTA Specimen Retrieval and Testing}

\subsubsection{MOTA Specimen Retrieval, Sorting, and Dispositioning}

A large number of microscopy and mechanical test specimens irradiated in FFTF were retrieved from an end-of-lifed building on the Hanford site that is slated for demolition. It was a seven year effort that required cooperation from a several organizations. The goal of the retrieval effort was to obtain very high dose ferritic-martensitic steel specimens to study as part of ongoing research to create the next generation of fast reactor clad and duct materials. In sorting operations that took place in early FY-09, it was found that about half of the specimens were ferritic-martensitic steel. Alloys include several different heats of HT-9, T-91, and MA-957. These specimens are now in-storage on in a PNNL-controlled hot cell. It has been determined that the non-ferritic-martensitic steel specimens have no immediate or potential long term value and thus are being disposed. The unwanted specimens will be sent to a burial site in early FY10 .

\subsubsection{MOTA Specimen Testing}

Two tasks to begin testing some of the retrieved specimens were initiated at PNNL in FY-09. The first effort, which began in February, 2009 was to perform fracture toughness testing of selected irradiated HT-9 and T-91 specimens. New equipment purchased by PNNL has been undergoing modification to allow testing of the specimens. The system is now ready for testing of dummy specimens, and it is expected that the first tests on irradiated specimens will begin in early FY-10.

The second task involves the characterization of the ODS steel MA-957. Goal for this task is to characterize the high dose mechanical properties of this material and relate it to microstructural observations. Properties to be measured include post irradiation tensile properties, creep response, and fracture response (using a notched tensile specimen). Because of the limited number of recovered MA957 tensile specimens, specimens for this task are being fabricated from recovered MA-957 pressurized tubes. The majority of the work in FY-09 was spent preparing these pressurized tubes for machining. The tubes are now down at LANL with machining set to begin in early FY-10. The in-reactor creep response of these materials irradiated at temperatures from $400-600^{\circ} \mathrm{C}$ was also performed. It was found that MA957 has a similar in-reactor creep response to HT-9 for temperatures up to $550^{\circ} \mathrm{C}$, while at higher temperatures, MA-957 has superior creep resistance as shown in Figure 37. The stress normalized steady state creep rate of MA-957 and HT-9 up to $600^{\circ} \mathrm{C}$ is shown in Figure 38. The creep study will continue in FY-10 with analysis of data to temperatures as high as $750^{\circ} \mathrm{C}$. For additional information, contact Mychailo Toloczko at mychailo.toloczko@pnl.gov.

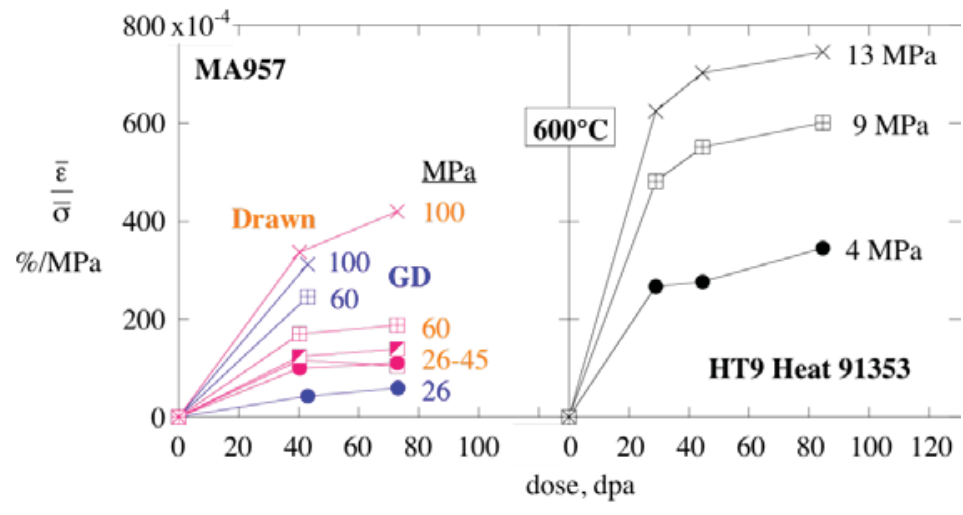

Figure 37. In-reactor creep response at $600^{\circ} \mathrm{C}$ of MA-957 compared to HT-9.

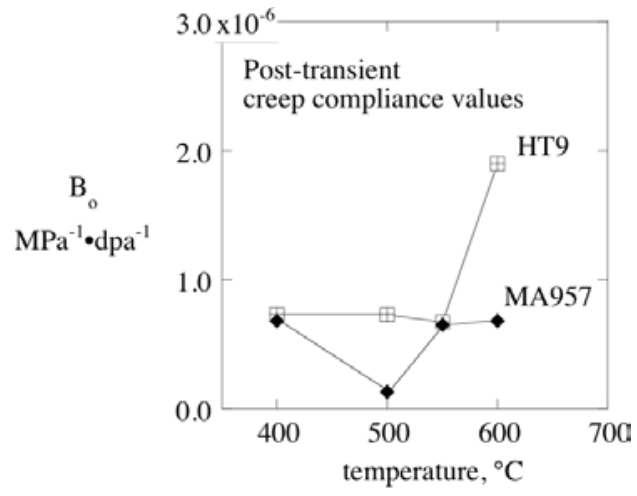

Figure 38. Steady state in-reactor creep response of MA-957 and HT-9 up to $600^{\circ} \mathrm{C}$. 


\subsection{Development of Cladding Barrier Coatings and Liners for $\mathrm{FCCl}$ Mitigation}

The transmutation fuel cladding development effort at the INL has focused on fabrication development, characterization and testing of barrier coatings and liners to mitigate or eliminate chemical interactions between nuclear fuel and cladding alloys. During FY-09 efforts centered on the continued testing of TiN coated cladding alloys and vanadium lined HT-9. Noteworthy progress was made in these areas during FY-09.

\subsubsection{Coating Development}

The evaluation of the efficacy of TiN coatings to inhibit FCCI and coating stability under high temperature cycling and irradiation continued from the previous year. The effectiveness of TiN in inhibiting FCCI was evaluated by applying a $\mathrm{Ce}$ coating (fuel surrogate) onto previously coated TiN samples. The samples were then annealed at temperatures up to $900^{\circ} \mathrm{C}$ and exhibited negligible interaction, demonstrating the inertness of the TiN to FCCI. The radiation stability of the TiN coatings was also evaluated. TiN coated samples were irradiated with protons at $500^{\circ} \mathrm{C}$ to 0.5 and $2.0 \mathrm{dpa}$. The coatings were stable under irradiation, maintaining their nanocrystalline nature and exhibiting little if any radiation-induced defect damage (Figure 39). Minor mixing (10 $\mathrm{nm}$ depth) was observed between the coating and the cladding using Rutherford backscatter spectroscopy (RBS). Following the initial coating investigations with HT-9, the work was expanded to include a more advanced oxide dispersion strengthened (ODS) cladding alloy MA957. Earlier diffusion couple studies have demonstrated, not surprisingly, that Fe-based ODS alloys are also susceptible to FCCI. TiN coatings were applied to the ODS alloy and initial properties testing of the coatings have revealed that coating thermal and mechanical stability is similar to the coatings applied to HT-9.

\subsubsection{Cladding Liner Studies}

The focus this year was on characterizing the effects of fabrication process variables on cladding and liner microstructure and thermal stability. In addition, techniques for performing non-destructive examination (NDE) to identify fabrication flaws in lined cladding tubes using eddy current methods were developed. A series of six vanadium-lined cladding tubes were fabricated at Century Tubing in San Diego, Ca early in the year. The six tubes were fabricated with processing parameters that varied the reduction and heat treatment schedules and the amount of tube-in-tube co-drawing. The studies revealed that the desired tempered martensite cladding microstructure was absent in all but the lined cladding tube that was assembled and co-drawn after the liner and cladding had been reduced to near final dimension, meaning the V and HT9 were not in contact during any of the elevated temperature processing steps. Elemental profiles across the cladding liner interface indicate that $\mathrm{Fe}$ and $\mathrm{Cr}$ diffused from the cladding into the liner and $\mathrm{V}$ diffused into the cladding during the elevated temperature processing steps. Additionally, there is a reduction or complete absence of carbide particles in the cladding and there is no tempered martensite near the liner-cladding interface (see Figure 40) an indication of cladding decarburization. These results suggest that high temperature extrusion processes would also encounter difficulties in maintaining the desired tempered martensitic structure in V-lined claddings. Measured gaps in the cladding tubes also varied with processing parameters and, in general, these gaps became wider during thermal cycling. 
However, in all cases the gaps were relatively small $(<10 \mu \mathrm{m})$. The mechanical strength of the cladding liner bond will be measured in the coming months to ensure adequate bonding is achieved during the cold co-drawing process. For additional information, contact Jim Cole at james.cole@inl.gov.

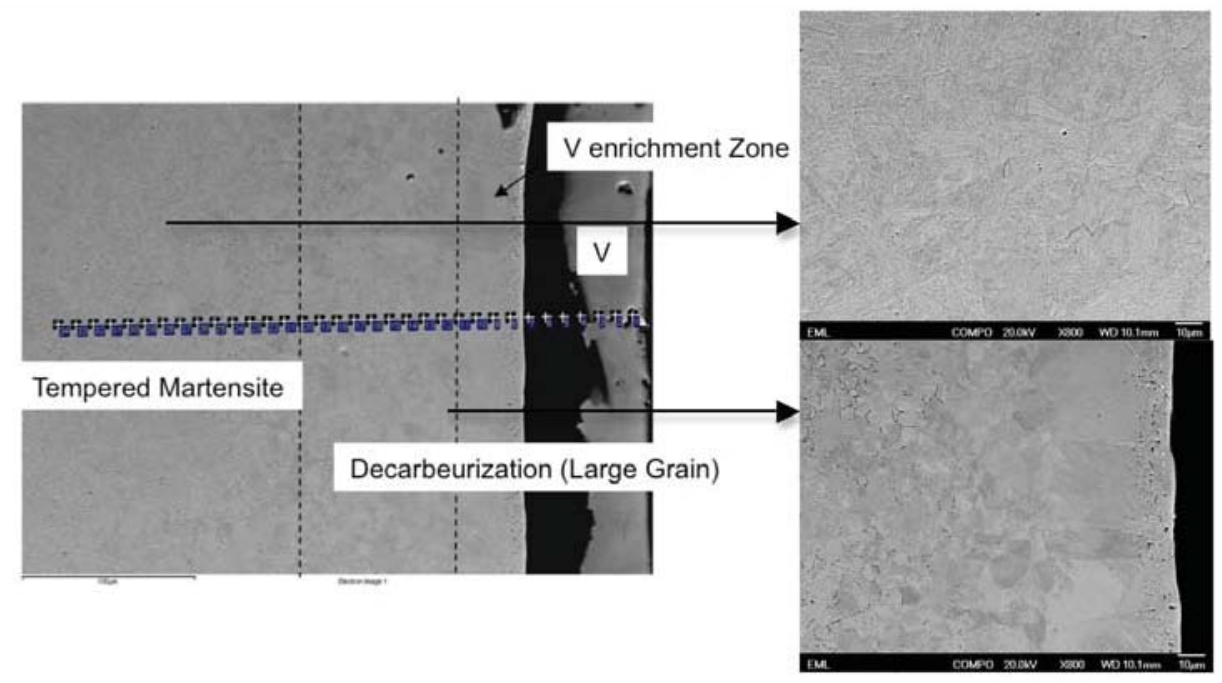

Figure 40. SEM image revealing absence of martensite and carbides near cladding-liner interface.

\subsection{Advanced Clad Material Development}

To burn fuels to greater than $20 \%$ burnup without changing the cladding requires development of materials to withstand doses greater than 200 dpa. Thus, advanced materials that are more radiation resistant than ferritic/martensitic steels (e.g. HT-9) must be developed and tested under irradiation. During this fiscal year, progress has been made in understanding radiation effects in advanced materials and development of new materials. Specimens made from oxide dispersion strengthened steel, F82-ODS, were analyzed after irradiation in the STIP irradiations at the Paul Scherrer Institute. These results showed that no hardening was observed from irradiation to a total dose of $13 \mathrm{dpa}$. In addition, new data will soon be available on advanced alloys such as 14YWT after irradiation in the Phénix reactor as this irradiation was completed in March 2009 and specimens should be available or testing in late 2010. A project to produce large scale ( $>50$ pound) heats of 14YWT (a leading radiation resistant alloy) has made excellent progress this fiscal year. It is being led by LANL in collaboration with ORNL, University of California Santa Barbara (UCSB), University of California-Berkeley (UCB), South Dakota School of Mining and Technology (SDSM\&T) and Crucible Inc. Three initial heats have been made and characterized while separate studies are underway to forge and roll the material to thin sheet form and determine friction stir weld parameters. Characterization of the initial heats of material using atom probe tomography shows that a fine distribution of oxide particles has been obtained uniformly throughout this material (see Figure 41).

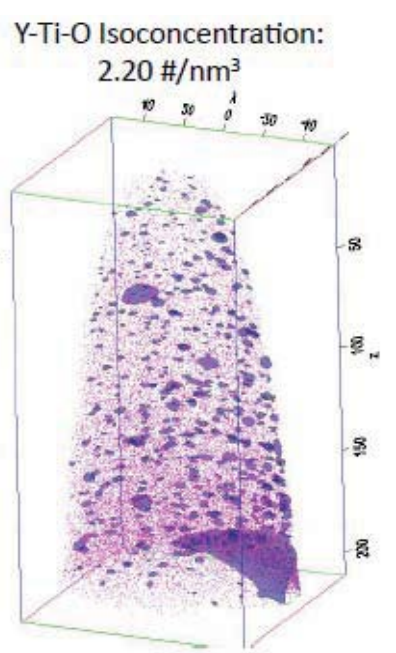

Figure 41. Atom probe tomographic image showing Y14YWT. Ti-O clusters in heat of 


\subsection{Weldability in ODS Alloys FOA}

\subsubsection{Experimental Materials}

Friction stir welding (FSW) on hot rolled plates of MA956 and MA754 alloys has been carried out at the Center for Friction Stir Processing at MS\&T. Also, MA957 cladding tubes and HT-9 end plugs were joined using the pressure resistance welding (PRW) technique. MA956 and MA957 alloys are mechanically alloyed ferritic steel, MA754 a mechanically alloyed nickel-base superalloy and HT9 a conventionally processed ferritic-martensitic steel.

\subsubsection{Friction Stir Welding}

A 12\%WC-Co cermet tool with $1 \mathrm{~mm}$ pin diameter/height and $10 \mathrm{~mm}$ shoulder was used. After trial and error runs, the following combination of parameters were used for friction stir welding both alloys; tool rotation rate of $1000 \mathrm{rpm}$, a traverse speed of $2 \mathrm{ipm}$, and tool plunge depth of about $1.25 \mathrm{~mm}$. The tool was slanted at an angle of $3^{\circ}$ to the surface of the plate. Thermal profiles during the FSW runs were obtained by embedding thermocouples near the welding zone. All FSW runs were made in a bead-onplate configuration.

Microstructural characterization studies have been done using a variety of tools, such as optical microscopy, transmission electron microscopy (TEM) and scanning electron microscopy (SEM) with electron-back scatter diffraction arrangements. Here some selected results from optical microscopy are presented. The other studies using advanced tools are ongoing.

Figure 42 shows a cross-section of the welded MA956 alloy with the full nugget (or stir zone) at the center. Grain structure in the stir zone turned to a fine grained one (10-12 $\mu \mathrm{m})$ (as also shown in Figure 43) from an elongated grain structure present in the base material. The microstructural refinement achieved during FSW is attributed to a dynamic recrystallization process.

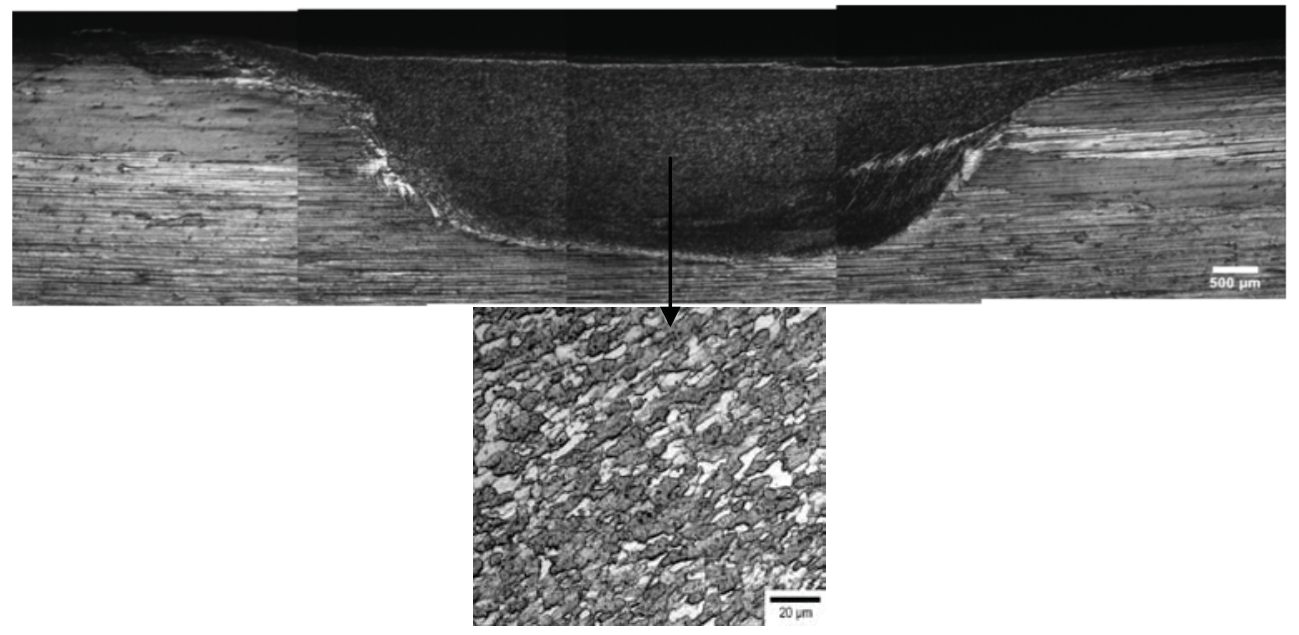

Figure 42. An optical macrograph of the transverse cross-section of FSW MA956 alloy (bead-on-plate configuration). Microstructure of the stir zone as observed via optical microscopy in the bottom image.

Figure 43 shows the transverse cross-section of FSW MA754 alloy. Here also a stark difference in the microstructure of the stir zone and the base material can be easily noted. The grain size of the stir zone is much finer (average grain size $\sim 2-3 \mu \mathrm{m}$ ) whereas the grain size of the base material is relatively large. 


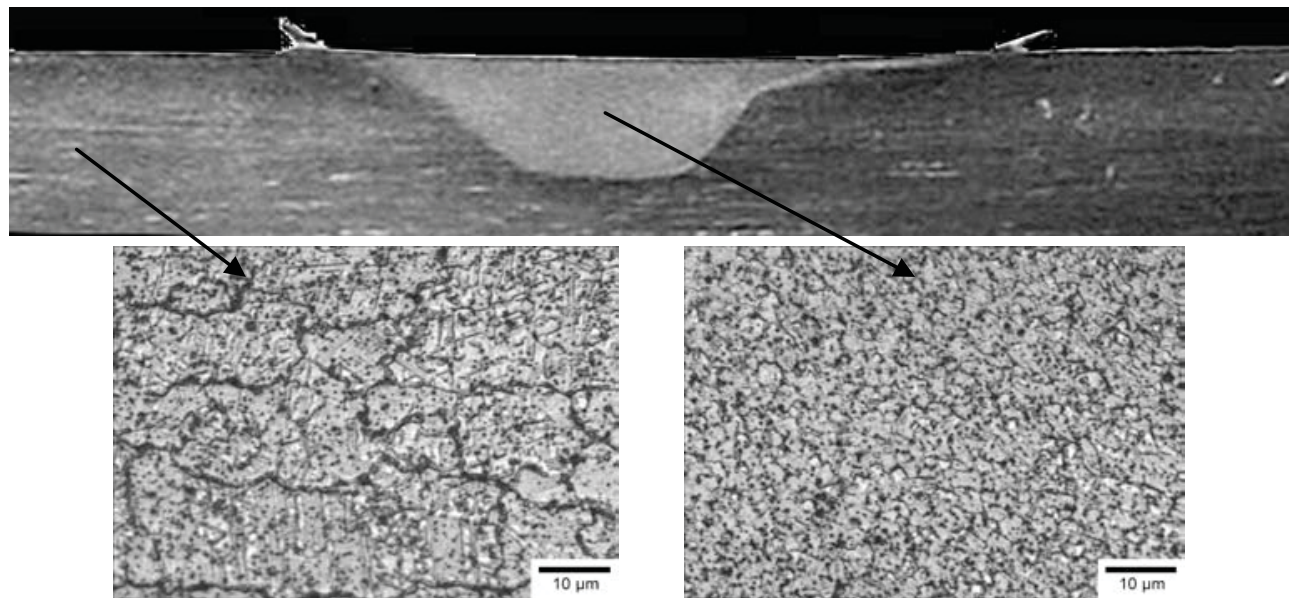

Figure 43. An optical micrograph of the transverse cross-section of FSW MA754 alloy. Also shown are the microstructure of the base material and the stir zone as revealed by optical microscopy.

While microhardness and tensile tests have been carried out on all the materials, Table 5 summarizes the tensile properties of both the base material and the stir zone of MA754 alloy. Note that mini-tensile specimens (1 mm gauge length and $1 \mathrm{~mm}$ width) were used. It is interesting to note that there is essentially very little loss of strength and even increase in ductility values in the FSW zone compared to those of the base material.

Table 5. A summary of tensile properties of MA754 alloy

\begin{tabular}{|c|c|c|c|c|c|c|}
\hline \multirow{2}{*}{$\begin{array}{c}\text { Tensile Test } \\
\text { Conditions } \\
\begin{array}{c}\text { Temperature } / \\
\text { Strain Rate }\end{array}\end{array}$} & \multicolumn{3}{|c|}{ Base Material MA754 } & \multicolumn{3}{c|}{ FSW Nugget MA754 } \\
\cline { 2 - 7 } & Y.S. (MPa) & $\begin{array}{c}\text { U.T.S. } \\
\text { (MPa) }\end{array}$ & $\begin{array}{c}\text { \% } \\
\text { Elongation }\end{array}$ & $\begin{array}{c}\text { Y.S. } \\
\text { (MPa) }\end{array}$ & $\begin{array}{c}\text { U.T.S. } \\
\text { (MPa) }\end{array}$ & $\begin{array}{c}\text { \% } \\
\text { Elongation }\end{array}$ \\
\hline $\mathbf{2 5}^{\mathbf{O}} \mathbf{C} / \mathbf{1 0}^{-3} \mathbf{s}^{-1}$ & $702 \pm 11$ & $1017 \pm 31$ & $18.7 \pm 1.5$ & $717 \pm 25$ & $969 \pm 9$ & $27.5 \pm 1.4$ \\
$\mathbf{5 3 8}^{\mathbf{0}} \mathbf{C} / \mathbf{1 0}^{-4} \mathbf{s}^{-1}$ & $625 \pm 25$ & $794 \pm 30$ & $11.6 \pm 2.2$ & $588 \pm 16$ & $794 \pm 49$ & $19.5 \pm 4.5$ \\
$\mathbf{5 3 8}^{\mathbf{0}} \mathbf{C} / \mathbf{1 0}^{-3} \mathbf{s}^{-1}$ & $666 \pm 43$ & $876 \pm 57$ & $14.8 \pm 1.3$ & $620 \pm 33$ & $837 \pm 23$ & $19.7 \pm 3.6$ \\
$\mathbf{5 3 8}^{\mathbf{0}} \mathbf{C} / \mathbf{1 0}^{-\mathbf{2}} \mathbf{s}^{-1}$ & $662 \pm 51$ & $865 \pm 48$ & $16.0 \pm 0.8$ & $626 \pm 16$ & $847 \pm 15$ & $21.5 \pm 2.0$ \\
\hline
\end{tabular}

\subsubsection{Pressure Resistance Welding}

A pressure resistance welding machine, designed and manufactured by Centerline Limited, was installed at the Center for Advanced Energy Studies (CAES) building in Idaho Falls during in the middle of 2009. Necessary electrical, plumbing and air-connections are currently being set up to create more PRW joints for further studies. Prior to the delivery of the machine, two researchers from the University of Idaho and Idaho National Laboratory visited the Centerline facility in Windsor, Canada, in the middle of June to inspect the machine and carry out some initial PRW runs (see Figure 44). They were able to create a number of joints of MA957 cladding tube and HT-9 end plugs successfully. These joints are currently being studied at respective institutions. 


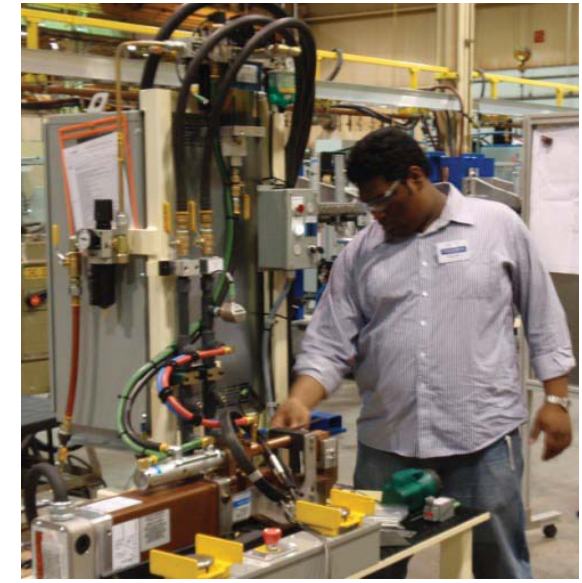

(a)

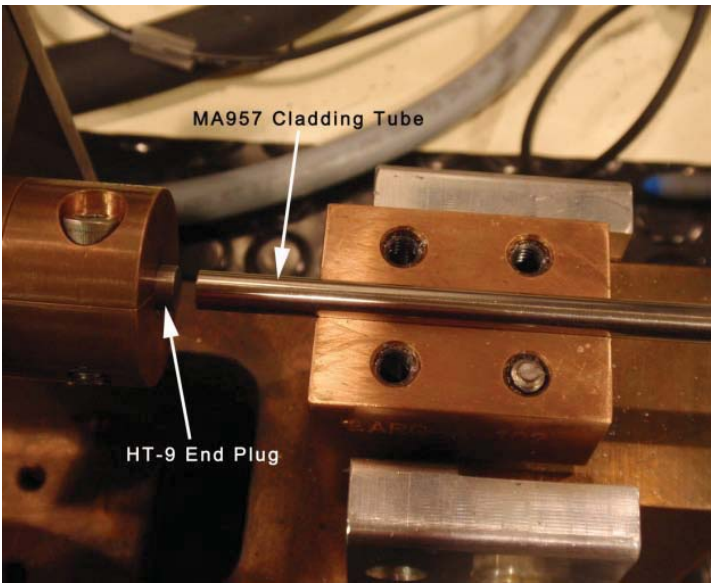

(b)

Figure 44. (a) A graduate student from the University of Idaho at work with the PRW machine. (b) Views of MA957 cladding tube and HT-9 end plug being set up for PRW.

An optical micrograph of a joint of MA957 cladding tube and HT-9 end plug is shown in Figure 45(a). Despite being a joint between dissimilar materials, the microstructure at the joint shows no evidence of porosity or delamination. This finding also supports the results obtained from simple bend tests. Bending tests were used to qualify the PRW welds. Figure 45(b) shows two joints after the test. No cracks or flaws were found at or near the PRW joint region after the test.

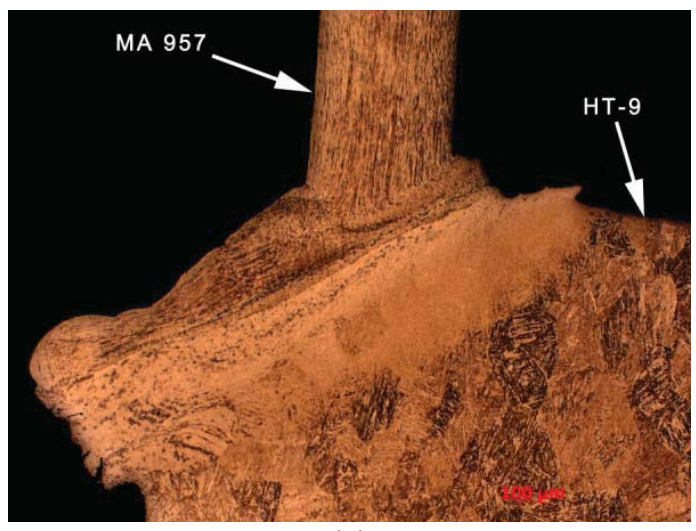

(a)

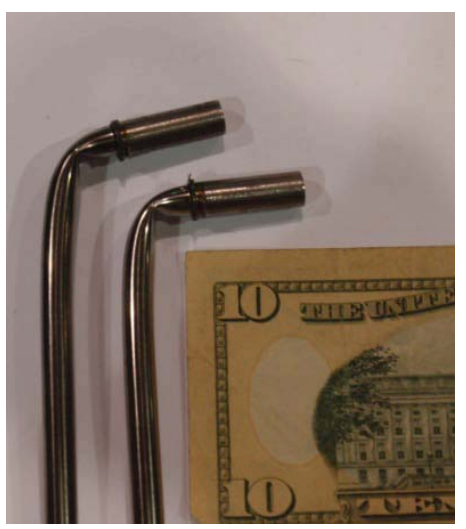

(b)

Figure 45. (a) An optical micrograph of the PRW joint cross-section. (b) Two bend-tested samples of the cladding tube - plug PRW joints.

\subsubsection{ATR Irradiation}

As part of a ATR Scientific User Facility Program, shear punch and TEM samples from MA956 and MA754 alloys (both base and stir zone) are being irradiated in the Advanced Test Reactor (ATR). The samples are receiving doses of 1 and 2 dpa after their insertion in ATR during February-March of 2009. Both types of samples will be studied for post-irradiation examination at the MFC.

\subsubsection{Students Working on the Project}

We have recruited a few students to work on this project (see Table 6). Involvement of students is critical as we develop the educational infrastructure needed for trained scientific workforce during the course of the project. Students are also interfacing with INL researchers gaining unique experience and perspective. For additional information, contact Indrajit Charit, Assistant Professor, at icharit@uidaho.edu. 
Table 6. A list of students involved in the project at different universities

\begin{tabular}{|l|l|l|}
\hline Institution & Student's name & Degree / Discipline \\
\hline University of Idaho & Ramprashad Prabhakaran & Ph.D. / MSE \\
& Kalyan Chitrada & M.S. / MSE \\
\hline Boise State University & Chris Stifter & B.S. / MSE \\
\hline North Carolina State University & Usama Elkazaz & Ph.D. / NE \\
\hline Missouri S\&T & Jiye Wang & Ph.D. / MSE \\
\hline
\end{tabular}

\section{IRRADIATION EXPERIMENTS}

The fuels testing activities are focused on conducting scoping irradiations of potential transmutation fuels compositions in the East Flux Trap of the Advanced Test Reactor (ATR) at INL and assessing the use of the flux trap region of the High Flux Isotope Reactor (HFIR) at ORNL. Results from these tests are then linked to irradiation tests conducted in the EBR-II, FFTF, and the Phénix fast spectrum reactors. This integrated activity presents multi-faceted challenges encompassing the acquisition of quality feedstocks for fabrication, fabrication of quality fuel compositions, shipping of fissile and radioactive materials, and the licensing and safety required to successfully irradiated fuel compositions in operating reactors.

\subsection{Transient Irradiations}

Capabilities of the Transient Reactor Test (TREAT) facility at INL, a brief history of transient irradiation experiments performed in TREAT, and the application of results from those experiments, were presented at an international Technical Workshop on Transient Testing held in Idaho Falls on May 4-5, 2009. The context of the workshop included international in-reactor transient testing capabilities and potential needs for experiments in those facilities. To aid future TREAT experiment program planning, documents pertaining to previous experiments in TREAT were collected and categorized. A review is underway to evaluate using the TREAT Upgrade core for experiments on single pins or seven-pin bundles. A description of neutronics models of the TREAT core and of fueled experiment hardware within the core which were developed during 2003-06 was completed. Samples from the Core Alloy Flow and Erosion (CAFÉ) laboratory experiments were examined via optical microscopy. The CAFÉ experiments, which had been funded by the Japan Atomic Energy Agency until mid-FY-09, investigated the flow, chemical interaction, and freezing of uranium metal and uranium-iron eutectic down open, inclined, stainless steel flow channels with optical and thermal diagnostics. The contact is Art Wright, ANL, at aewright@anl.gov.

\subsection{Experiment Definition and Preliminary Planning for R\&D Emphasis}

An AFCI Irradiation Testing Workshop was held July 21-22 in Idaho Falls, ID. Attendees included experimenters and modelers from INL, LANL, LLNL, and ORNL. The intent of this meeting was to bring experimenters and modelers together to rethink the AFCI irradiation testing program in light of the new, science-based R\&D direction. The AFCI irradiation testing program should include small-scale experiments and separate effects experiments to better understand fuel and material behavior, develop theory, and guide Modeling and Simulation.

The goals of the AFCI Irradiation Testing Workshop were to identify tools and techniques that support various fuel forms and to determine the fundamental questions to be answered via irradiation testing. 
Presenters at the workshop reviewed the current AFCI irradiation testing program, irradiation testing capabilities, and needs within the AFCI program. Workshop participants brainstormed to identify irradiation testing needs for different fuel forms, materials, and the Modeling \& Simulation program. The lists of ideas collected at the workshop will be used to inform the future of the AFCI irradiation testing program. For more information, contact Heather Maclean at heather.maclean@inl.gov.

\subsection{ATR Irradiations}

In FY-09, the AFC -1D, 1G, 1H, and 2A reached their target burnup levels at the end of ATR Cycles 139A, 142A, 142B, and 142B respectively. The average lobe power in the East Flux Trap during irradiation of these experiments was $22.5 \mathrm{MW}$. After appropriate cooling in the ATR Canal, the experiments were loaded into a leased GE-2000 cask for shipment. In accordance with established procedure, the shipment from ATR was completed and received at MFC on December 8, 2008. This resulted in achievement of an established Level 2 Milestone.

As-run analyses were performed for the on-going irradiation of AFC-2B, 2C, and 2D during FY-09. AFC-2B was removed from the reactor at the end of Cycle 144A and placed in the ATR Canal for future shipment. AFC-2C and 2D continued irradiation through the remainder of FY-09 and are scheduled to meet their targeted burnup in FY-10 and FY-11, respectively. The as-run analyses at the end of Cycle 144A are noted in Table 7.

Table 7. Cycle 144A As-Run LHGR, Fission Heat Rates, and Burnup Distribution for AFCI Fuel in the EFT at 43.7 EFPDs (Scaled to East Lobe Source Power of 22.1 MW. ${ }^{2}$

\begin{tabular}{|c|c|c|c|c|c|c|c|c|c|c|}
\hline \multicolumn{2}{|c|}{$\begin{array}{c}\text { Test Position } \\
\text { and ID }\end{array}$} & \multirow{2}{*}{$\begin{array}{c}\begin{array}{c}\text { Linear } \\
\text { Heat Rate } \\
\text { (W/cm) }\end{array} \\
233.76\end{array}$} & \multirow{2}{*}{$\begin{array}{c}\begin{array}{c}\text { Fission } \\
\text { Heat Rate } \\
(\mathbf{W} / \mathbf{g})\end{array} \\
132.75\end{array}$} & \multirow{2}{*}{\begin{tabular}{|c|c}
$\begin{array}{c}\text { Fission } \\
\text { Density } \\
(\mathbf{f} / \mathbf{c c})\end{array}$ \\
$5.57 \mathrm{E}+20$
\end{tabular}} & \multirow{2}{*}{$\begin{array}{c}{ }^{239} \mathrm{Pu} \\
\text { Depletion } \\
\text { (atom\%) }\end{array}$} & \multirow{2}{*}{$\begin{array}{c}\begin{array}{c}\text { Heavy } \\
\text { Metal } \\
\text { Depletion } \\
\text { (atom\%) }\end{array} \\
3.61 \% \\
\end{array}$} & \multirow{2}{*}{\begin{tabular}{|c}
${ }^{{ }^{241} \mathrm{Am}}$ \\
Depletion \\
(atom\%)
\end{tabular}} & \multirow{2}{*}{$\begin{array}{c}{ }^{235} \mathbf{U} \\
\begin{array}{c}\text { Depletion } \\
\text { (atom\%) }\end{array} \\
6.52 \%\end{array}$} & \multirow{2}{*}{\begin{tabular}{|c}
${ }^{{ }^{237} \mathrm{~Np}}$ \\
$\begin{array}{c}\text { Depletion } \\
\text { (atom\%) }\end{array}$ \\
$9.88 \%$ \\
\end{tabular}} & \multirow{2}{*}{\begin{tabular}{|c|}
$\begin{array}{c}{ }^{239} \mathbf{P u}+ \\
{ }^{235} \mathbf{U} \\
\text { Depletion } \\
\text { (atom\%) }\end{array}$ \\
$6.42 \%$
\end{tabular}} \\
\hline \multirow{6}{*}{$\begin{array}{c}\text { E-1 } \\
\text { AFC-2D }\end{array}$} & 1 & & & & & & & & & \\
\hline & Rodlet 2 & 306.84 & 172.26 & $7.66 \mathrm{E}+20$ & $8.26 \%$ & $4.34 \%$ & $23.44 \%$ & $8.57 \%$ & -- & $8.47 \%$ \\
\hline & Rodlet 3 & 326.94 & 187.13 & $8.24 \mathrm{E}+20$ & $9.18 \%$ & $5.24 \%$ & $26.88 \%$ & $9.46 \%$ & $13.53 \%$ & $9.36 \%$ \\
\hline & Rodlet 4* & -- & -- & -- & -- & -- & -- & -- & -- & -- \\
\hline & Rodlet 5 & 305.94 & 173.90 & $7.60 \mathrm{E}+20$ & $8.46 \%$ & $4.86 \%$ & $25.32 \%$ & $8.70 \%$ & $12.94 \%$ & $8.61 \%$ \\
\hline & Rodlet 6 & 252.71 & 144.02 & $6.19 \mathrm{E}+20$ & $6.92 \%$ & $3.99 \%$ & $20.83 \%$ & $7.14 \%$ & $10.91 \%$ & $7.06 \%$ \\
\hline \multirow{6}{*}{$\begin{array}{c}\text { E-2 } \\
\text { AFC-2B }\end{array}$} & Rodlet 1 & 335.36 & 154.03 & $2.30 \mathrm{E}+21$ & $12.92 \%$ & $10.21 \%$ & $28.61 \%$ & $10.97 \%$ & $15.40 \%$ & $11.40 \%$ \\
\hline & Rodlet 2 & 329.23 & 165.25 & $2.43 \mathrm{E}+21$ & $15.60 \%$ & $11.23 \%$ & $37.91 \%$ & $15.26 \%$ & $21.19 \%$ & $15.36 \%$ \\
\hline & Rodlet 3 & 323.89 & 155.92 & $2.22 \mathrm{E}+21$ & $16.51 \%$ & $9.64 \%$ & $41.85 \%$ & $17.82 \%$ & $24.54 \%$ & $17.32 \%$ \\
\hline & Rodlet 4 & 350.92 & 167.53 & $2.49 \mathrm{E}+21$ & $17.58 \%$ & $10.98 \%$ & $38.08 \%$ & $17.50 \%$ & $24.00 \%$ & $17.54 \%$ \\
\hline & Rodlet 5 & 315.37 & 165.78 & $2.21 \mathrm{E}+21$ & $15.92 \%$ & $11.22 \%$ & $36.54 \%$ & $16.62 \%$ & $22.67 \%$ & $16.29 \%$ \\
\hline & Rodlet 6 & 295.51 & 154.31 & $2.07 \mathrm{E}+21$ & $13.55 \%$ & $11.12 \%$ & $29.89 \%$ & $12.78 \%$ & $18.17 \%$ & $13.07 \%$ \\
\hline \multirow{6}{*}{$\begin{array}{c}\text { E-3 } \\
\text { AFC-2C }\end{array}$} & Rodlet 1 & 221.88 & 125.30 & $5.32 \mathrm{E}+20$ & $5.79 \%$ & $3.43 \%$ & $17.94 \%$ & $6.23 \%$ & $9.49 \%$ & $6.07 \%$ \\
\hline & Rodlet 2 & 292.84 & 164.05 & $7.27 \mathrm{E}+20$ & $7.85 \%$ & $4.18 \%$ & $22.14 \%$ & $8.27 \%$ & -- & $8.12 \%$ \\
\hline & Rodlet 3 & 314.41 & 179.66 & $7.87 \mathrm{E}+20$ & $8.67 \%$ & $5.00 \%$ & $25.38 \%$ & $8.99 \%$ & $13.13 \%$ & $8.88 \%$ \\
\hline & Rodlet 4 & 321.67 & 179.76 & $8.18 \mathrm{E}+20$ & $8.85 \%$ & $4.64 \%$ & $24.77 \%$ & $9.12 \%$ & -- & $9.02 \%$ \\
\hline & Rodlet 5 & 291.19 & 165.93 & $7.23 \mathrm{E}+20$ & $7.89 \%$ & $4.68 \%$ & $24.06 \%$ & $8.47 \%$ & $12.60 \%$ & $8.27 \%$ \\
\hline & Rodlet 6 & 233.54 & 132.75 & $5.82 \mathrm{E}+20$ & $6.51 \%$ & $3.74 \%$ & $19.53 \%$ & $6.73 \%$ & $10.28 \%$ & $6.65 \%$ \\
\hline
\end{tabular}

* Dummy Rodlet 
As-built neutronic analysis of the AFC-2E experiment was performed using MCNP and ORIGEN-2 to determine the maximum linear and fission heat rate and projected burnup. This analysis assumed a lobe power of 22.9 MW. Thermal hydraulic analysis was performed using ABABCUS at a bounding linear heat generation rate (LHGR) of 500 $\mathrm{W} / \mathrm{cm}$. The results of these analyses were documented in an Experiment Safety Assurance Package (ESAP) which was approved on July 28, 2009 by the Safety Operations Review Committee (SORC). This approval enabled shipment of the AFC-2E capsule to the ATR Complex which occurred on August 19, 2009 (see Figure 46). The

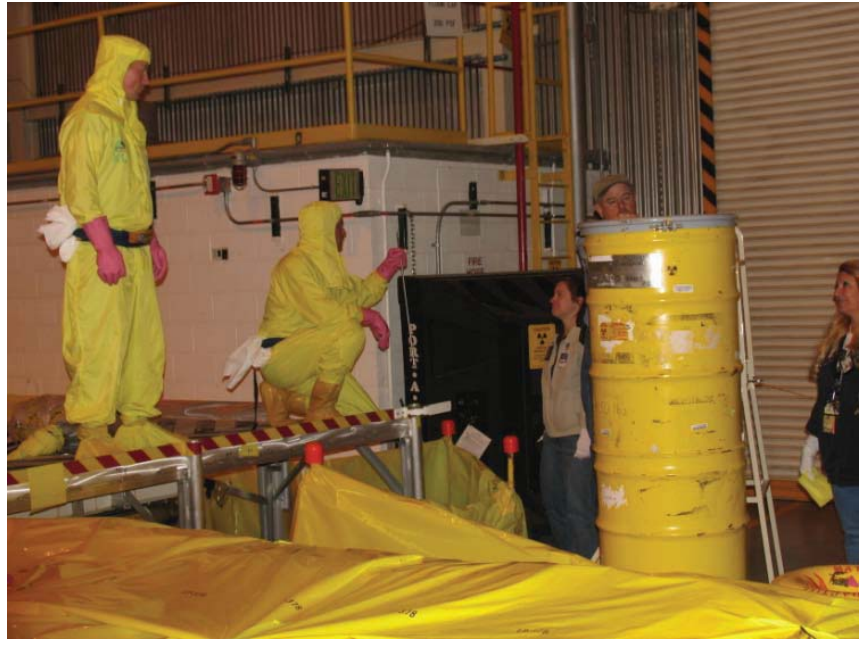

Figure 46. Receipt of AFC-2E Capsule at ATR. experiment was inserted in the ATR for initial irradiation in Cycle 145A which commenced on September 8, 2009. The completion and approval of the ESAP achieved an established Level 2 Milestone.

Because the Department of Transportation ceased to officially certify the 110 gallon shipping container at the end of CY-2008, it was necessary to prepare and obtain approval of a Transportation Plan to continue its use. This Plan was developed in accordance with DOE guidelines and established practice. The Plan was submitted for DOE review and on June 26, 2009 approval was received. This approval allowed for transport of AFC-2E capsule from MFC to the ATR-Complex and met a Level 3 Programmatic Milestone.

The design effort to relocate the AFCI experiments from the East Flux Trap to the outboard A (see Figure 47) positions in the ATR was initiated and continued through the fiscal year. The preliminary structural, thermal, and neutronic analyses are expected to be completed in the first quarter of FY-10. Re-design of the cadmium basket is necessary to accommodate the smaller diameter of the A position relative to the previous locations in the EFT. This task is expected to complete in FY-10 to enable fabrication to support experiment insertion starting in FY-11. For more information contact Debra Utterbeck at debra.utterbeck@inl.gov. 


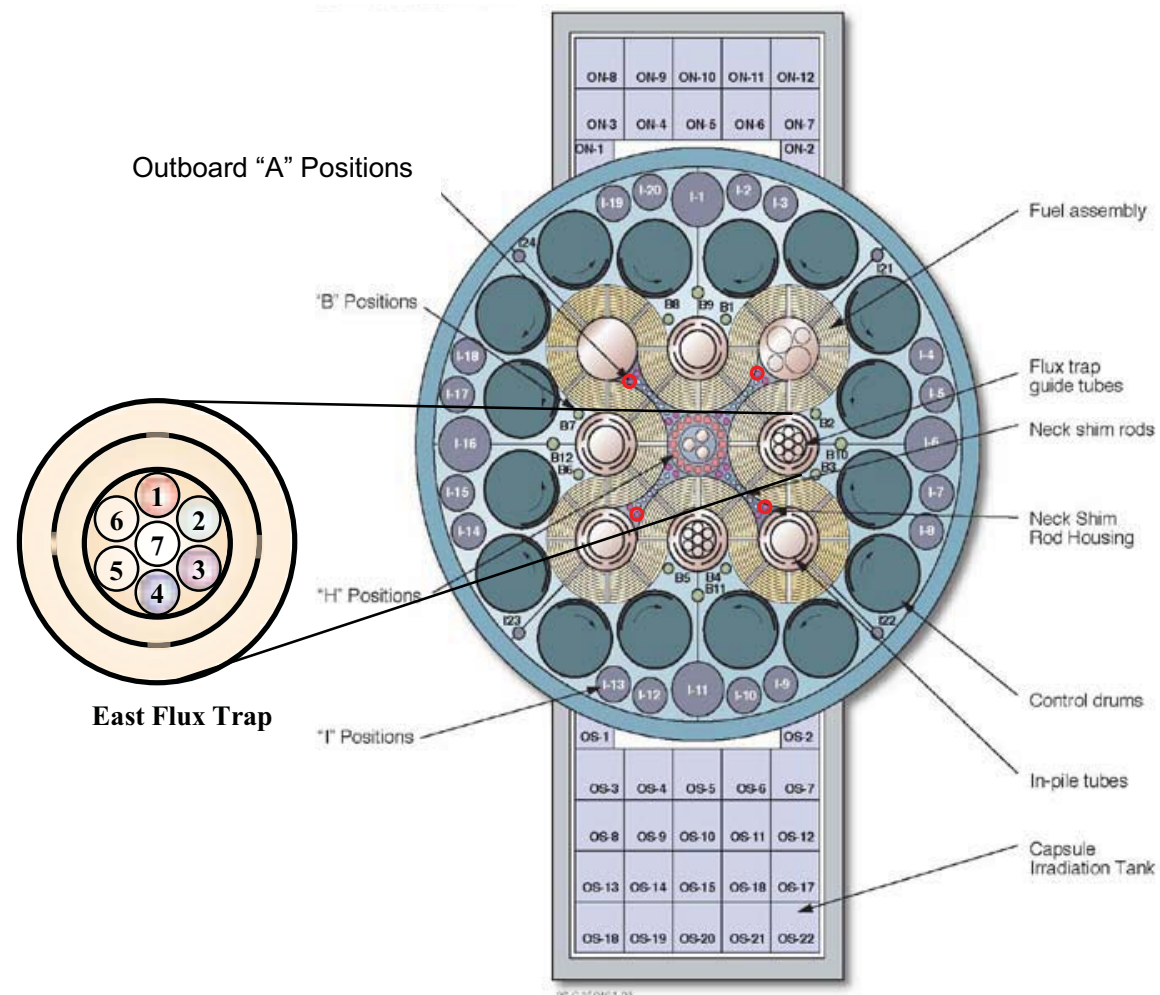

Figure 47. ATR Core Cross Sectional Diagram Identifying EFT and Outboard A Positions

\subsection{HFIR Irradiation Assessment Update}

Based on discussions with INL, a range of metallic and oxide fuel compositions (see Table 8) were considered as possible material for fuel pins to be irradiated in the flux trap region of the High Flux Isotope Reactor (HFIR) at ORNL (see Figure 48). The neutron flux level in this region of HFIR is very large and predominantly thermal $\left(2.5 \mathrm{e} 15 \mathrm{n} / \mathrm{cm}^{2} \cdot \mathrm{s}\right.$ thermal, $\left.1.2 \mathrm{e} 15 \mathrm{n} / \mathrm{cm}^{2} \cdot \mathrm{s}>0.1 \mathrm{MeV}\right)$. However, by using a thermal neutron shield (comprised of europia, $\mathrm{Eu}_{2} \mathrm{O}_{3}$ ) in an irradiation facility design, the thermal neutrons can be removed and the remaining fast spectrum neutrons is large $\left(>1.0 \mathrm{e} 15 \mathrm{n} / \mathrm{cm}^{2} \cdot \mathrm{s}\right)$. In this project to-date, a tri-pin configuration with a thermal shield was modeled and the effectiveness of the thermal neutron shield was assessed; the shroud should last several HFIR cycles. The thermal flux level in the test fuel pins within the shield was found to be a factor of 200 to 400 times less than the fast neutron flux. For four metallic fuel compositions, and two oxide fuel compositions (covering a range of fuel densities, Pu content, and other variables) the linear heat generation rates (LHGRs) were calculated for contributions from fission energy in the fuel pins and gamma heating from the HFIR core gamma radiation, as presented in Table 9. For the range of test fuel compositions, the LHGR ranged from 300 to $400 \mathrm{~W} / \mathrm{cm}$. The effect of the inclusion of the tri-pin irradiation facility in the flux trap region on the HFIR fuel cycle length and on the HFIR power distribution were both seen to be within tolerance. The methods and interim results of this work were presented at the June and August TFCIG meetings and at the July Irradiations Workshop at INL. For additional information, contact Ron Ellis at ellisrj@ornl.gov. 
Table 8. Material compositions of metallic and oxide fuels, assessed for LHGRs in HFIR flux trap irradiation scenarios (as used in ORNL calculations)

\begin{tabular}{lrrrr} 
& \multicolumn{4}{l}{ these are in wt fractions! } \\
\cline { 3 - 5 } & \multicolumn{2}{l}{ Met1 } & \multicolumn{2}{l}{ Met3 } \\
u-234 & 0.000 & 0.000 & 0.000 & 0.000 \\
u-235 & 0.010 & 0.008 & 0.008 & 0.006 \\
u-236 & 0.005 & 0.004 & 0.004 & 0.003 \\
u-238 & 0.636 & 0.538 & 0.508 & 0.411 \\
& 0.650 & 0.550 & 0.520 & 0.420 \\
pu-238 & 0.004 & 0.004 & 0.005 & 0.005 \\
pu-239 & 0.130 & 0.130 & 0.194 & 0.194 \\
pu-240 & 0.049 & 0.049 & 0.073 & 0.073 \\
pu-241 & 0.008 & 0.008 & 0.011 & 0.011 \\
pu-242 & 0.011 & 0.011 & 0.016 & 0.016 \\
& 0.200 & 0.200 & 0.300 & 0.300 \\
am-241 & 0.028 & 0.028 & 0.046 & 0.046 \\
am-242m & 0.00002 & 0.00002 & 0.00004 & 0.00004 \\
am-243 & 0.002 & 0.002 & 0.004 & 0.004 \\
& 0.030 & 0.030 & 0.050 & 0.050 \\
np-237 & 0.020 & 0.020 & 0.030 & 0.030 \\
& & & & \\
zr & 0.100 & 0.200 & 0.100 & 0.200 \\
& & & & \\
density & 15.911 & 13.374 & 16.004 & 13.459
\end{tabular}

\begin{tabular}{lrr} 
& \multicolumn{2}{c}{ NOTE: these are atom numbers } \\
\cline { 2 - 3 } & \multicolumn{1}{c}{ oxide1 } & \multicolumn{1}{c}{ oxide2 } \\
u-234 & 0.000 & 0.000 \\
u-235 & 0.011 & 0.009 \\
u-236 & 0.005 & 0.004 \\
u-238 & 0.733 & 0.606 \\
& 0.750 & 0.620 \\
pu-238 & 0.004 & 0.006 \\
pu-239 & 0.130 & 0.195 \\
pu-240 & 0.048 & 0.073 \\
pu-241 & 0.007 & 0.011 \\
pu-242 & 0.011 & 0.016 \\
& 0.200 & 0.300 \\
am-241 & 0.028 & 0.046 \\
am-242m & 0.00002 & 0.00004 \\
am-243 & 0.002 & 0.004 \\
& 0.030 & 0.050 \\
np-237 & 0.020 & 0.030 \\
& & \\
o16 & 2.000 & 2.000 \\
& & \\
density & 10.545 & 10.604
\end{tabular}

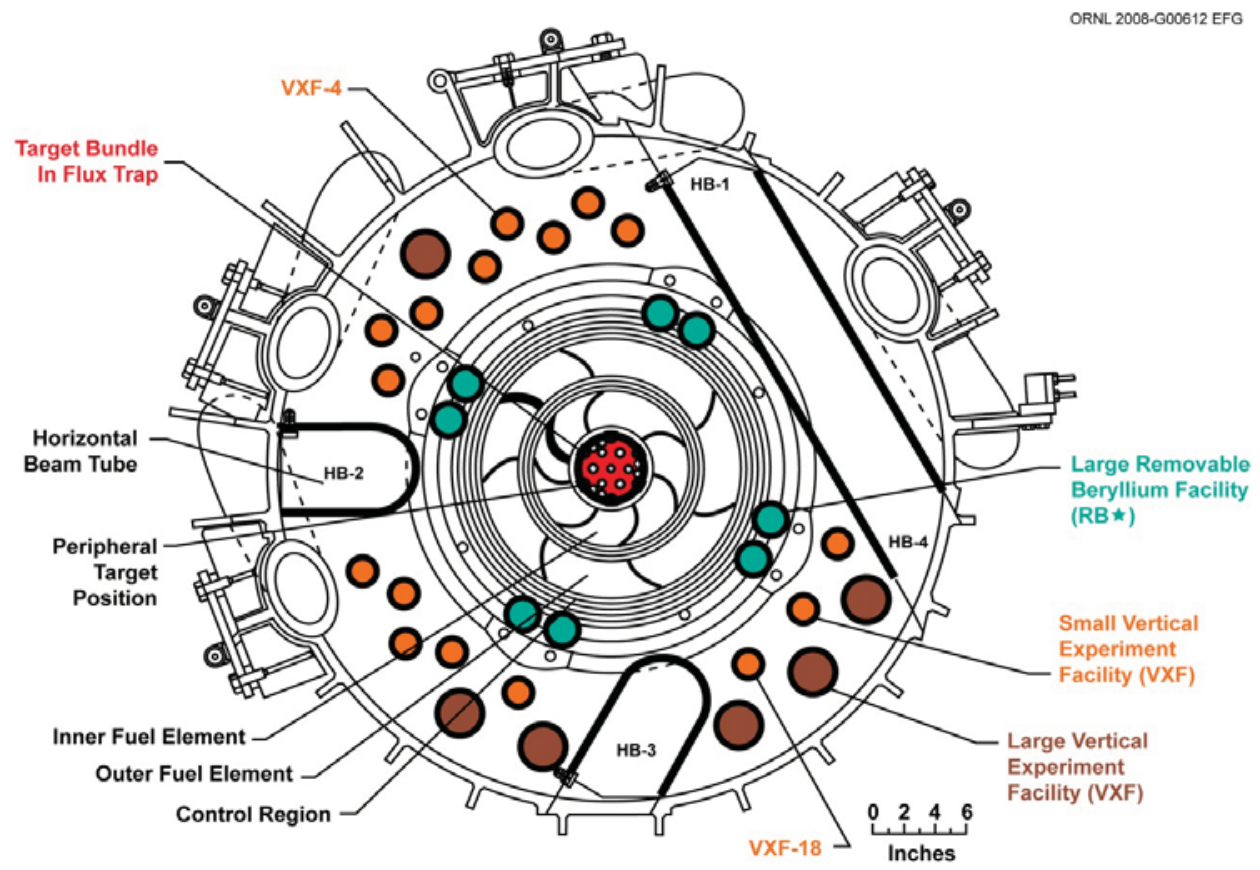

Figure 48. Schematic of the HFIR reactor system; the flux trap region is in the center. 
Table 9. Summary of linear heat generation rates and neutron flux levels for irradiation in the HFIR flux trap region

\begin{tabular}{|c|c|c|c|c|c|c|c|c|}
\hline & & $\begin{array}{c}\text { LHGR } \\
\text { (Fission } \\
+ \text { gamma) } \\
\text { W/cm }\end{array}$ & $\begin{array}{c}\text { LHGR } \\
\text { (Fission } \\
+ \text { gamma) } \\
\text { W/cm }\end{array}$ & & $\begin{array}{c}\text { Flux } \\
\text { (fast, } \\
\text { thermal) } \\
\mathbf{n} / \mathbf{c m}^{2} \cdot \mathbf{s}\end{array}$ & $\begin{array}{c}\text { Flux } \\
\text { (fast, } \\
\text { thermal) } \\
\mathbf{n} / \mathrm{cm}^{2} \cdot \mathbf{s}\end{array}$ & $\begin{array}{c}\text { Fast-to- } \\
\text { thermal } \\
\text { flux } \\
\text { ratio }\end{array}$ & $\begin{array}{c}\text { Fast-to- } \\
\text { thermal } \\
\text { flux } \\
\text { ratio }\end{array}$ \\
\hline & & BOC & $E O C$ & & BOC & EOC & BOC & EOC \\
\hline \multirow[t]{2}{*}{ Met1 } & avg & 337 & 301 & Fast & $1.2 \mathrm{e} 15$ & $9.9 \mathrm{e} 14$ & 259 & 261 \\
\hline & peak & 387 & 333 & Thermal & $4.5 \mathrm{e} 12$ & $3.8 \mathrm{e} 12$ & & \\
\hline \multirow[t]{2}{*}{ Met3 } & avg & 298 & 265 & Fast & $1.2 \mathrm{e} 15$ & $9.8 \mathrm{e} 14$ & 267 & 202 \\
\hline & peak & 345 & 291 & Thermal & $4.3 \mathrm{e} 12$ & $5.0 \mathrm{e} 12$ & & \\
\hline \multirow[t]{2}{*}{ Met4 } & avg & 395 & 346 & Fast & $1.2 \mathrm{e} 15$ & $9.9 \mathrm{e} 14$ & 396 & 403 \\
\hline & peak & 461 & 389 & Thermal & $3.0 \mathrm{e} 12$ & $2.6 \mathrm{e} 12$ & & \\
\hline \multirow[t]{2}{*}{ Met6 } & avg & 337 & 303 & Fast & $1.2 \mathrm{e} 15$ & $1.0 \mathrm{e} 15$ & 328 & 329 \\
\hline & peak & 401 & 330 & Thermal & $3.6 \mathrm{e} 12$ & $3.1 \mathrm{e} 12$ & & \\
\hline \multirow[t]{2}{*}{ Oxide1 } & avg & 289 & 260 & Fast & $1.1 \mathrm{e} 15$ & $9.9 \mathrm{e} 14$ & 235 & 201 \\
\hline & peak & 335 & 282 & Thermal & $4.8 \mathrm{e} 12$ & $4.9 \mathrm{e} 12$ & & \\
\hline \multirow[t]{2}{*}{ Oxide2 } & avg & 350 & 315 & Fast & $1.1 \mathrm{e} 15$ & $9.4 \mathrm{e} 14$ & 299 & 274 \\
\hline & peak & 414 & 332 & Thermal & $3.8 \mathrm{e} 12$ & $3.5 \mathrm{e} 12$ & & \\
\hline
\end{tabular}

\subsection{Status of PIE Activities}

Major highlights of the INL PIE work package during FY-09 include completing the Postirradiation Plan for AFC-1H, AFC-1D, AFC-1G and AFC-2A satisfying a Level 1 and Level 2 Milestone, microhardness testing of intermediate burnup AFC-1 irradiation tests, non-destructive examinations of AFC-1H, AFC$1 \mathrm{D}, \mathrm{AFC}-1 \mathrm{G}$ and AFC-2A, neutron radiography using both photographic film and digital imaging panel as transfer media and neutron radiography of FFTF high burnup ACO-3 mixed plutonium-uranium oxide (MOX) fuel pins.

Preliminary results of particular significance for the Non-destructive Examination Phase are AFC-1H AND AFC-1G appear intact, indications of liquid phase formation (LPF) in AFC-2A fuel rodlets and possibly two of the AFC-1D rodlets observed by neutron radiography, the additional rare earth is not primary cause resulting in fuel failure and LPF, and typical high burnup fast reactor MOX fuel features of central void, cracking were observed in the FFTF fuel pins.

\subsubsection{Postirradiation Plan for AFC-1H, AFC-1D, AFC-1G and AFC-2A}

AFC-1B, AFC-1F, and AFC-1Æ are the first set of irradiation tests that were studied. AFC-1F and AFC$1 \mathrm{~B}$ contain low-fertile (uranium) and non-fertile actinide-bearing metallic alloy fuel compositions. AFC$1 \nRightarrow$ contains both non-fertile and low-fertile actinide-bearing nitride fuel compositions. AFC-1H, AFC$1 \mathrm{D}$, and $\mathrm{AFC}-1 \mathrm{G}$ are the high burnup sibling tests. AFC-2A is an intermediate burnup test that contains low-fertile (uranium) actinide-bearing metallic alloy fuel compositions that include rare earth (RE) additions. The PIE Plan describes the tasks to examine the latter four tests AFC-1H, AFC-1D, AFC-1G, and AFC-2A.

The tests were irradiated in the Idaho National Laboratory's (INL) Advanced Test Reactor (ATR) to a final peak burnup of 30 - 40 at.\%. for AFC-1H, AFC-1D, and AFC-1G and to a peak burnup of 11 at.\% for AFC-2A. 
The primary purpose of the PIE is to provide irradiation performance data on fertile and non-fertile, actinide-bearing fuel forms, specifically, irradiation growth and swelling, helium production, fission gas release, fission product and fuel constituent migration, fuel phase equilibria, and fuel-cladding chemical interaction.

The PIE results at 4-8 at $\%$ burnup provided assurance that the test fuels would behave in accordance with design predictions and in conformance to the approved safety envelope. The PIE results at 30-40 at.\% burnup will provide a basis to establish burnup limits for these fuel forms and will provide invaluable data for understanding mechanisms and irradiation behavior at very high burnup and is an important step in demonstrating the high burnup potential of these fuel forms.

The PIE plan summarized the AFC-1 and AFC-2 Test Series and Objectives of the PIE Campaigns; a description of the Irradiation Test Assembly and Fuel Specimens; and outlined the non-destructive examination and destructive examination PIE subtasks.

\subsubsection{Microhardness Testing}

Microhardness testing of intermediate burnup AFC-1 irradiation tests was completed for eleven metallic alloy transmutation fuel rodlets. Figure 49 shows micrographs of a $35 \mathrm{U}-29 \mathrm{Pu}-4 \mathrm{Am}-2 \mathrm{~Np}-30 \mathrm{Zr}$ sample as typical of the microhardness testing results. The preliminary conclusions are summarized below:

- There is no indication of fuel/cladding chemical interaction in the six AFC-1F fertile (uranium bearing) metallic fuel samples irradiated to peak burnup of 6.34 at.\%.

- There is no indication of fuel/cladding chemical interaction in the five AFC-1B non-fertile metallic fuel compositions irradiated to peak burnup of 6.34 at.\%.

- The linear heat generation rates experienced by these fuel rodlets are in the lower range of fast reactors, so there is a possibility of interaction at higher linear powers, which would have higher fuel/cladding temperatures. 

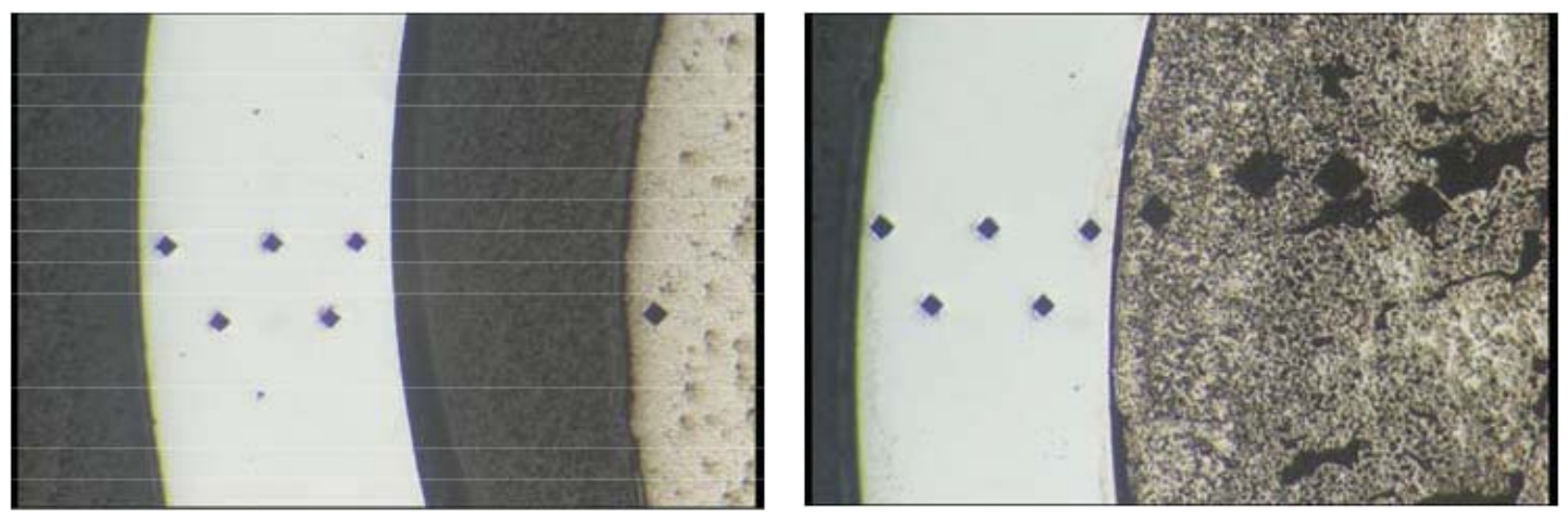

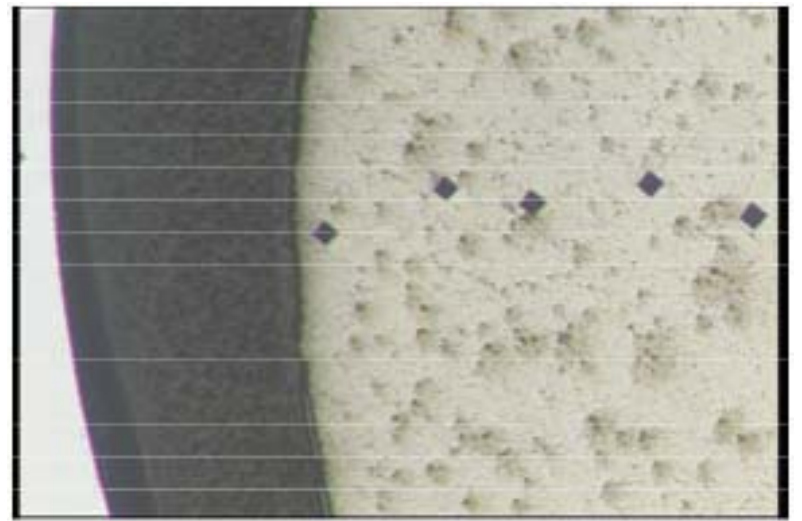

(a)

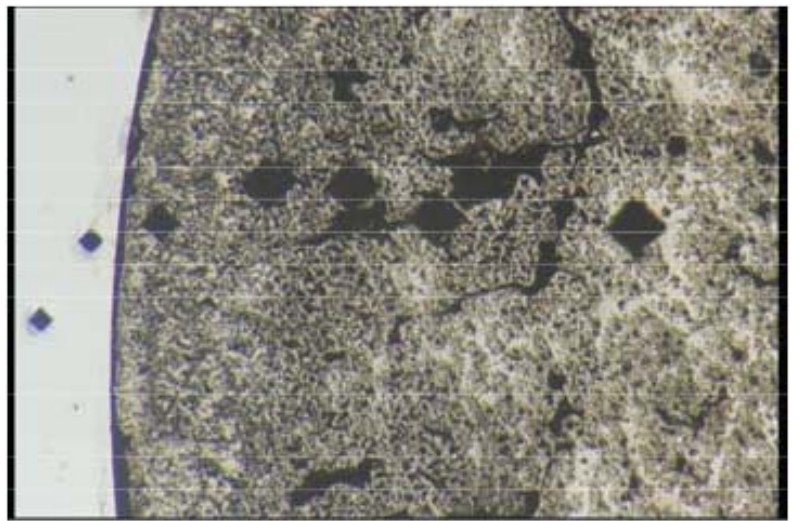

(b)

Figure 49. Microhardness testing micrographs of 35U-29Pu-4Am-2Np-30Zr metallic alloy fuel irradiated to (a) 4.1 and (b) 5.8 at.\% burnup.

\subsubsection{Non-destructive Examinations of AFC-1H, AFC-1D, AFC-1G and AFC-2A}

Non-destructive examinations of AFC-1H, AFC-1D, AFC-1G and AFC-2A consisted of capsule visual inspection, capsule gamma scan, capsule neutron radiography, rodlet visual inspection, rodlet dimensional inspection, rodlet gamma scan, and rodlet neutron radiography. Figure 50 shows the Capsule neutron radiography of AFC-1H, AFC-1D, AFC-1G and AFC-2A using dysprosium and indium converter foils. The preliminary conclusions are summarized below:

- Visual inspection: No observed defects, upper and lower welds intact, heat zones corresponding to fuel regions

- Dimensional inspection: minimal change in diameter and axial length, no ovality

- Neutron radiography: AFC-1H, AFC-1G appear within predicted behavior; AFC-2A and AFC1D reveal some rodlets with fuel around the lower end plug

- Gamma scanning: AFC-1H, AFC-1G profiles appear within predicted behavior; AFC-2A indicate 1-2 rodlets with atypical Cs profile 
A discussion of the interpretation based on 'Fuel cladding chemical interaction studies' [J. Cole, R. Kennedy, Sep. 2008 and possible explanation for the formation of LFP in AFC-2A was presented at the TFCIG in June 2009. The major points inferred from Cole and Kennedy report are the following:

- AFC-2A compositions 60U-20Pu-3Am-2Np$15 \mathrm{Zr}$ and $42 \mathrm{U}-30 \mathrm{Pu}-5 \mathrm{Am}-3 \mathrm{~Np}-20 \mathrm{Zr}+(0,1,8)$ $\mathrm{RE}(\mathrm{Nd}, \mathrm{Pr}, \mathrm{Ce}, \mathrm{La})$ were studied as diffusion couples (DCs) at $550^{\circ} \mathrm{C}, 650^{\circ} \mathrm{C}$ and $750^{\circ} \mathrm{C}$ for 300,140 , and $25 \mathrm{hr}$.

- Cladding temperature exceeded $550^{\circ} \mathrm{C}$ [no interdiffusion phases observed after 300 hours].

- Cladding temperature likely reached $650^{\circ} \mathrm{C}$ [significant interdiffusion observed after 140 hours and some evidence of fuel melting] and up to around $750^{\circ} \mathrm{C}$ for short times [significant melting observed after 25 hours].

- Gamma scanning: AFC-1H, AFC-1G profiles appear within predicted behavior; AFC-2A indicate 1-2 rodlets with atypical Cs profile.

A possible explanation of the observations is summarized below:

- Initial failure of rodlet A2A2 (root cause to be
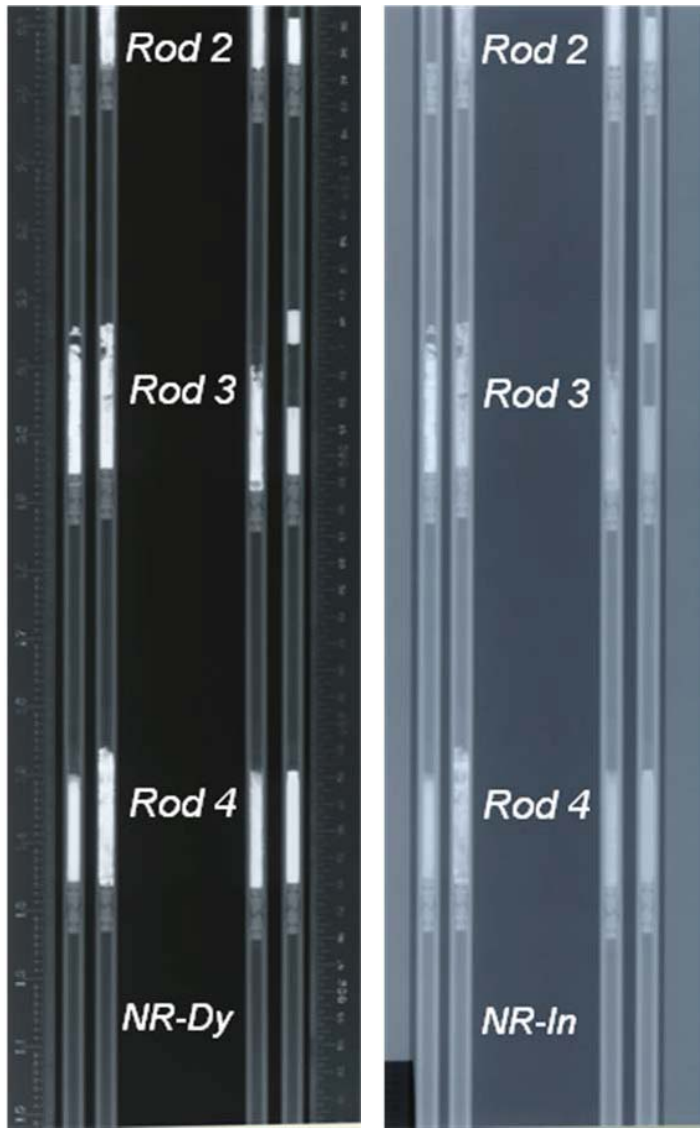

Figure 50. Capsule neutron radiography of AFC$1 \mathrm{H}, \mathrm{AFC}-1 \mathrm{D}, \mathrm{AFC}-1 \mathrm{G}$ and AFC-2A using converter (a)dysprosium foil and (b) indium foil. determined) releases all fission gas from plenum into Capsule free void volume

- Xe and $\mathrm{Kr}$ gas lower thermal conductivity of annular gap

- Scoping calculations indicate cladding temperatures would well exceed $650^{\circ} \mathrm{C}(\mathrm{H}$. MacLean)

- Differential thermal expansion between the rodlet cladding and the Capsule will close the annular gap; equilibrium condition is iterative solution (modeling in progress)

- $\mathrm{A} 2 \mathrm{~A} 3$ different behavior suggests a peak temperature below $550^{\circ} \mathrm{C}$; rod specific conditions could have resulted in a lower temperature drop across the annular gap (faster closure or possibly dispelled sodium from A2A2)

\subsection{Post Irradiation Examination Equipment}

The PIE Equipment Upgrade project is a challenging and extremely important activity. It has overcome political, operational, and execution challenges since its inception in FY-2007. It has several multi-year procurement and installation activities planned through FY-2010. This project has achieved all of its milestones significantly ahead of schedule.

Microscale X-Ray Diffractometer (MXRD), Focused Ion Beam (FIB), Thermal Ionization Mass Spectrometer (TIMS), and Scanning Thermal Diffusivity Microscope (STDM) were all installed and 
accepted in FY-09. The Electron Probe Micro-Analyzer (EPMA) will be delivered in FY-10. The Fresh Fuel Thermo-physical properties characterization line enhancement will install a new inert glovebox in the MFC Analytical Laboratory in FY-10. Installation of these instruments at the Material and Fuels Complex (MFC) will enhance PIE capabilities that support the INL in the establishment of a state-of-theart capability for the development and qualification of transmutation fuels. The technical and functional requirements were developed for the new Irradiated Material Characterization Laboratory (IMCL) to host some of these instruments. This shielded facility, scheduled for design/construction in FY-11, will house the EPMA, MXRD, and FIB to allow PIE of irradiated materials. The contact for the PIE equipment installation is Bert Michelbacher at j.michelbacher@inl.gov.

Figure 51 shows a photograph of the new $\mu$-XRD instrument installed at the INL by the PIE Characterization project. This instrument provides a key measurement capability needed to accurately understand nuclear fuels and materials phase structure.

The TFC requested a review of the AFCI Fuels PIE and Characterization needs to support a science based research and development approach. A review committee convened on July 20, 2009 to review the status of PIE equipment purchases and to provide input on a ten-year strategy for capability development. ${ }^{3}$

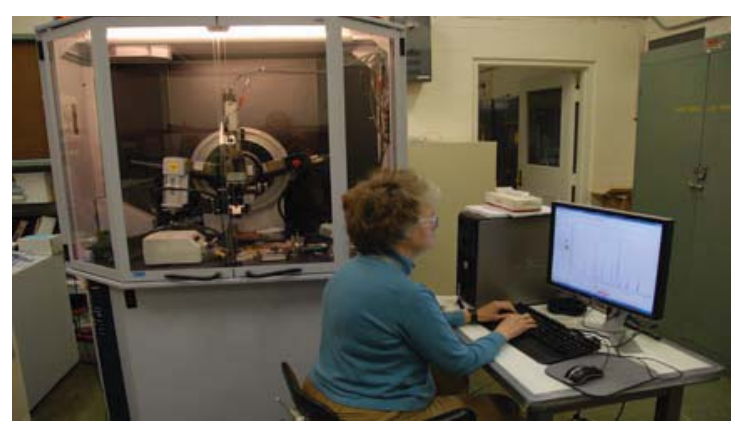

Figure 51. Photograph of the new MXRD instrument installed at INL.
In addition to the PIE characterization upgrade project at the INL, a CM08 attritor mill was purchased and delivered to Oak Ridge National Laboratory for installation. This attritor mill will be used to investigate the scale-up of the 14YWT Nanostructured Ferritic Alloy. The attritor will also be used to study the effect of milling time on homogenizing the distribution of yttrium, titanium, and oxides in milled powders.

A new Instron Servohydraulic machine to be used for fracture toughness testing of retrieved Materials Open Test Assembly (MOTA) specimens was set up at Pacific Northwest National Laboratory. There are approximately 850 ferritic-martensitic steels specimens recovered from the MOTA storage container to be tested. A high temperature furnace for in-situ measurement of microstructure evolution using the laser-based resonant ultrasound measurement technique has also been built at the Idaho National Laboratory and installed in a hot cell facility.

\section{REFERENCES}

1. "Transmutation Fuels Campaign Implementation Plan," AFCI-FUEL-PMO-MI-DV-2009-000157, Rev. 0, September 30, 2009.

2. Advanced Fuel Cycle Initiative AFC-2B, AFC-2C, and AFC-2D End of FY 2009 Irradiation Report, H.J. Maclean, D. J. Utterbeck, G. S. Chang, M. A. Lillo, September 2009.

3. "Fuel and Materials Post Irradiation and Characterization Capability Review," AFCI-FUEL-PMOMI-DV-2009-000126, August 2009. 